\title{
A National Study of Health Behaviors and Health-Related Quality of Life Among Survivors of Breast, Prostate, and Colorectal Cancer Compared to Propensity Score Matched Controls, as well as, Comparisons by Cancer Type \& Gender
}

Traci J. LeMasters

West Virginia University

Follow this and additional works at: https://researchrepository.wvu.edu/etd

\author{
Recommended Citation \\ LeMasters, Traci J., "A National Study of Health Behaviors and Health-Related Quality of Life Among \\ Survivors of Breast, Prostate, and Colorectal Cancer Compared to Propensity Score Matched Controls, as \\ well as, Comparisons by Cancer Type \& Gender" (2012). Graduate Theses, Dissertations, and Problem \\ Reports. 4885. \\ https://researchrepository.wvu.edu/etd/4885
}

This Thesis is protected by copyright and/or related rights. It has been brought to you by the The Research Repository @ WVU with permission from the rights-holder(s). You are free to use this Thesis in any way that is permitted by the copyright and related rights legislation that applies to your use. For other uses you must obtain permission from the rights-holder(s) directly, unless additional rights are indicated by a Creative Commons license in the record and/ or on the work itself. This Thesis has been accepted for inclusion in WVU Graduate Theses, Dissertations, and Problem Reports collection by an authorized administrator of The Research Repository @ WVU. For more information, please contact researchrepository@mail.wvu.edu. 
"A National Study of Health Behaviors and Health-Related Quality of Life Among Survivors of Breast, Prostate, and Colorectal Cancer Compared to Propensity Score Matched Controls, as well as, Comparisons by Cancer Type \& Gender"

\author{
Traci J. LeMasters ${ }^{1}$ \\ Thesis submitted to the School of Pharmacy \\ at West Virginia University \\ in partial fulfillment of the requirements \\ for the degree of
}

Master of Science

in

Pharmaceutical Sciences

Suresh Madhavan, Ph.D. Chair ${ }^{1}$

Usha Sambamoorthi, Ph.D. ${ }^{1}$

Sobha Kurian, M.D. ${ }^{2}$

${ }^{1}$ Department of Pharmaceutical Systems and Policy, School of Pharmacy, West Virginia University

${ }^{2}$ Mary Babb Randolph Cancer Center, West Virginia University

Morgantown, West Virginia

2012

Keywords: Cancer Survivor; Health-Related Quality of Life; Health Behaviors; Propensity Score Matched Controls; Breast Cancer; Prostate Cancer; Colorectal Cancer

Copyright 2012 Traci J. LeMasters 


\section{ABSTRACT \\ "A National Study of Health Behaviors and Health-Related Quality of Life Among Survivors of Breast, Prostate, and Colorectal Cancer Compared to Propensity Score Matched Controls, as well as, Comparisons by Cancer Type \& Gender"}

\section{Traci J. LeMasters}

Among the 12 million cancer survivors currently living in the U.S., over half are comprised of survivors of breast $(22 \%)$, prostate $(20 \%)$, and colorectal cancers $(9 \%)$. While about $2 / 3$ of cancer survivors are living longer than 5 years since the time of diagnosis, many continue to experience late or long-lasting symptoms and effects of the cancer and its treatment that often negatively affect their Health-Related Quality of Life (HRQOL). What is more, previous research has observed that many survivors are further burdened with a greater number of obesity related chronic and co-morbid health conditions compared to those without a history of cancer. In fact, over $70 \%$ of breast, prostate, and colorectal cancer survivors have been found to be overweight or obese. However, despite having had a health scare that many may consider a cue to action, studies have shown that most cancer survivors do not engage in healthy behaviors at levels superior to those without a history of cancer. Previous studies of HRQOL and health behaviors among cancer survivors have been limited by small sample size and samples of cancer survivors limited by age and/or time since diagnosis. Furthermore, studies that made comparisons using non-cancer controls primarily matched on age and gender alone, or nothing at all, thus not rigorously controlling for confounding bias. Finally, no study has comprehensively compared HRQOL and health behaviors among the largest groups of survivors to stringently matched controls to understand clearly how survivors of breast, prostate and colorectal cancer may differ from those without a history of cancer, while also comparing these outcomes by type of cancer and gender to clearly understand how these outcomes may vary between cancer survivors and genders. Therefore, the objectives of this study were to 1) compare the prevalence of specific measures of HRQOL between breast, prostate, female, and male colorectal cancer survivors to propensity score matched controls, and to compare HRQOL by type of cancer and gender and 2) compare the prevalence of specific health conditions and health behaviors between breast, prostate, female, and male colorectal cancer survivors to propensity score matched controls, and to compare health behaviors by type of cancer and gender. A cross-sectional study was conducted using a sample of breast, prostate, and colorectal cancer survivors 18 years of age and older and > 1 year past diagnosis were selected from the 2009 BRFSS. A greedy algorithm and matching without replacement used propensity scores to match 3 controls to every 1 case on age, gender, race/ethnicity, income, insurance status, and region of the U.S. HRQOL measures compared were life satisfaction, perceived emotional support, activity limitations, perceived general, physical and mental health, and sleep quality. Health conditions compared were arthritis, asthma, heart disease, diabetes, hypertension, high cholesterol, stroke, activity limitations, and perceived general health. Health behaviors compared were flu immunization, physical check-up, cholesterol check, BMI, physical activity, fruit and vegetable consumption, smoking, and alcohol use. Chi-square tests were used to test for covariate balance and compared prevalence of health conditions and behaviors. Binomial and multinomial logistic regression models were used to estimate the probabilities of behaviors for cancer cases compared to 
controls. The final study sample consisted of 6,393 breast, 3,636 prostate, 1,111 female colorectal, and 824 male colorectal cancer survivors. Compared to matched controls, cancer survivors were up to 3.67 times more likely $(95 \% \mathrm{CI}$ : $2.09,6.47)$ at $1-5$ years since diagnosis, and up to 1.91 times more likely (95\%CI: 1.30, 2.79). Breast, female, and male colorectal cancer survivors were up to 2.62 times more likely $(95 \% \mathrm{CI}: 1.72,3.99)$ to report activity limitations compared to matched controls. Additionally, colorectal cancer survivors were more likely to report worse physical health than their matched controls. Male colorectal and prostate cancer survivors were more likely to report worse mental health, and prostate cancer survivors were more likely to report a lack of emotional support and not enough sleep compared to their matched controls. Comparisons by cancer type found that male colorectal cancer survivors were more likely to report activity limitations and perceive their general and physical health to be worse than prostate cancer survivors. Gender comparisons found that females were more likely to hold poorer perceptions of their general, physical, and mental health, report not enough sleep, and not receiving enough emotional support, but more likely to be satisfied with life. Breast and prostate cancer survivors reported a greater prevalence of chronic health conditions than matched controls. Breast cancer survivors were more likely to engage in healthier behaviors $1-5$ years after diagnosis, but were more likely to be obese at $>5$ years after diagnosis than controls. Male colorectal cancer survivors were less likely to engage in clinical preventive care at $>5$ years after diagnosis than controls. Female colorectal and breast cancer survivors were less likely be overweight and/or obese, former and/or current smokers, drink any alcohol, and more likely to consume $\geq 5$ servings of fruits and vegetables per day, but more likely to engage in none or insufficient levels of physical activity compared to male colorectal and prostate cancer survivors, respectively. All cancer survivor groups reported more limitations and held poorer perceptions of their general health. Differences between matched controls for other HRQOL measure vary by type of cancer, although compared to similar males without cancer, male cancer survivors reported worse outcomes on measures such as mental health, sleep, and emotional support. However, when female survivors were compared to male survivors, females reported worse outcomes for all measures except life satisfaction. Breast and prostate cancer survivors have more chronic health conditions compared to matched controls than do female and male colorectal cancer survivors. Breast cancer survivors are more likely to engage in healthy behaviors than their matched controls. Female cancer survivors engage healthier lifestyle behaviors, with the exception of physical activity, compared to male cancer survivors. 


\section{ACKNOWLEDGEMENTS}

I would like to sincerely thank individuals who have made it possible for me to have completed this Master's Thesis project. First, I would like to thank my major advisor and committee chair, Dr. Suresh Madhavan for his patient guidance and wisdom that led me to this milestone. I would also like to thank faculty and committee member, Dr. Usha Sambamoorthi for her time and patience spent on the many hours of tedious SAS programming and then explaining each step and interpretation to me, as I am still learning. Thank you to oncologist and committee member, Dr. Sobha Kurian from taking time out her busy schedule to provide her expert opinion on the study objectives as they relate to cancer survivors.

In addition to my committee, I would also like to acknowledge and thank Dr. Ginger Scott for advising me through the first few years of the program before graciously handing me over to Dr. Madhavan.

Last, but not least, I would like to thank my husband and family for supporting me in my continued years of education. 


\section{TABLE OF CONTENTS}

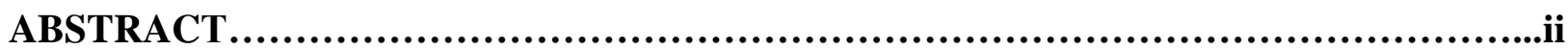

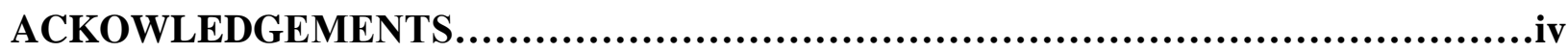

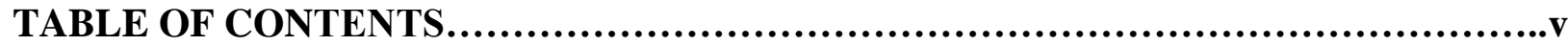

CHAPTER 1: INTRODUCTION \& BACKGROUND...................................1

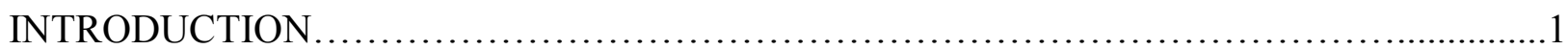

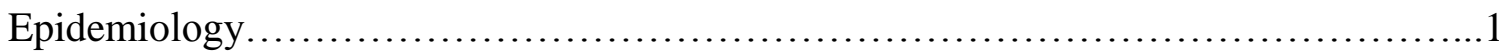

Factors Influencing HRQOL.........................................................

Health \& Health Behaviors of Cancer Survivors........................................

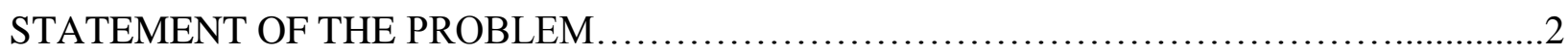

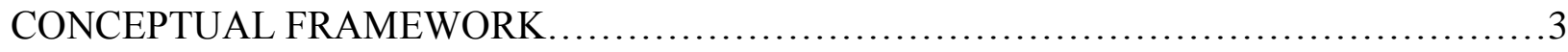

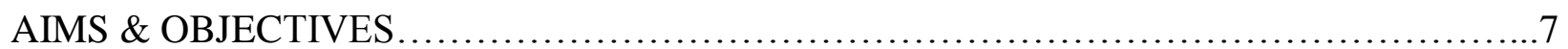

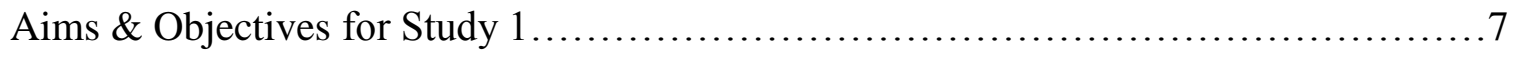

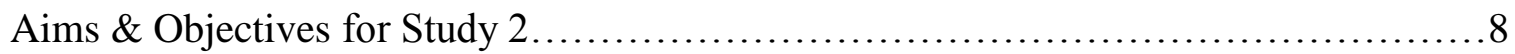

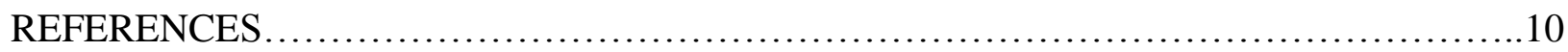

CHAPTER 2: MANUSCRIPT 1 "HRQOL"

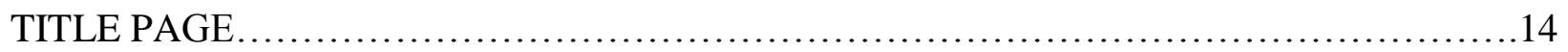

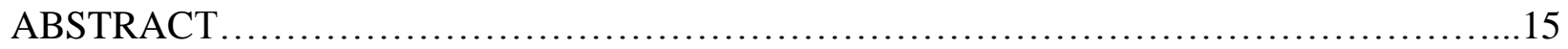

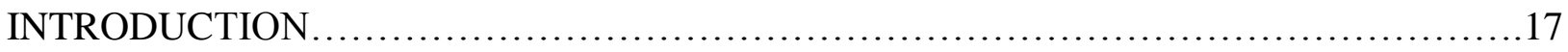

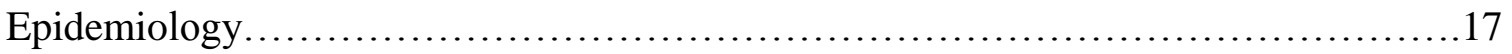

Literature Review............................................................ 18

HRQOL Comparisons by Cancer Type and Gender...........................18

HRQOL Comparisons between Survivors and Controls.........................19 
Statement of the Problem..................................................... 19

Study Aims.............................................................. 20

Conceptual Framework...................................................... 21

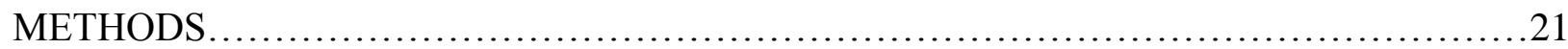

Data Source.................................................................. 21

Study Sample............................................................22

Measures...............................................................23

Dependent Variables....................................................23

Independent Variables.............................................24

Analysis................................................................

Propensity Score Matching.......................................... 25

Statistical Methods..................................................25

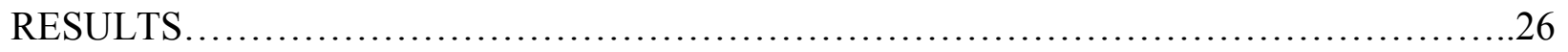

Description and Covariate Balance...........................................26

Aim 1 Results...........................................................28

Aim 2 Results........................................................... 28

Aim 3 Results.......................................................... 31

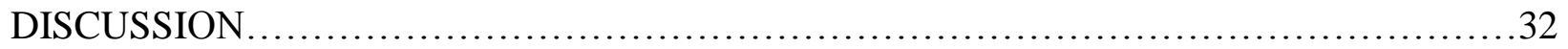

Strengths \& Limitations...................................................

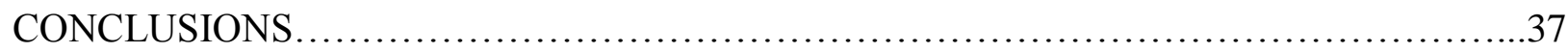

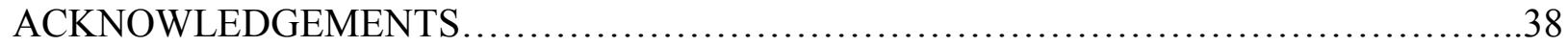

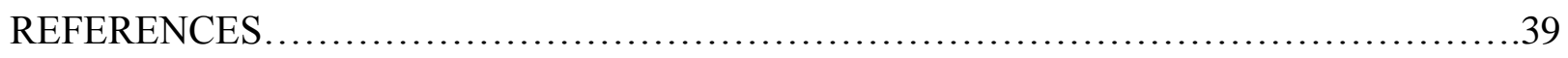

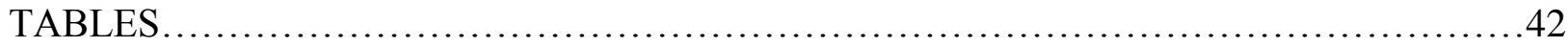


Table 1: Description of Cancer Survivors and Matched Controls....................42

Table 2: Comparison of Health Conditions between Survivors and Controls...........44

Table 3: Comparison of HRQOL between Survivors and Controls..................45

Table 4: Models of HRQOL between Survivors and Controls.......................46

Table 5: Models of HRQOL between Cancer Types and Genders.........................47

CHAPTER 3: MANUSCRIPT 2 “HEALTH \& HEALTH BEHAVIORS”......................48

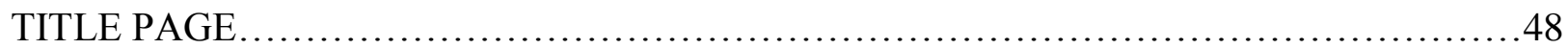

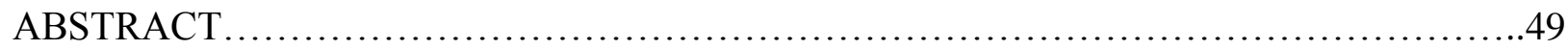

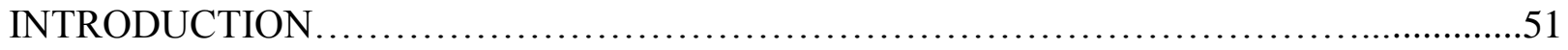

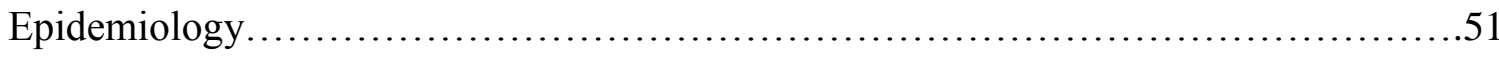

Literature Review.......................................................51

Health of Cancer Survivors...........................................51

Benefits of Healthy Behaviors on Survivors' Health...........................52

Comparison of Health Behaviors between Survivors and Controls..............52

Comparisons of Health Behaviors by Cancer Type and Gender................53

Statement of the Problem......................................................

Study Aims........................................................... 54

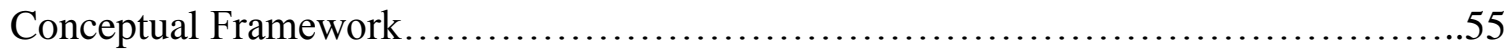

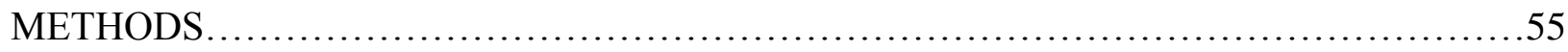

Data Source............................................................ 55

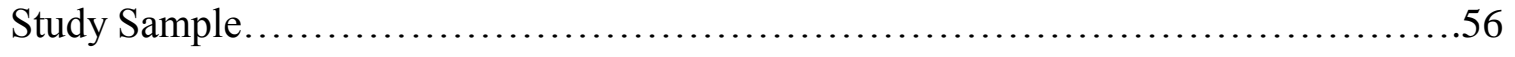

Measures............................................................... 57

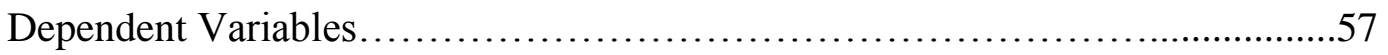


Independent Variables.............................................58

Analysis................................................................ 59

Propensity Score Matching............................................59

Statistical Methods......................................................59

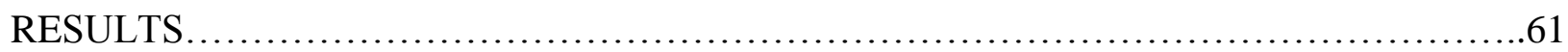

Description and Covariate Balance.........................................61

Aim 1 Results..........................................................61

Aim 2 Results........................................................62

Aim 3 Results..........................................................63

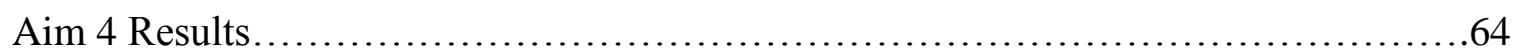

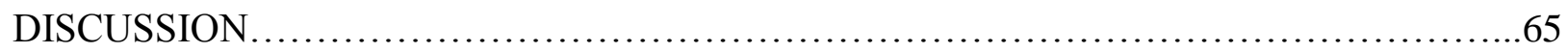

Strength $\&$ Limitations................................................... 70

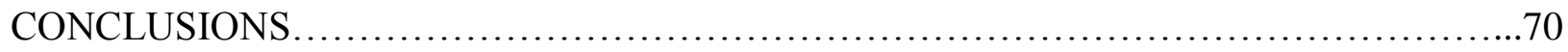

ACKOWLEDGEMENTS ........................................................ 71

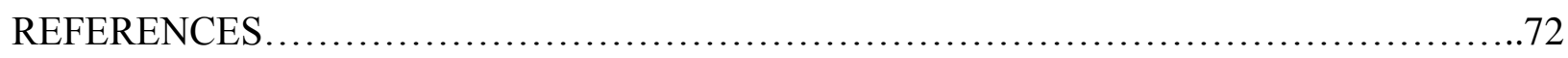

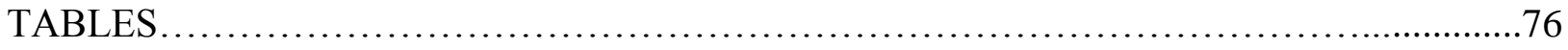

Table 1: Description of Cancer Survivors and Matched Controls............................76

Table 2: Comparison of Health Conditions between Survivors and Controls..............77

Table 3: Comparison of Health Behaviors between Survivors and Controls.............78

Table 4: Models of Health Behaviors between Survivors and Controls.................79

Table 5: Models of Health Behaviors between Cancer Types and Genders...............80

CHAPTER 4: SUMMARY OF FINDINGS.............................................81

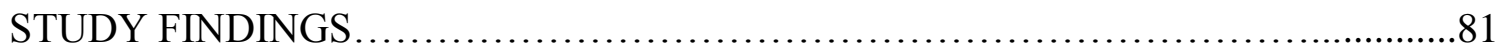




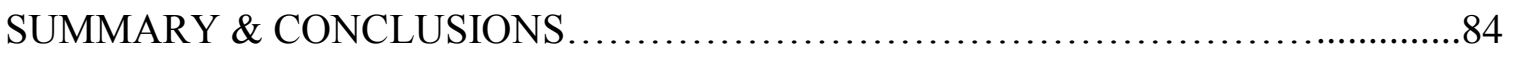

STRENGTHS \& LIMITATIONS ..............................................86

IMPLICATIONS \& FUTURE RESEARCH.................................... 86

CURRICULUM VITAE...........................................................................88 


\section{CHAPTER 1}

\section{Introduction}

An individual is considered to be a "cancer survivor" from the time of their cancer diagnosis throughout the rest of their life ${ }^{1}$. Nearing 12 million, the number of cancer survivors alive in the U.S. today is greater than ever before. This growing population can be attributed to increased adoption of regular cancer screenings, advances in cancer detections and treatments, as well as an aging population ${ }^{1 \& 2}$. Not only is the number of cancer survivors increasing, but also the number of cancer survivors living 5 years or longer. As of 2008 , about $66 \%$ of the cancer survivors were living 5 or more years post diagnosis ${ }^{3}$. Survivors of breast $(22 \%)$, prostate (20\%), and colorectal cancers (9\%) consist of the three largest groups of cancer survivors in the U.S. ${ }^{3}$.

In spite of improved survival rates, many survivors continue to experience long lasting symptoms and or late effects of the cancer and its treatment which can negatively affect their physical and mental health, psychosocial well-being, functional status, and consequently their health-related quality of life (HRQOL) ${ }^{4-10}$. Specific symptoms and effects commonly experienced by cancer survivors include problems with physical functioning, chronic pain, lymph edema, cognitive impairment, fatigue, sleep disturbances, depression, anxiety, sexual dysfunction, and infertility. Whether these sequelae are a result of the malignancy itself, surgery to the cancer site, chemotherapy, radiation, adjuvant therapy, or just owing to the distress of the cancer experience, these problems can persist for many years, remaining unresolved and even untreated for a large number of cancer survivors ${ }^{4,5,8,11-15}$. Moreover, when compared to their age matched non cancer controls, many survivors report lower scores in one or more domains of HRQOL ${ }^{16} \& 17$. 
What is more, rates of obesity have been reportedly high among certain groups of survivors, with prevalence as high as $70 \%$ among survivors of breast, prostate, and colorectal cancer, increasing their risk of developing obesity related chronic and co-morbid conditions ${ }^{3,18-}$ 21. In fact, when compared to age-matched non cancer controls, cancer survivors exhibit a greater number of obesity related chronic and co-morbid conditions further worsening their health and HRQOL ${ }^{22 \& 23}$. Despite this revelation and having had a health scare that some would consider a "cue to action", many cancer survivors do not meet levels of dietary intake or physical activity as recommended by the American Cancer Society ${ }^{24 \& 25}$, nor do they engage in superior levels of these and other health behaviors than their age-matched non cancer controls ${ }^{22}$, ${ }^{26,27}$, even though they have been shown to enhance cancer survival, decrease the risk of cancer recurrence, decrease the risk of all-cause mortality, increase functional status and overall health, and subsequently, improve HRQOL ${ }^{24,28-31}$. Furthermore, while cancer survivors may engage in greater levels of recommended cancer screenings, they do not differ from non cancer controls in receipt of general clinical preventive care $32 \& 33$.

\section{Statement of Problem}

The late and long lasting symptoms and effects following treatment for cancer that are experienced by many survivors are issues that remain unresolved or untreated and are known to have detrimental effects upon their HRQOL. Further affecting HRQOL and functional status are the high rates of chronic and co-morbid conditions associated with obesity among certain groups of survivors. Previous work has identified how these post-treatment sequelae affecting HROL can differ in prevalence and severity by age, race, income, metro status, level of social and emotional support, time since diagnosis, and type of treatment, but little research has directly compared how domains of HRQOL may differ from controls rigorously matched on known 
confounders and how these domains may vary type of cancer and gender ${ }^{8-10,34-41}$. Similarly, studies of health behaviors and clinical preventive care among cancer survivors have identified variations by age, race, and education. However, few studies have compared how HRQOL and health behaviors among breast, prostate, and colorectal cancer survivors may differ from rigorously matched controls or between types of cancers and genders ${ }^{7,22,23,26,40,42}$.

Given that, survivors of breast, prostate, and colorectal cancer comprise over $50 \%$ of the cancer survivor population, it is important to understand how affected HROL domains may vary from those without a history of cancer and by cancer type and gender in order to address any unmet individual health care needs ${ }^{3}$. Furthermore, with up to $70 \%$ of breast, prostate and colorectal cancer survivors reported to be overweight and/or obese, it is imperative to identify if these specific groups are indeed burdened with a high number of chronic and co-morbid conditions as the literature has suggested and assess which health behaviors to target for improvement.

To address these unmet and increasing needs of a growing population, this project will conduct two separate studies, one that is focused on HRQOL and the other upon health and health behaviors.

\section{Conceptual Framework}

The conceptual framework of these two studies will be based upon the final Andersen Behavioral Model of Health Services Use. Originally developed by Ronald M. Andersen in the 1960's, the initial version of the model was intended to determine what either facilitates or impedes a family's use health services, define and measure equal access to health care services, and to aid in policy development for equal access to health care services. The model then shifted to focus on the individual as the unit of analysis rather than the family, due to its difficulty to 
measure. This first phase examined how predisposing characteristics, enabling resources, and need for care were related to the use of health care services. Predisposing characteristics encompasses measures of demographics (age, race, gender, ect.), social structure (education, occupation, ect.), and health beliefs (attitudes, values, and beliefs about health services). Enabling resources measure access via personal/family characteristics (marital status, income, insurance, usual source of care, available transportation, ect.) and community characteristics (ex. number of health care facilities and providers in the area). Measures of need include the individual's perceived need for services as well as evaluated health status ${ }^{43}$.

The second phase of the model was adapted to include characteristics of the health care system and their relation to utilization of health care services. Characteristics of the health care system include national health policy, resources, and organization of the health care system. This phase also included consumer satisfaction as an outcome, as well as distinguishing types of health services use by type, site, purpose, and by coordination of services used for a particular episode of service ${ }^{43}$.

The third phase of the model includes the external environment (physical, political, and economic) as a factor related to utilization of health care services. In this phase, the model was also adapted to include the relation of personal health practices (diet, exercise, ect.) to health care utilization and to health outcomes, also added to the model. Health outcomes included perceived health status, evaluated health status, and consumer satisfaction, allowing researchers and policy makers to understand the relationship between health care service utilization, health status, and consumer satisfaction $^{43}$.

The fourth and fifth phases of the model were modified to include feedback loops that demonstrate how outcomes affect population characteristics, perceptions, and health behaviors, 
allowing for a more accurate depiction of the interaction between various factors, rather than just a linear relationship to outcomes. It was further modified to place more emphasis on the individual and contextual determinants of health care service utilization. The framework for the currently proposed studies will utilize the fourth phase of the Andersen model (Figure 1).

\section{Figure 1. Phase 4 of the Andersen Behavioral Model of Health Service Use}

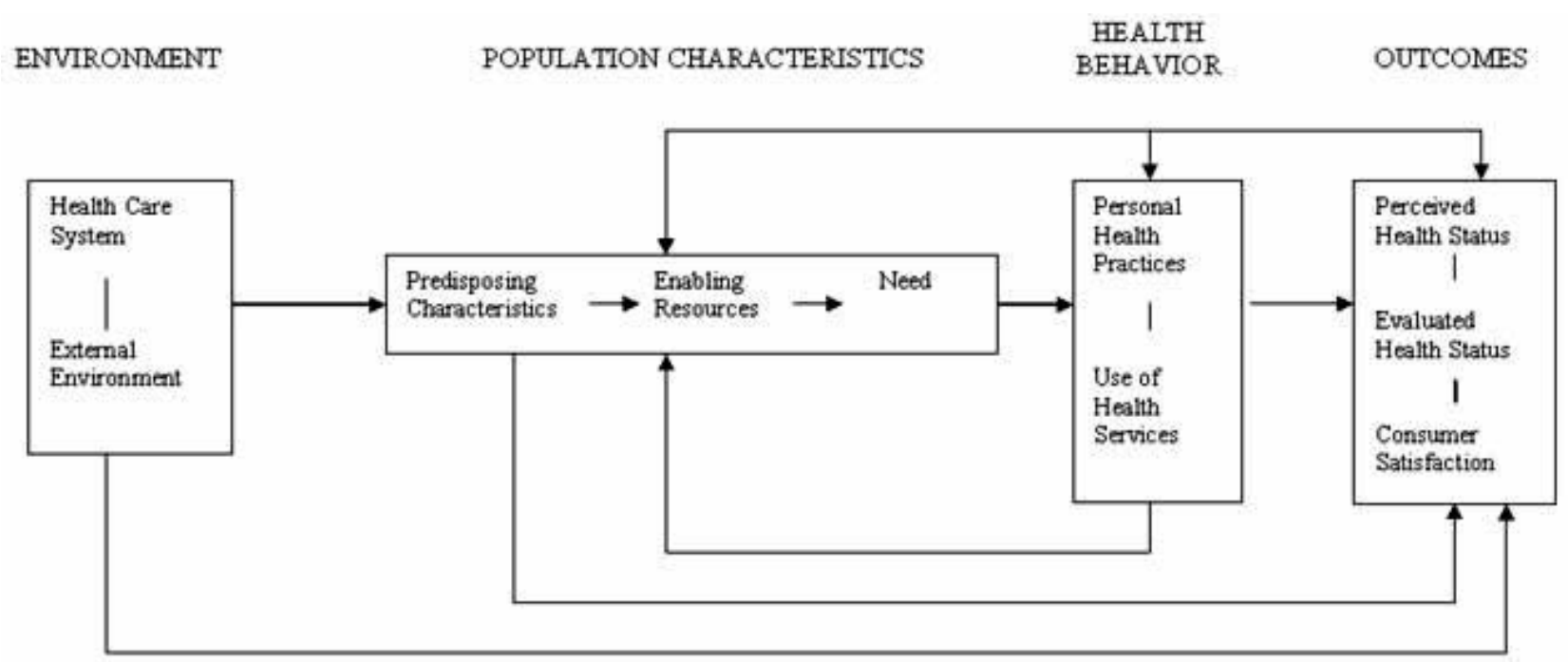

The initial creation of the model was intended to identify conditions that either facilitate or impede utilization of health services using a national survey administered by the Center for Health Administration Studies and the National Opinion Research Center, and since then the model has been broadly used in studies utilizing data from other national health surveys ${ }^{43} \& 44$. The model's fundamental purpose is to identify what facilitates and/or impedes health care service utilization by studying the interrelationships between an individual's contextual characteristics, individual characteristics, health behaviors, and outcomes in order to help direct national health care policy. The Centers for Disease Control and Prevention's (CDC) Behavioral Risk Factor Surveillance System (BRFSS) survey is one such national survey that if often used in studies guided by the Behavioral Model of Health Service Use. The BRFSS collects information on health care access related to chronic disease and injury, preventive health care 
practices, and risky health behaviors. It also collects information on perceived and evaluated health status, sociodemographic and environmental characteristics.

Using data provided by the 2009 BRFSS questionnaire ${ }^{45}$, the first study will examine association between environmental, predisposing, enabling, and need factors and HRQOL outcomes between survivors of breast, prostate, colorectal cancer survivors and propensity score matched controls and by type of cancer and gender. Environmental factors studied will be region of United States and metro status. Predisposing characteristics will include age, gender, race, and education. Enabling factors will be comprised of employment status, insurance status, income, usual source of care, marital status, and emotional support. Measures of need will be presence of cancer, type of cancer, time since diagnosis, presence of heart disease, diabetes, hypertension, high cholesterol, stroke, asthma, and arthritis. HRQOL outcomes will be measured by perceived general health status, activity limitations, perceived number of healthy physical days in the past month, perceived number of healthy mental health days in the past month, perceived number days of not enough sleep in the past month, emotional support, and life satisfaction.

The second study will examine the association between environmental, predisposing, enabling, and need factors and health behaviors between survivors of breast, prostate, colorectal cancer survivors and propensity score matched controls and by type of cancer and gender. Environmental factors studied will be region of United States and metro status. Predisposing characteristics will include age, gender race, and education. Enabling factors will be comprised of employment status, insurance status, income, usual source of care, and marital status. Measures of need will be presence of cancer, type of cancer, time since diagnosis, presence of heart disease, diabetes, hypertension, high cholesterol, stroke, asthma, and arthritis. Measures of 
health behaviors will be categorized by lifestyle behaviors and general clinical preventive care utilization. Lifestyle behaviors include, physical activity, nutritional intake, BMI, tobacco use, and alcohol use. General clinical preventive care includes last routine check-up, last cholesterol check, and last flu immunization.

\section{$\underline{\text { Aims \& Objectives }}$}

\section{$\underline{\text { Study } 1}$}

Aim 1: To compare measures of HRQOL, specifically activity limitations, perceived general health, perceived physical health, perceived mental health, perceived amount of sleep, emotional support, and life satisfaction, between breast, prostate, colorectal cancer survivors and propensity score matched controls matched for age, gender, race/ethnicity, income, insurance status, and region of the U.S.

Objective 1.1: To determine significant differences between measures of HRQOL, specifically activity limitations, perceived general health, perceived physical health, perceived mental health, perceived amount of sleep, emotional support, and life satisfaction, between breast, prostate, colorectal cancer survivors and propensity score matched controls.

Objective 1.2: To estimate the likelihood of HRQOL outcomes, specifically activity limitations, perceived general health, perceived physical health, perceived mental health, perceived amount of sleep, emotional support, and life satisfaction, for breast, prostate, colorectal cancer survivors compared to propensity score matched controls by time since diagnosis.

Aim 2: To compare measures of HRQOL, specifically activity limitations, perceived general health, perceived physical health, perceived mental health, perceived amount of sleep, emotional support, and life satisfaction, between survivors of breast, prostate, and colorectal cancers by type of cancer and gender. 
Objective 2.1: To estimate the likelihood of HRQOL outcomes, specifically activity limitations, perceived general health, perceived physical health, perceived mental health, perceived amount of sleep, emotional support and life satisfaction, for survivors of breast cancer compared to female survivors of colorectal cancer and for survivors of prostate cancer compared to male survivors of colorectal cancer.

Objective 2.2: To estimate the likelihood of HRQOL outcomes, specifically activity limitations, perceived general health, perceived physical health, perceived mental health, perceived amount of sleep, emotional support, and life satisfaction, for female survivors of a gender-neutral (colorectal) cancer compared to male survivor of a gender-neutral (colorectal) cancer.

Objective 2.3: To estimate the likelihood of HRQOL outcomes, specifically activity limitations, perceived general health, perceived physical health, perceived mental health, perceived amount of sleep, emotional support, and life satisfaction, for survivors of a female-specific (breast) compared to male-specific (prostate) cancer.

\section{$\underline{\text { Study } 2}$}

Aim 1: To compare differences in evaluated health status, specifically perceived general health, activity limitations, prevalence of certain chronic conditions and number of co-morbid or chronic conditions, and health behaviors, specifically level of physical activity, nutritional intake, BMI, tobacco use, alcohol use, and general clinical preventive care, between breast, prostate, colorectal cancer survivors and propensity score matched controls matched for age, gender, race/ethnicity, income, insurance status, and region of the U.S.

Objective 1.1: To determine significant differences in evaluated health status, specifically perceived general health, activity limitations, BMI, prevalence of diabetes, heart disease, 
hypertension, high cholesterol, stroke, asthma and arthritis between breast, prostate, colorectal cancer survivors and propensity score matched controls.

Objective 1.2: To significant differences in health behaviors, specifically level of physical activity, nutritional intake, BMI, tobacco use, alcohol use, and general clinical preventive care, between breast, prostate, colorectal cancer survivors and propensity score matched controls. Objective 1.3: To estimate the likelihood of health behaviors, specifically level of physical activity, nutritional intake, BMI, tobacco use, alcohol use, and general clinical preventive care, of breast, prostate, colorectal cancer survivors compared to propensity score matched controls by time since diagnosis.

Aim 2: To compared differences in health behaviors, specifically level of physical activity, nutritional intake, BMI, tobacco use, alcohol use, and general clinical preventive care between breast, prostate, colorectal cancer survivors by type of cancer and gender.

Objective 2.1: To estimate the likelihood health behaviors, specifically level of physical activity, nutritional intake, BMI, tobacco use, alcohol use, and general clinical preventive care, for a female-specific (breast) compared to a male-specific (prostate) cancer.

Objective 2.2: To estimate the likelihood of health behaviors, specifically level of physical activity, nutritional intake, BMI, tobacco use, alcohol use, and general clinical preventive care for female survivors of a gender-neutral (colorectal) cancer compared to male survivors of a gender-neutral cancer.

Objective 2.3: To estimate the likelihood of health behaviors, specifically level of physical activity, nutritional intake, BMI, tobacco use, alcohol use, and general clinical preventive care for survivors of breast cancer compared to female survivors of colorectal cancer and for survivors of prostate cancer compared to male survivors of colorectal cancer. 


\section{$\underline{\text { References }}$}

1. Howlander N, Noone AM, Krapcho M, et. al. Estimated United States cancer prevalence. SEER Cancer Statistics Review, 1975 - 2008. National Cancer Institute, Bethesda, MD, 2011. Available at http://seer.cancer.gov/csr/1975_2008/. Last accessed April 9, 2012.

2. Hewitt M, Greenfield S and Stovall E, Editors. From cancer patient to cancer survivor: lost in transition. National Cancer Policy Board (U.S.). Committee on Cancer Survivorship: Improving Care and Quality of Life. Washington, DC: The National Academies Press, 2005. Available at http://www.nap.edu/catalog.php?record_id=11468. Last accessed April 16, 2012.

3. Altekruse SF, Kosary CL, Krapcho M, et. al. Estimated number of persons alive in the U.S. diagnosied with cancer on January 1, 2008 by site. SEER Cancer Statistics Review, 1975 - 2008. National Cancer Institute, Bethesda, MD, 2011. Available at http://seer.cancer.gov/csr/1975_2008/. Last accessed April 9, 2012.

4. Harrington CB, Hansen JA, Moskowitz M, Todd BL, and Feuerstein M. It's not over when it's over: long-term symptoms in cancer survivors - a systematic review. Int J Psychiat Med. 2010; 40(2): 163 - 181.

5. Ewertz M and Jensen AB. Late effects of breast cancer treatment and potentials for rehabilitation. Acta Oncol. 2011; 50: 187 - 193.

6. Lee ES, Lee MK, Kim SH, et. al. Health-related quality of life in survivors with breast cancer 1 year after diagnosis compared with the general population. Ann Surg. 2011; 253(1): $101-108$.

7. Richardson LC, Wingo PA, Zack MM, Zahran HS, and King JB. Health-related quality of life in cancer Survivors between ages 20 and 64 years: population-based estimates from the behavior risk factor surveillance system. Cancer. 2008; 112(6): 1380 - 1389.

8. Jansen L, Koch H, and Brenner AV. Quality of life among long-term ( $\geq 5$ years) colorectal cancer survivors - systematic review. Eur J Cancer. 2010; 46(16): 2879 - 2888.

9. Phipps E, Braitman LE, Stites S, and Leighton JC. Quality of life and symptom attribution in long-term colon cancer survivors. J Eval Clin Pract. 2008; 14: 254 - 258.

10. Arndt V, Merx H, Stegmainer C, Ziegler H, and Brenner H. Quality of life in patients with colorectal cancer 1 year after diagnosis compared with the general population: a population-based study. J Clin Oncol. 2004; 22(23): 4829 - 4836.

11. Jensen MP, Chang HY, Lai YH, Syrjala KL, Fann JR, and Gralow JR. Pain in long-term breast cancer survivors: frequency, severity, and impact. Pain Med. 2010; 11: 1099 1106. 
12. Saylor PJ and Smith MR. Adverse effects of androgen deprivation therapy: defining the problem and promoting health among men with prostate cancer. $\mathrm{J}$ Natl Compr Canc Netw. 2010; 8(2): 211- 223.

13. Schilder CM, Eggens PC, Seyaeve C, et. al. Neuropsychological functioning in postmenopausal breast cancer patients treated with tamoxifen or exemestane after ACchemotherapy: cross-sectional findings from the neuropsychological TEAM-side study. Acta Oncol. 2009; 48: 76 - 85.

14. Grov EK, Fossa SD, and Dahl AA. Insomnia in elderly cancer survivors - a populationbased controlled study of associations with lifestyle, morbidity, and psychosocial factors. Results from the Health Survey of North-Trondelag County. Support Care Cancer. 2011; 19(9): 1319 - 1326.

15. Greimel ER, Winter R, Kapp KS, and Haas J. Quality of life and sexual functioning after cervical cancer treatments: a long-term follow-up study. Psycho-Oncol. 2009; 18: 476 482.

16. Bloom JR, Peterson DM, and Kang SH. Multi-dimensional quality of life among long-term (5+ years) adult cancer survivors. Psycho-Oncol. 2007; 16: 691 - 706.

17. Baker F, Denniston M, Haffer SC, and Liberatos P. Change in health-related quality of life of newly diagnosed cancer patients, cancer survivors, and controls. Cancer. 2009; 115 : $3024-2033$.

18. Thomson CA, Thompson PA, Wright-Bea J, Nardi E, Frey GR, and Stopeck A. Metabolic syndrome and elevated c-reactive protein in breast cancer survivors on adjuvant hormone therapy. J Womens Health. 2009; 18(12): 2041 - 2047.

19. Kintzel PE, Chase SL, Schultz LM, and O'Rourke TJ. Increased risk of metabolic syndrome, diabetes mellitus, and cardiovascular disease in men receiving androgen deprivation therapy for prostate cancer. Pharmacotherapy. 2008; 28(12): 1511 - 1522.

20. Denmark-Wahnefried W, Aziz NM, Rowland JH, and Pinto BM. Riding the crest of the teachable moment: promoting long-term health after the diagnosis of cancer. $\mathrm{J} C \mathrm{Clin}$ Oncol. 2005; 23(24): $5814-5830$.

21. Haydon AMM, Maclnnis RJ, English DR, and Giles GG. Effect of physical activity and body size on survival after diagnosis with colorectal cancer. Gut. 2006; 55: 62 - 67.

22. Eakin EG, Youlden DR, Baade PD, et. al. Health behaviors of cancer survivors: data from an Australian population-based survey. Cancer Cause Control. 2007; 18 : 881 - 894.

23. Eakin EG, Youlden DR, Baade PD, et. al. Health status of long-term cancer survivors: data from an Australian population-based sample. Cancer Epidem Biomar. 2006; 15(10): 1969 - 1976. 
24. Blanchard CM, Courneya KS, and Stein K. Cancer survivors' adherence to lifestyle behavior recommendations and associations with health-related quality of life: results from the American Cancer Society's SCS-II. J Clin Oncol. 2008; 26(13): 2198 - 2204.

25. Doyle C, Kushi LH, Byers T, et. al. Nutrition and physical activity during and after cancer treatment: an American Cancer Society guide for informed choices. CA-Cancer J Clin. 2006; 56: $323-353$.

26. Coups EJ and Ostroff JS. A population-based estimate of the prevalence of behavioral risk factors among adult cancer survivors and noncancer controls. Prev Med. 2005; 40: $702-711$.

27. Smith SG and Chagpar AB. Adherence to physical activity guidelines in breast cancer survivors. Am Surg. 2010; 76(9): 962 - 965.

28. Ibrahim EM and Al-Homaidh A. Physical activity and survival after breast cancer diagnosis: meta-analysis of published studies. Med Oncol. 2011;28(3): 753 - 765.

29. Morey MC, Snyder DC, Sloane R, et. al. Effects of home-based diet and exercise on functional outcomes among older, overweight long-term cancer survivors. JAMA. 2009; 301(18): $1883-1891$.

30. Keogh JW, Shepherd D, Krageloh CU, et. al. Predictors of physical activity and quality of life in New Zealand prostate cancer survivors undergoing androgen-deprivation therapy. N Z Med J. 2010; 123(1325): 20 - 29.

31. Thomson CA, Rock CL, Thompson PA, et. al. Vegetable intake is associated with reduced breast cancer recurrence in tamoxifen users: a secondary analysis from the women's healthy eating and living study. Breast Cancer Res T. 2010; 125(2): 519 - 527.

32. Kahn NF, Ward A, Watson E, Austoker J, and Rose PW. Long-term survivors of adult cancers and uptake of primary health services: a systematic review. Eur J Cancer. 2008; 44: $195-204$.

33. Khan NF, Carpenter L, Watson E, and Rose PW. Cancer screening and preventive care among long-term cancer survivors in the United Kingdom. Brit J Cancer. 2010; 102: $1085-1090$.

34. Sapp AL, Trentham-Dietz A, Newcomb PA, Hampton JM, Moinpour CM, and Remington PL. Social networks and quality of life among female colorectal long-term cancer survivors. Cancer. 2003; 98: $1749-1758$.

35. Krouse RS, Herrinton LJ, Grant M, et. al. Health-related quality of life among long-term rectal cancer survivors with an ostomy: manifestations by sex. J Clin Oncol. 2009; 27(28): $4664-4670$. 
36. Harden J, Northhouse L, Cimprich B, Pohl JM, Liang J, and Kershaw T. The influence of developmental life stage on quality of life in survivors of prostate cancer and their partners. J Cancer Surviv. 2008; 2: $84-94$.

37. Reid-Arnet SA, and Cox CR. Does rurality affect quality of life following treatment for breast cancer? J Rural Health. 2010; 26: 402 - 405.

38. Ashing-Giwa KT and Lim J. Examining the impact of socioeconomic status and socioecologic stress on physical and mental health quality of life among breast cancer survivors. Oncol Nurs Forum. 2009; 36(1): 79 - 88.

39. Bown DJ, Alfano CM, McGregor BA, et. al. Possible socioeconomic and ethnic disparities in quality of life in a cohort of breast cancer survivors. Breast Cancer Res Treat. 2007; 106: $85-95$.

40. Wilder Smith A, Reeve BB, Bellizzi KM, et. al. Cancer, comorbidities, and health-related quality of life of older adults. Health Care Financ R. 2008; 29(4): 41 - 56.

41. Harrison SA, Hayes SC, and Newman B. Age-related differences in exercise and quality of life among breast cancer survivors. Med Sci Sports Exerc. 2010; 42(1): 67 - 74.

42. Bellizzi KM, Rowland JH, Jeffery DD, and McNeel T. Health behaviors of cancer survivors: examining opportunities for cancer control intervention. J Clin Oncol. 2005; 23(34): $8884-8893$.

43. Andersen RM. Revisiting the behavioral model and access to medical care: does it matter? J Health Soc Behav. 1995; 36: 1 - 10.

44. Andersen RM. Health surveys and the behavioral model of health services use. Med Care. 2008; 46(7): $647-653$.

45. Centers for Disease Control and Prevention (CDC). Behavioral risk factor surveillance system survey data. Atlanta, GA: U.S. Department of Health and Human Services, Centers for Disease Control and Prevention, 2009. 


\section{CHAPTER 2}

"A National Study Comparing Differences in HRQOL of Breast, Prostate, and Colorectal Cancer Survivors Vs. Propensity Score Matched Controls, and by Cancer Type and Gender"

Traci LeMasters, M.A. ${ }^{1}$

Suresh Madhavan, Ph.D. ${ }^{1}$

Usha Sambamoorthi, Ph.D. ${ }^{1}$

Sobha Kurian, M.D. ${ }^{2}$

${ }^{1}$ Department of Pharmaceutical Systems and Policy, School of Pharmacy, West Virginia University, Morgantown, WV

${ }^{2}$ Mary Babb Randolph Cancer Center, West Virginia University, Morgantown WV 


\begin{abstract}

\section{Objectives}

The objectives of this study were to compare the prevalence of specific measures of HRQOL between breast, prostate, female, and male colorectal cancer survivors to propensity score matched controls, and to compare HRQOL by type of cancer and gender.
\end{abstract}

\title{
$\underline{\text { Methods }}$
}

A cross-sectional study was conducted using a sample of breast, prostate, and colorectal cancer survivors 18 years of age and older and > 1 year past diagnosis were selected from the 2009 BRFSS. A greedy algorithm and matching without replacement used propensity scores to match 3 controls to every 1 case on age, gender, race/ethnicity, income, insurance status, and region of the U.S. HRQOL measures compared were life satisfaction, perceived emotional support, activity limitations, perceived general, physical and mental health, and sleep quality. Chi-square tests were used to test for covariate balance and compared prevalence of health conditions and behaviors. Binomial and multinomial logistic regression models were used to estimate the probabilities of behaviors for cancer cases compared to controls.

\section{$\underline{\text { Results }}$}

The final study sample consisted of 6,393 breast, 3,636 prostate, 1,111 female colorectal, and 824 male colorectal cancer survivors. Compared to matched controls, cancer survivors were up to 3.67 times more likely (95\%CI: $2.09,6.47)$ at $1-5$ years post diagnosis, and up to 1.91 times more likely $>5$ years post diagnosis to perceive their general health to be fair/poor (95\%CI: 1.30, 2.79). Breast, female, and male colorectal cancer survivors were up to 2.62 times more likely $(95 \% \mathrm{CI}: 1.72,3.99)$ to report activity limitations compared to matched controls. Additionally, colorectal cancer survivors were more likely to report worse physical health than 
their matched controls. Male colorectal and prostate cancer survivors were more likely to report worse mental health, and prostate cancer survivors were more likely to report a lack of emotional support and not enough sleep compared to their matched controls. Comparisons by cancer type found that male colorectal cancer survivors were more likely to report activity limitations and perceive their general and physical health to be worse than prostate cancer survivors. Gender comparisons found that females were more likely to hold poorer perceptions of their general, physical, and mental health, report not enough sleep, and not receiving enough emotional support, but more likely to be satisfied with life.

\section{Conclusions}

All cancer survivor groups reported more limitations and held poorer perceptions of their general health. Differences between matched controls for other HRQOL measure vary by type of cancer, although compared to similar males without cancer, male cancer survivors reported worse outcomes on measures such as mental health, sleep, and emotional support. However, when female survivors were compared to male survivors, females reported worse outcomes for all measures except life satisfaction. 


\section{$\underline{\text { Introduction }}$}

Approaching 12 million strong, cancer survivors are a growing population within the United States (U.S.) attributable to increased adoption of regular cancer screenings, advances in cancer detections and treatments, as well as an aging population ${ }^{1 \& 2}$. Not only is the number of cancer survivors increasing, but also the number of cancer survivors living 5 years or longer. As of 2008 , about $66 \%$ of the cancer survivors were living 5 or more years post diagnosis ${ }^{3}$. In spite of these improved survival rates, many survivors continue to experience long lasting symptoms and or late effects of the cancer and its treatment which can negatively affect their physical and mental health, psychosocial well-being, functional status, and consequently their health-related quality of life (HRQOL) $)^{4-9}$. Common symptoms and treatment effects experienced by cancer survivors that can affect HRQOL, defined by Testa \& Simonson as the "physical, psychological, and social domains of health, seen as distinct areas that are influenced by a person's experiences, beliefs, expectations, and perceptions" ${ }^{10}$, may include physical limitations, chronic pain, lymph edema, fatigue, sleep disturbances, depression, anxiety, sexual dysfunction, and infertility 5, 6,1115.

Among cancer survivors living in the U.S., survivors of breast (22\%), prostate (20\%), and colorectal cancer $(9 \%)$ are the three most numerous groups of survivors ${ }^{3}$. Numerous studies have examined HRQOL among breast, prostate, or colorectal cancer alone ${ }^{16-18}$. However, these studies did not directly compared measures of HRQOL between survivors of breast, prostate, and colorectal cancer to matched non-cancer controls to identify differences between survivors and similar individuals without a history of cancer, and/or within cancer survivors to identify differences by cancer type and gender. 


\section{$\underline{\text { Previous Research }}$}

\section{Comparisons by Cancer Type \& Gender}

Between cancer types, Deshields and colleagues (2011) observed that among a small group of recently diagnosed survivors, colorectal cancer survivors reported a greater prevalence of difficulty sleeping (71\%) and lack of energy (79\%), followed by breast (59\% \& 71\%) and then prostate cancer survivors (39\% \& 41\%), respectively. Yet, breast cancer survivors reported a greater prevalence of pain (64\%) worrying (53\%) and feeling sad (50\%), followed by colorectal $(53 \%, 38 \%$, and $47 \%)$, then prostate cancers survivors $(26 \%, 27 \%$, and $24 \%)$, respectively ${ }^{19}$. In a small group of cancer survivors sampled from the 2000 National Health Interview Survey, Yabroff and colleagues (2004) observed that a greater prevalence of colorectal (39.9\%) and prostate cancer survivors reported limitations (33.7\%) compared to breast cancer survivors (30.6\%), but a greater prevalence of breast $(37.4 \%)$ and prostate cancer survivors $(36.6 \%)$ perceived their general health status as excellent/very good, compared to colorectal cancer survivors $(26.2 \%)^{20}$. Similar findings were observed among a small sample of long-term Australian cancer survivors studied by Eakin and colleagues (2006). Prostate (35.9\%) and breast cancer survivors $(31.7 \%)$ more often perceived their general health status to be excellent/very good, compared to colorectal cancer survivors $(17.9 \%)^{21}$. However, survivors of breast (38.5\%) and colorectal cancer $(34.8 \%)$ had a higher prevalence of moderate/high risk mental health scores compared to prostate cancer survivors $(24.5 \%)$.

Concerning gender differences in HRQOL, findings from two studies of quality of life among colorectal cancer survivors suggest that females may experience worse physical health, mental health, and pain as compared to male cancer survivors $8 \& 22$. 


\section{Comparisons Between Cancer Survivors and Non-Cancer Controls}

Compared to those without a history of cancer, Yabroff and colleages (2004) observed that breast, prostate, and colorectal cancer survivors reported a greater prevalence of activity limitations (39.9\% - 30.6\% vs. $23.8 \%$ ) and perceived their general health to be excellent/very good less often (26.2\% - $37.4 \%$ vs. $53.1 \%)$ compared to non-cancer controls matched for age,

gender, and education ${ }^{20}$. Eakin and colleagues also observed that survivors of breast, prostate, and colorectal cancer perceived their general health to be excellent/very good less than noncancer controls (35.9\% - 17.9\% vs. $45.1 \%)$ matched for age and gender ${ }^{21}$. However, survivors of breast (38.5\%) and colorectal cancer (34.8\%) had a higher prevalence of moderate/high risk mental health scores $(38.5 \% \& 34.8 \%$ vs. $32.6 \%)$ compared to non-cancer controls, but prostate cancer survivors had a lower prevalence of moderate/high risk mental health score (24.5\% vs. $32.6 \%)$ compared to non-cancer controls ${ }^{21}$. Finally, Smith and colleagues (2008) observed that among a large, national sample of Medicare beneficiaries, age $\geq$ 65 years, survivors of breast, prostate, colorectal cancer had significantly worse physical health scores than those without a history of cancer, but only survivors of breast and colorectal cancer had significantly worse mental health scores than those without a history of cancer ${ }^{23}$. Statement of the Problem

While some consistent findings regarding general health, mental health and activity limitations have emerged from the previously described research, it remains unknown how breast compared to female colorectal cancer survivors and how prostate compared to male colorectal cancer survivors may differ across measures of HRQOL, as colorectal cancer survivors have not been compared to other cancer survivors stratified by gender. Furthermore, these studies have been limited in various ways. Limitations in study design include a small number of HRQOL 
measures examined, small sample size, only survivors age $\geq 65$ years, only survivors living $\geq 5$ years post diagnosis, and/or studies utilizing a comparison group, used controls not matched to cases, or matched only for age and gender or age, gender, and education, and therefore not controlling for remaining confounding bias. Because observational studies are at risk for confounding effects due to the lack of randomization inherent to experimental studies, researchers should implement methods to control for confounding effect to reduce threats to validity. Reeve et. al. describe how the method of propensity score matching can effectively reduce bias in cancer research when utilizing control groups to compare outcomes between cancer survivors and those without a history of cancer ${ }^{24}$. While traditional methods of matched sampling, stratification, and covariate adjustment are often limited by the number of variables they can control for and/or are limited by assumptions such as normal distributions and linearity, propensity score matching is not limited in these ways.

Bearing these thoughts in mind, the aims of this study are to 1) compare the prevalence of HRQOL outcome measures, specifically life satisfaction, perceived level of emotional support, activity limitations, perceived general health, perceived physical health, perceived mental health, and sleep quality between breast, prostate, female colorectal and male colorectal cancer survivors to their unique non-cancer control groups matched or age, gender, race/ethnicity, income, insurance status, and region of the U.S. using a propensity score; 2) compare the estimated probabilities of specific HRQOL outcomes for each cancer type to their propensity score matched controls by fitting logistic regression models stratified by time since diagnosis $(1-5$ years and $>5$ years) to examine how these behaviors may change in comparison to matched controls over the course of the cancer survivorship continuum; and 3) compare the estimated probabilities of specific HRQOL outcomes between cancer types (breast cancer vs. female 
colorectal and prostate vs. male colorectal) and gender (female vs. male colorectal and breast vs. prostate), in order to measures differences in HRQOL associated with cancer type and gender.

The current study will utilize Ronald M. Andersen's Behavioral Model of Health Services Use framework to examine the association between environmental, predisposing, enabling, need factors, and HRQOL between survivors of breast, prostate, colorectal cancer survivors, and propensity score matched controls. The Behavioral Model of Health Services Use is commonly used to guide studies utilizing national health survey data ${ }^{25}$. This study will analyze a large, nationally representative sample, the 2009 Behavioral Risk Factor Surveillance System (BRFSS) population based survey. The environmental factors assessed are region of United States and metro status. Predisposing characteristics include age, gender, race, education and time since diagnosis. Enabling factors are marital status, employment status, insurance status, income, and usual source of care. Measures of need are presence of cancer, type of cancer, presence of arthritis, asthma, diabetes, hypertension, high cholesterol, heart disease, and stroke. Measures of HRQOL life satisfaction, perceived level of emotional support, presence of activity limitation, perceived general health status, perceived physical health status, perceived mental health status, and sleep quality.

\section{Methods}

\section{$\underline{\text { Data Source }}$}

Data analyzed was provided by the 2009 Centers for Disease Control's national Behavioral Risk Factor Surveillance System (BRFSS) survey ${ }^{26}$. The BRFSS is an annual, statebased telephone survey administered to non-institutionalized citizens of all 50 states, the District of Columbia, Puerto Rico, the U.S. Virgin Islands, and Guam adults aged 18 years and older. The survey collects information pertaining to prevalence of diseases, risky health behaviors, 
preventive health care utilization, perceived health status, access to health care services, sociodemographic, and environmental characteristics. The core component is a standard set of questions administered to all states and territories. Optional modules, however, collect information of specific health topics and are up to the discretion of each state as to whether they will be administered. Moreover, additional questions that are not evaluated by the CDC may be added to the questionnaire by individual states. The 2009 BRFSS response rate was 52.5\%, resulting in a total sample size of $432,607^{27 \& 28}$. Post-stratification weights are used to insure representative national population based estimates ${ }^{29}$. All data used in this study was taken from the core component file, and excluded responses from Puerto Rico, the U.S. Virgin Islands, and Guam.

\section{$\underline{\text { Study Sample }}$}

The cases of breast, prostate, and colorectal cancer survivors was identified through a series of questions in the 2009 BRFSS. The Cancer Survivors section of the core module begins by asking, "Have you ever been told by a doctor, nurse, or other health professional that you had cancer?" Of those who answered "yes" to this question, they were then asked, "How many different types of cancer have you had?" For purposes of this study, we only included survivors of one primary cancer. Cancers of the breast, prostate, colon, and rectum were identified with the question, "What type of cancer was it?" Colon and rectum were combined to form colorectal cancer. Male survivors of breast cancer were excluded from the sample. Only survivors age $\geq$ 18 years were included in the sample in order to comprise an adult sample. The question, "At what age were you told that you had cancer?", allowed for the calculation of time since diagnosis by subtracting the age at diagnosis from the currently reported age. To avoid the competing interest of possible ongoing treatment, only breast, prostate, and colorectal survivors who were > 
1 year post diagnosis were included in the study sample. However, questions regarding the type of treatment received and stage at diagnosis were not asked, and therefore these covariates could not be controlled for in this study. Finally, participants with missing information for any dependent variables were excluded from the sample. The final case sample consisted of 6,393 breast, 3,636 prostate, 1,111 female and 824 male colorectal cancer survivors.

\section{$\underline{\text { Measures }}$}

\section{Dependent Variables}

Measures of HRQOL were assessed by the following survey questions: life satisfaction = "In general, how satisfied are you with your life?" (very satisfied, satisfied, dissatisfied, or very dissatisfied), perceived level of emotional support = "How often do you get the social and emotional support that you need?" (always, usually, sometimes, rarely, or never), presence of activity limitations = "Are you limited in any way in any activities because of physical, mental, or emotional problems?" (yes or no), perceived general health status = "Would you say that in general your health is:" (excellent, very good, good, or fair, poor). Perceived physical and mental health $=$ "Now thinking about your physical health, which includes physical illness and injury, for how many days during the past 30 days was your physical health not good?" and "Now thinking about your mental health, which includes stress, depression, and problems with emotions, for how many days during the past 30 days was your mental health not good?" (number or days or none), and sleep quality = "How many days did you not get enough sleep in the past 30 days?" (number of days or none). For purposes of this study, responses to questions about physical health, mental health, and sleep quality were categorized as "none", "1 - 15 days", and "> 15 days". 


\section{Independent Variables}

Environmental factors were metro status (metro or non-metro) where metro $=$ in center city of an MSA, outside center city of an MSA, but inside the county containing the center city, and inside a suburban county of the MSA and non-metro = in an MSA that has no center city and not in an MSA; and region of the U.S. (Northeast, Midwest, West, and South) grouped by state according to defined U.S census regions [10A]. Measures of enabling factors included marital status (married, widowed, separated/divorced, and never married); employment status (employed or unemployed) where employed $=$ employed for wages and self-employed and unemployed $=$ out of work for more than 1 year, out of work for less than 1 year, homemaker, student, retired and unable to work; annual household income $(<\$ 25,000, \$ 25,000$ - $\$ 35,000, \$ 35,000$ $\$ 50,000, \$ 50,000-\$ 75,000,>\$ 75,000$, and missing/don't know), insurance status (insured or uninsured), and have a usual source of care (yes or no).

Predisposing factor were age $(18-49,50-54,55-59,60-64,65-69,70-74$, and $\geq$ 75 years), gender (male or female), race/ethnicity (White, African American, Latino, and Other), education (< high school, high school graduate, some college or technical school, and college or technical school graduate) and time since diagnosis calculated by subtracting the cancer survivor's age at diagnosis from their current age.

Measures of need were considered to be the presence of specific health condition according to an affirmative response to ever being told so by a health professional. Health condition are as follows: heart disease (answered yes to ever been told to have myocardial infarction, angina or coronary heart disease), hypertension (yes to every been told to have high blood pressure), high cholesterol (adults who had their blood cholesterol checked and told it was high), diabetes (yes to ever been told to have it, have it only during pregnancy, or borderline 
diabetes), stroke (yes to ever been told to have had a stroke), asthma (yes to ever been told to have asthma), and arthritis (yes to ever been told to arthritis).

\section{$\underline{\text { Analysis }}$}

\section{Propensity Score Matched Controls}

Like the cancer cases, potential controls were selected if they were of age $\geq 18$ years and did not have missing responses for the dependent variables. Logistic regression was used to derive a propensity score for each case and potential control based upon the probability of the individual having cancer and belonging to various categories of age, gender, race/ethnicity, income, insurance status, and region of the U.S. Matching without replacement was performed using a greedy matching algorithm to assign three controls to every case. A 3:1 control sample was used to control for the effects of any remaining bias. After matching, Chi-square tests were performed to determine if balance was achieved on the covariates between the cases and controls.

\section{Statistical Methods}

Descriptive statistics and Chi-square tests were performed to compare socio-demographic factors, health conditions, and measures of HRQOL between cases and controls. Differences were determined to be significant for $p$ values $\leq .05$. The probabilities of reporting specific outcomes of HRQOL measures were compared between cases and controls using binary and multinomial logistic regression adjusting for selected covariates. Specific covariates adjusted for in regression models were the presence of cancer (case vs. control comparisons only), race/ethnicity, age, marital status, metro status, region of the U.S., education, employment, income, health insurance, usual source of care, CVD-MS (Cardiovascular Disease - Metabolic Syndrome, includes the presence of heart disease, high cholesterol, hypertension, and or 
diabetes), stroke, asthma, and arthritis. Regression models were stratified by time since diagnosis ( $1-5$ years and $>5$ years), preserving the propensity score matched control pairings for each group of survivors. The same HRQOL comparisons were modeled between the types of cancers and genders, omitting the time since diagnosis stratifications. Specific covariates adjusted for in regression models were the presence of cancer (case vs. control comparisons only), race/ethnicity, age, marital status, metro status, region of the U.S., education, employment, income, health insurance, usual source of care, CVD-MS (Cardiovascular Disease - Metabolic Syndrome, includes the presence of heart disease, high cholesterol, hypertension, and or diabetes), stroke, asthma, and arthritis. HRQOL measures modeled using binary logistic regression were life satisfaction (very satisfied/satisfied) and activity limitations (yes). Multinomial logistic regression was used to model level of emotional support (rarely/never and sometimes), perceived general health status (fair/poor and good), perceived physical health (bad and medium), perceived mental health (bad and medium), and sleep quality (bad and medium). Reference categories are shown in parenthesis. Parameter estimates calculated in the regression models were converted to odds ratios and corresponding $95 \%$ confidence intervals.

Data was weighted so that all estimates provided are nationally representative. Poststratification weighs were applied to the data before the propensity score matching process. All analysis were conducted using SAS version 9.2 software (SAS Institute Inc., Cary, NC), to account for the complex sample design.

\section{$\underline{\text { Results }}$}

\section{Description: Table 1}

A comparison of demographic characteristics between adult survivors of breast, colorectal, and prostate cancers living > 1year post diagnosis who participated in the 2009 
BRFSS to their propensity score matched controls is presented in Table 1 . While the age $\geq 75$ years represented was the majority age group of breast (28.7\%), female colorectal (39.5\%), male colorectal $(29.9 \%)$ and prostate $(45.3 \%)$ cancer survivors. All cancer survivor groups were mostly white $(78.6 \%-83.3 \%)$, married $(56.4 \%-77.1 \%)$, unemployed $(63.8 \%-76.6 \%)$, insured $(95.7 \%-97.9 \%)$, reported a usual source of care $(94.6 \%-96.4 \%)$, residing in the South region of the U.S. (33.8\% - 40.3\%), and living in a metropolitan area $(77.9 \%-82.1 \%)$. Survivors of breast, male colorectal and prostate cancer reported higher levels of education attainment, whereas the majority of female colorectal cancer survivors were only high school graduates. The majority of prostate cancer survivors had an annual income $\geq \$ 75,000$, while breast, female and male colorectal cancer survivors had an annual income $<\$ 25,000$.

Balance was achieved between cancer survivors and their matched controls for all covariates modeled in the propensity score matching process. Additionally, there was no difference between cancer survivors and their matched controls for metro status and marital status. However, survivors of breast cancer were more frequently reported being a college or technical school graduate compared to their matched controls $(36.5 \%$ vs. $32.1 \%)(p<.000)$ and prostate cancer survivors more frequently reported being unemployed compared to their matched controls $(76.2 \%$ vs. $73.1 \%)(p=.049)$. All cancer groups, with the exception of female colorectal, more frequently reported having a usual source of care $(p<.000)$ compared to their matched controls.

A comparison of the prevalence of specific health conditions between cancer survivor and matched controls is shown in Table 2. Compared to their matched controls, survivors of breast cancer reported a greater prevalence of arthritis $(52.9 \%$ vs. $48.4 \%)(p=.001)$, diabetes $(17.8 \%$ vs. $15.9 \%)(p=.050)$, and high cholesterol $(48.7 \%$ vs. $46.1 \%)(p=.001)$. In similar 
fashion, survivors of prostate cancer reported a greater prevalence of arthritis (47.8\% vs. $41.5 \%)$ $(p=.000)$, hypertension $(58.2 \%$ vs. 53.7\%) $(p=.007)$, and high cholesterol $(53.8 \%$ vs. $48.1 \%)$ $(p<.000)$ compared to their matched controls. Compared to their controls, male colorectal cancer survivors reported a greater prevalence of asthma $(13.3 \%$ vs. $8.0 \%)(p=.003)$. $\underline{\text { Aim 1: Table } 3}$

All cancer groups significantly differed from their matched controls with respect to activity limitations and perceived general health status. In comparison to their matched controls, survivors of breast $(30.6 \%$ vs. $25.6 \%)(p<.000)$, female colorectal $(37.0 \%$ vs. $28.4 \%)(p=$ $.003)$, male colorectal $(39.4 \%$ vs. $23.9 \%)(p<.000)$, and prostate $(29.3 \%$ vs. $25.2 \%)(p=.005)$ reported a greater prevalence of activity limitations. However, when compared to their matched controls on perceived general health status, survivors of breast $(41.7 \%$ vs. $52.8 \%)(p<.000)$, female colorectal (32.3\% vs. 44.9\%) ( $p<.000)$, male colorectal $(31.8 \%$ vs. $48.5 \%)(p<.000)$, and prostate $(38.1 \%$ vs. $46.1 \%)(p<.000)$ less frequently perceived their general health to be excellent/very good. Male colorectal cancer survivors reported more bad physical health days compared to their matched controls $(60.5 \%$ vs. $68.7 \%)(p=.004)$, while female colorectal cancer survivors reported more bad mental health days compared to their matched controls (67.2\% vs. 72. 6\%) $(p=.039)$. Additionally, male colorectal cancer survivors less frequently reported being very satisfied/satisfied with their life compared to their matched controls $(92.7 \%$ vs. $95.9 \%)(p=.025)$, and prostate cancer survivors reported more days they did not get enough sleep than did their matched controls $(55.8 \%$ vs. $59.4 \%)(p=.021)$.

\section{Aim 2: Table 4}

Adjusted logistic regression models estimates of HRQOL stratified by time since diagnosis showed that every cancer type was more likely to perceive their general health status 
as fair/poor or good as compared to excellent/very good than their matched controls for almost every each time stratification. This was especially so at $1-5$ years post diagnosis for survivors of breast $(\mathrm{OR}=3.26,(95 \% \mathrm{CI}: 2.43-4.37)$, female colorectal ( $\mathrm{OR}=3.51,95 \% \mathrm{CI}: 2.09-5.92)$, and male colorectal cancer $(\mathrm{OR}=3.67,95 \% \mathrm{CI}: 2.09-6.47)$ who were more than 3 times as likely to perceive their general health as fair/poor as compared to their matched controls, and survivors of prostate cancer were 1.72 times as likely (95\%CI: $1.26-2.35)$ to perceive their general health as fair/poor as compared to excellent/very good than their matched controls. Likewise, at $1-5$ years post diagnosis, survivors of breast ( $\mathrm{OR}=2.42,95 \% \mathrm{CI}: 1.91-3.06)$, female colorectal $(\mathrm{OR}=2.04,95 \% \mathrm{CI}: 1.19=3.49)$, male colorectal $(\mathrm{OR}=1.81,95 \% \mathrm{CI}: 1.05-$ 3.13), and prostate cancer ( $\mathrm{OR}=1.52,95 \% \mathrm{CI}: 1.17-1.97)$ were more likely to perceive their general health as good as compared to excellent/very good than their matched controls. Continuing this trend at $>5$ years post diagnosis, survivors of breast ( $\mathrm{OR}=1.38,95 \% \mathrm{CI}: 1.15-$ 1.65), female colorectal ( $\mathrm{OR}=1.91,95 \% \mathrm{CI}: 1.30-2.79)$, and male colorectal $(\mathrm{OR}=1.91$, 95\%CI: $1.26-2.90)$ were still more likely to perceive their general health as fair/poor as compared to excellent that their matched controls. Survivors of breast (OR $=1.44,95 \%$ CI: 1.23 - 1.68), male colorectal ( $\mathrm{OR}=2.24,95 \% \mathrm{CI}: 1.59-3.17)$, and prostate cancer $(\mathrm{OR}=1.27$, 95\%CI: $1.05-1.54)$ were also more likely to perceive their general health as good as compared to excellent/very good than their matched controls during this time period.

Activity limitations at $1-5$ years post diagnosis were more likely to be reported by survivors of breast ( $\mathrm{OR}=1.41,95 \% \mathrm{CI}: 1.11-1.80)$, female colorectal $(\mathrm{OR}=2.25,95 \% \mathrm{CI}: 1.45$ $-3.51)$, male colorectal $(\mathrm{OR}=2.62,95 \% \mathrm{CI}: 1.72-3.99)$ as compared to their matched controls. Survivors of breast $(\mathrm{OR}=1.18,95 \% \mathrm{CI}: 1.04-1.35)$ and male colorectal $(\mathrm{OR}=1.70,95 \% \mathrm{CI}$ : 
$1.23-2.36$ ) were still more likely to report activity limitations at $>5$ years post diagnosis than their matched controls.

While all groups of survivors perceived their general health to be less than excellent/very good at both time stratification and survivors of breast, female and male colorectal were also more likely to report activity limitations as compared to their matched controls, cancer survivors did not distinguish as much on measures of perceived physical and mental health. Only female colorectal cancer survivors were 1.64 times more likely (95\%CI: $1.06-2.54)$ to perceive their physical health as bad $1-15$ days vs. none in the past month as compared to their matched controls at $1-5$ years post diagnosis, and male colorectal cancer survivors were 1.77 times more likely (95\%CI: $1.23-2.55)$ to perceive their physical health as bad $1-15$ days vs. none as compared to their matched controls as $>5$ years post diagnosis. Male colorectal cancer survivors were 2.00 times more likely (95\%CI: $1.17-3.42)$ to perceive their mental health as bad $1-15$ days vs. none in the past month as compared to their matched controls at $1-5$ years post diagnosis. Prostate cancer survivors were 1.40 times more likely (95\%CI: $1.01-1.93)$ to perceive their mental health as bad $1-15$ days vs. none in the past month as compared to their matched controls at $1-5$ years post diagnosis. Moreover, prostate cancer survivors were 1.48 times more likely (95\%CI: $1.01-2.16)$ at $1-5$ years post diagnosis and 1.78 times more likely (95\%CI: $1.08-2.95)$ to report rarely/never or only sometimes vs. always/usually receiving needed emotional support as compared to their matched controls. Prostate cancer survivors were also 1.61 times more likely (95\%CI: $1.13-2.29)$ at $1-5$ years post diagnosis to report > 15 days of not enough sleep vs. none in the past month as compared to their matched controls.

With regards to life satisfaction, female colorectal cancer survivors were 3.32 times more likely (95\%CI: $1.21-9.13)$ at $1-5$ years post diagnosis to be very satisfied/satisfied vs. very 
dissatisfied/ dissatisfied with their life than their matched controls. However, male colorectal cancer survivors were 0.33 times less likely $(95 \% \mathrm{CI}: 0.17-0.65)$ at $>5$ years post diagnosis to be very satisfied/satisfied vs. very dissatisfied/ dissatisfied with their life as compared to their matched controls.

$\underline{\text { Aim 3: Table 5 }}$

Between females, breast cancer survivors were 0.68 times less likely (95\%CI: 0.50 0.93) to perceive their general health as fair/poor as compared to excellent/very good than female colorectal cancer survivors. Between males, prostate cancer survivors were 0.63 times less likely (95\%CI: $0.45-0.88)$ to perceive their general health as fair/poor as compared to excellent/very good, 0.70 times less likely $(95 \% \mathrm{CI}$ : $051-0.95)$ to perceive their physical health as bad $1-15$ days vs. none in the past month, and 0.61 times less likely (95\%CI: $0.45-0.83)$ to report activity limitations than male colorectal cancer survivors.

Comparing females and males in the gender-neutral cancer (colorectal), female colorectal cancer survivors were 0.67 times less likely $(95 \% \mathrm{CI}: 0.45-0.98)$ to perceived their general health as good as compared to excellent/very good, 0.63 times less likely (95\%CI: $0.45-0.87$ ) to report activity limitations, and 2.20 times more likely to be very satisfied/satisfied with their life compared to male colorectal cancer survivors. However, female colorectal cancer survivors were 1.86 times more likely (95\%CI: $1.16-2.98)$ to perceive their mental health as bad $1-15$ days vs. none mental health in the past month, 3.17 times more likely (95\% CI: $1.76-5.71)$ to report rarely/never vs. always/usually receiving needed emotional support, and 1.53 times more likely to report not getting enough sleep $1-15$ days vs. none in the past month compared to male colorectal cancer survivors. Comparisons of women and men between gender-specific cancers (breast and prostate) found that breast cancer survivors were 1.35 times more likely (95\% CI: 
$1.13-1.63)$ and 1.58 times more likely $(95 \% \mathrm{CI}: 1.28-1.94)$ to perceive their physical and mental health as bad $1-15$ days vs. none in the past month compared to prostate cancer survivors. Breast cancer survivors were also 2.12 (95\%CI: $1.58-2.84)$ and 1.56 (95\%CI: $1.08-$ 2.24) times more likely to report rarely/never and sometimes vs. always/usually receiving needed emotional support and were 1.33 (95\%CI: $1.04-1.70)$ and 1.49 (95\%CI: $1.26-1.77)$ times more likely to report not getting enough sleep > 15 days and $1-15$ days vs. none in the past month compared to prostate cancer survivors.

\section{$\underline{\text { Discussion }}$}

It has been well documented that survivors of breast, prostate and colorectal cancer often continue to experience a diminished HRQOL over the course of a lifetime due to the late and long lasting symptoms and effects of cancer and its treatment, but little research has studied how the measures of HRQOL may differ from those without a history of cancer in their cohort, or from one another by type of cancer and gender. This is the first study to compare these survivors to groups of controls stringently matched for each cancer type in order to minimize bias and capture the unique experience that having had cancer has upon multiple measures of HRQOL. Furthermore, this is the first study these authors know of to compare these HRQOL measures between cancer type and gender it order to provide a better understanding as to how these differences may be associated with variations in HRQOL.

Compared to their matched controls survivors of breast, female colorectal, male colorectal, and prostate cancer at $1-5$ years and $>5$ years post diagnosis were all more likely to perceive their general health as only fair/poor and good vs. excellent/very good. Additionally, breast, female colorectal, and male colorectal cancer survivors at $1-5$ years post diagnosis and breast and male colorectal cancer survivor at $>5$ years post diagnosis were more likely to report 
activity limitations than their matched controls. However, cancer survivors did differentiate from their controls as much on their perceptions of physical and mental health. Only female colorectal cancer survivors at $1-5$ years post diagnosis, and male colorectal cancer survivors at $>5$ years post diagnosis, perceived themselves to have more bad physical health days, and only male colorectal and prostate cancer survivors, at $1-5$ years post diagnosis, perceived themselves to have more bad mental health days in the past month as compared to their matched controls. Moreover, male colorectal cancer survivors at $>5$ post diagnosis were more likely to report low levels of life satisfaction, and prostate cancer survivors at $1-5$ years post diagnosis were more likely to report not getting enough sleep, compared to their matched controls.

While the current study findings concerning perceptions of general health and activity limitations between these survivor groups and controls are in agreement with previous research, the current finding regarding perception of physical and mental health are contrast to previous study findings of mental health between these cancer survivor types. Yabroff and colleagues (2004) found that survivors of breast, colorectal, and prostate cancer reported their general health to be fair/poor and good vs. excellent/very good and the presence of activity of limitations with greater frequency than did a single group of controls matched for age, gender, and education ${ }^{20}$. Eakin and colleagues (2006) also found that an Australian sample of breast, and colorectal cancer survivors 65 years and older, $>5$ years post diagnosis were more likely to perceive their general health as fair/poor and good vs. excellent as compared to a single group of controls matched for age and gender ${ }^{21}$. However, current study findings pertaining to perceived physical and mental health status are more difficult to compare to those of previous research. A study by Smith and colleagues (2008) used a large national survey of Medicare beneficiaries to compare physical component summary scores of breast, prostate, and colorectal cancer survivors to those 
without a history of cancer. They found small, but significant differences, indicating physical health to be slightly worse among all three survivors groups compared to those without a history of cancer ${ }^{23}$. Similarly, a comparison of mental health component summary scores also showed small, but significantly worse outcomes among breast and colorectal cancer survivors as compared to those without a history of cancer. Eakin and colleagues (2006) found only colorectal cancer survivors to be more likely to have worse mental health scores compared to age and gender matched controls ${ }^{21}$. All studies found worse physical health outcomes among colorectal cancer survivors, but this study did not also observe worse physical health among survivors of breast and prostate cancer in comparison to matched controls as was the finding by Smith and colleagues (2008) ${ }^{23}$. This differential finding may be explained by sample characteristics and study design. The data selected for analysis in the study by Smith and colleagues was limited to individuals age > 65 years and older and the comparison group was not matched to the cancer survivors on any measure, and survivors of breast, prostate and colorectal cancers were found to have a significantly greater number of comorbid conditions than those without a history of cancer. The older age group, lacking of matching, and increased comorbidity may explain physical health outcomes observed among all three survivor groups in that study.

HRQOL comparisons between cancer types found that breast cancer survivors were less likely to perceive their general health as fair/poor than were female colorectal cancer survivors. Likewise, prostate cancer survivors were less likely to perceive their general health to be fair/poor, and perceive more bad physical health days, or report activity limitations as compared to male colorectal cancer survivors. The increase in activity limitations and poorer health perceptions among colorectal cancer survivors are most likely attributable to the large 
proportion, $45 \%$ - 71\%, of rectal cancer patients who undergo nonrestorative proctectomy surgery, resulting in the presence of a stoma ${ }^{30}$. Colorectal and rectal patients with stomas report greater limitations and physical problems compared to those without a permanent stoma $22 \& 31$.

Comparisons between genders revealed differences in HRQOL extending beyond activity limitations and general and physical health perceptions. Compared to male colorectal cancer survivors, females were less likely to report activity limitations and perceptions of worse general, however, females were more likely to report not getting enough sleep, not receiving adequate emotional support, as well a greater number of perceived bad mental health days. Yet, female colorectal cancer survivors were almost three times as likely to report being very satisfied/ satisfied with their life in comparison to male colorectal cancer survivors. Differences in HRQOL outcomes between breast cancer survivors and prostate cancer survivors showed a similar pattern. Breast cancer survivors were more likely to report not getting enough sleep, not receiving adequate emotional support, and a greater number of bad mental health days. Additionally, survivors of breast cancer were also more likely to report a greater number of bad physical health days than survivors of prostate cancer. While cancer type cannot be controlled for when comparing breast and prostate cancer survivors, the pattern of HRQOL differences are similar enough to those observed between female and male colorectal cancer survivors to suggest that the differences are a function of gender. In both gender comparisons, women were more likely to report worse outcomes related to sleep quality, emotional support and mental health. Sleep disturbances, insomnia, and fatigue among cancer survivors have been associated with poorer health perceptions, psychosocial outcomes, and increased depression and anxiety ${ }^{14 \& 32}$. Furthermore, female cancer survivors have been found to be more likely to experience insomnia, depression and anxiety than males ${ }^{14 \& 33}$. A recent study by Deshields and colleagues (2011) 
comparing symptom experience between different types of cancer survivors observed that breast $(59 \%)$ and colorectal $(71 \%)$ experienced a greater difficulty sleeping than prostate cancer survivors (39\%). Breast (50\%) and colorectal cancer survivors (47\%) also reported a greater prevalence of feeling sad than prostate cancer survivors $(24 \%){ }^{19}$. A qualitative study comparing gender differences in HRQOL between long-term female and male colorectal cancer survivors with ostomies found that women were more likely to discuss difficulties with sleep and depression than men ${ }^{31}$.

Despite worse HRQOL outcomes regarding psychological and emotional well-being, female cancer survivors, especially, female colorectal, were less likely to report activity limitations and a worse perceived general health than their male comparisons. Studies of physical activity have shown that men tend to be more physical active than women ${ }^{34 \& 35}$. Therefore if baseline levels of physical activity prior to cancer had been higher among men than women, men who have a stoma, or who have had surgery on the lower half of their bodies, may feel that they are more limited and that their general health has been compromised, as compared to those who were not as active prior to cancer. This may also explain why female colorectal cancer survivors reported greater life satisfaction than their male counterparts.

This study was conducted using a large sample of data from a recent national survey. Cancer survivors sampled represented a diverse range in age and time since diagnosis. The method of propensity score matching was used to matching cases to controls in order to provide rigorous control of confounding bias. This study compared a variety of HRQOL measures that encompassed the physical, mental, emotional domains, as well as functional and symptomatic outcomes such as activity limitations and sleep disturbances. These measures were compared to matched controls for each cancer type and between cancer types and genders. Moreover, this 
study was also able to examine differences in both short and long-term survivors in comparison to matched controls. However, this comparison of short and long-term survivors was not able to be conducted in a longitudinal nature, but rather by division of point-in-time measures among a cross-sectional sample. The current study was conducted using self-reported data that may contain responder bias. Furthermore, stage at diagnosis and type of treatment received, both of which are known to be associated with HRQOL outcomes, were not assessed in the survey. Finally, the HRQOL of survivors who have died could not be included in the study. It remains unknown if they would have had a worse HRQOL due to a later stage of diagnosis or if they died of non-cancer related mortality and there HRQOL would have been similar to the study sample.

\section{Conclusions}

The current study has shown that survivors of breast, female colorectal, male colorectal, and prostate cancers experience a diminished HRQOL throughout the survivorship continuum in comparison to similar individuals without a history of cancer. All cancer survivor types reported more activity limitations and poorer perceptions of general health compared to controls. Additional HRQOL outcomes that differed from controls and the magnitude of their severity varied according to cancer type. Some differences were observed between cancer types, with male colorectal cancer survivors reporting poorer general and physical health and more activity limitations that prostate cancer survivors, most likely attributable to treatment. However, numerous differences emerged between men and women. Female colorectal cancer survivors experienced less activity limitations and poor perceptions of general health than did male colorectal cancer survivors, and a similar trend was observed between breast and prostate cancer survivors. Yet, both female cancer survivor groups reported less sleep, poorer mental health, and less emotional support than the male cancer survivors. These findings suggest that physical and 
activity domains of HRQOL among male cancer survivors is more vulnerable to be negatively affected after cancer, while the psychological well-being of female cancer survivors is at a greater risk for decline. As the population of cancer survivors grow due to increasing survival rates, so will the need for monitoring and treatment of the late and long lasting symptoms and their effects upon HRQOL after primary cancer treatment. Whether cancer survivors receive follow-up care from oncology specialists or primary care physicians, it is important that all health care providers recognize the decrements in HRQOL experienced by cancer survivors in comparison to those who have not had cancer. Moreover, it may be equally important to recognize the ways in which cancer survivors may differ from one another with respect to cancer type and/or gender in order to provide care according to the unique needs of each individual.

\section{Acknowledgements}

The study authors acknowledge partial financial funding by the WV CoHORTS Center and AHRQ Grant \# 1R24H5018622-01. 


\section{$\underline{\text { References }}$}

1. Howlander N, Noone AM, Krapcho M, et. al. Estimated United States cancer prevalence. SEER Cancer Statistics Review, 1975 - 2008. National Cancer Institute, Bethesda, MD, 2011. Available at http://seer.cancer.gov/csr/1975_2008/. Last accessed April 9, 2012.

2. Hewitt M, Greenfield S and Stovall E, Editors. From cancer patient to cancer survivor: lost in transition. National Cancer Policy Board (U.S.). Committee on Cancer Survivorship: Improving Care and Quality of Life. Washington, DC: The National Academies Press, 2005. Available at http://www.nap.edu/catalog.php?record_id=11468. Last accessed April 16, 2012.

3. Altekruse SF, Kosary CL, Krapcho M, et. al. Estimated number of persons alive in the U.S. diagnosed with cancer on January 1, 2008 by site. SEER Cancer Statistics Review, 1975 - 2008. National Cancer Institute, Bethesda, MD, 2011. Available at http://seer.cancer.gov/csr/1975_2008/. Last accessed April 9, 2012.

4. Harrington CB, Hansen JA, Moskowitz M, Todd BL, and Feuerstein M. It's not over when it's over: long-term symptoms in cancer survivors - a systematic review. Int J Psychiat Med. 2010; 40(2): $163-181$.

5. Ewertz M and Jensen AB. Late effects of breast cancer treatment and potentials for rehabilitation. Acta Oncol. 2011; 50: 187 - 193.

6. Lee ES, Lee MK, Kim SH, et. al. Health-related quality of life in survivors with breast cancer 1 year after diagnosis compared with the general population. Ann Surg. 2011; 253(1): $101-108$.

7. Richardson LC, Wingo PA, Zack MM, Zahran HS, and King JB. Health-related quality of life in cancerSurvivors between ages 20 and 64 years: population-based estimates from the behavior risk factor surveillance system. Cancer. 2008; 112(6): 1380 - 1389.

8. Phipps E, Braitman LE, Stites S, and Leighton JC. Quality of life and symptom attribution in long-term colon cancer survivors. J Eval Clin Pract. 2008; 14: 254 - 258.

9. Arndt V, Merx H, Stegmainer C, Ziegler H, and Brenner H. Quality of life in patients with colorectal cancer 1 year after diagnosis compared with the general population: a population-based study. J Clin Oncol. 2004; 22(23): 4829 - 4836.

10. Testa MA and Simonson DC. Assessment of quality-of-life outcomes. JAMA. 1996; 334(13): $835-840$.

11. Ewertz M and Jensen AB. Late effects of breast cancer treatment and potentials for rehabilitation. Acta Oncol. 2011; 50: 187 - 193. 
12. Jensen MP, Chang HY, Lai YH, Syrjala KL, Fann JR, and Gralow JR. Pain in long-term breast cancer survivors: frequency, severity, and impact. Pain Med. 2010; 11: 1099 1106.

13. Kyrdalen AE, Dahl AA, Hernes E, Hem E, and Fossa SD. Fatigue in prostate cancer survivors treated with definitive radiotheraphy and LHRH analogs. Prostate. 2010; 70: $1480-1489$.

14. Grov EK, Fossa SD, and Dahl AA. Insomnia in elderly cancer survivors - a populationbased controlled study of associations with lifestyle, morbidity, and psychosocial factors. Results from the Health Survey of North-Trondelag County. Support Care Cancer. 2011; 19(9): 1319 - 1326.

15. Greimel ER, Winter R, Kapp KS, and Haas J. Quality of life and sexual functioning after cervical cancer treatments: a long-term follow-up study. Psycho-Oncol. 2009; 18: 476 482.

16. Montazeri A. Health-related quality of life in breast cancer patients: a bibliographic review of the literature from 1974 to 2007. J Exp Clin Cancer Res. 2008; 27(32): 1 - 32.

17. Eton DT and Lepore SJ. Prostate cancer and health-related quality of life: a review of the literature. Pyscho-Oncol. 2002; 11(4): 307 - 326.

18. Jansen L, Koch H, and Brenner AV. Quality of life among long-term ( $\geq 5$ years) colorectal cancer survivors - systematic review. Eur J Cancer. 2010; 46(16): 2879 - 2888.

19. Deshields TL, Potter P, Olsen S, Liu J, and Dye L. Documenting the symptom experience of cancer patients. J Support Oncol. 2011; 9(6): 216 - 223.

20. Yabroff KR, Lawrence WF, Clauser S, Davis WW, and Brown ML. Burden of illness in cancer survivors: findings from a population-based national sample. J Natl Cancer I. 2004; 96(17): 1322 - 1330.

21. Eakin EG, Youlden DR, Baade PD, Lawler SP, et. al. Health status of long-term cancer survivors: results from an Australian population-based sample. Cancer Epidem Biomar. 2006; 15: 1969 - 1976.

22. Krouse RS, Herrinton LJ, Grant M, et. al. Health-related quality of life among long-term rectal cancer survivors with an ostomy: manifestations by sex. J Clin Oncol. 2009; 27(28): $4664-4670$.

23. Smith AW, Reeve BB, Bellizzi KM, et. al. Cancer, comorbidities, and health-related quality of life of older adults. Health Care Financ R. 2008; 29(4): 41 - 56.

24. Reeve BB, Wilder Smith A, Arora NK, and Hays RD. Reducing bias in cancer research: application of propensity score matching. Health Care Financ R. 2008; 29(4): 69 - 80. 
25. Andersen RM. Health surveys and the behavioral model of health services use. Med Care. 2008; 46(7): $647-653$.

26. Centers for Disease Control and Prevention (CDC). Behavioral risk factor surveillance system survey data. Atlanta, GA: U.S. Department of Health and Human Services, Centers for Disease Control and Prevention, 2009.

27. Centers for Disease Control and Prevention (CDC). 2009 Summary data quality report. Atlanta, GA: U.S. Department of Health and Human Services, Centers for Disease Control and Prevention, 2009. Available at http://www.cdc.gov/brfss/technical_infodata/quality.htm. Last accessed April 9, 2012.

28. Centers for Disease Control and Prevention (CDC). 2009 BRFSS codebook. Atlanta, GA: U.S. Department of Health and Human Services, Centers for Disease Control and Prevention, 2009. Available at http://www.cdc.gov/brfss/technical_infodata/surveydata/2009.htm\#survey. Last accessed April 9, 2012.

29. Centers for Disease Control and Prevention (CDC). 2009 BRFSS overview. Atlanta, GA: U.S. Department of Health and Human Services, Centers for Disease Control and Prevention, 2009. Available at http://www.cdc.gov/brfss/technical_infodata/surveydata/2009.htm . Last accessed April 9, 2012.

30. Ricciardi R, Roberts PL, Read TE, Baxter NN, Marcello PW, and Schoetz DJ. Presence of specialty surgeons reduces the likelihood of colostomy after proctectomy for rectal cancer. Dis ColonRectum. 2011; 54: 207 - 213.

31. Grant M, McMullen CK, Altschuler A, et. al. Gender differences in quality of life among long-term colorectal cancer survivors with ostomies. Oncol Nurs Forum. 2011; 38(5): $587-596$.

32. Theobald DE. Cancer pain, fatigue, distress, and insomnia in cancer patients. Clin Cornerstone. 2004; 6(Suppl 1D): S15 - S21.

33. Deimling GT, Bowman KF, Sterns S, Wagner LJ, and Kahana B. Cancer-related health worries and psychological distress among older adult, long-term cancer survivors. Psycho-Oncol. 2006; 15: 306 - 320.

34. Lin YC, Yeh MC, Chen YM, and Huang LH. Physical activity status and gender differences in community-dwelling older adults with chronic diseases. J Nurs Res. 2010; 18(2): 88 97.

35. Kim HK, Kim MJ, Park CG, and Kim HO. Gender differences in physical activity and its determinants in rural adults in Korea. J Clin Nurs. 2010; 19: 876 - 883. 
Table 1.

Description of Cancer Survivors and Non-Cancer Controls

Behavioral Risk Factor Surveillance System, 2009

\begin{tabular}{|c|c|c|c|c|c|c|c|c|c|c|c|c|c|c|c|c|c|c|c|c|}
\hline \multirow[b]{3}{*}{ All } & \multirow{3}{*}{$\begin{array}{l}\text { BC } \\
N \\
6393 \\
\end{array}$} & \multirow{3}{*}{$\begin{array}{r}\text { Wt. \% } \\
25.0 \\
\end{array}$} & \multicolumn{2}{|c|}{ BC Controls } & \multirow{3}{*}{$\begin{array}{l}\text { Sig. } \\
p \text { value }\end{array}$} & \multicolumn{2}{|c|}{ CC (Female) } & \multicolumn{2}{|c|}{ CC Controls } & \multirow{3}{*}{$\begin{array}{l}\text { Sig. } \\
p \text { value }\end{array}$} & \multicolumn{2}{|c|}{ CC (Male) } & \multicolumn{2}{|c|}{ CC Controls } & \multirow{3}{*}{$\begin{array}{l}\text { Sig. } \\
p \text { value }\end{array}$} & \multirow{3}{*}{$\begin{array}{l}\text { PC } \\
\mathrm{N} \\
\mathbf{3 6 3 6} \\
\end{array}$} & \multirow{3}{*}{$\begin{array}{r}\text { Wt. \% } \\
25.0 \\
\end{array}$} & \multicolumn{2}{|c|}{ PC Controls } & \multirow{3}{*}{$\begin{array}{l}\text { Sig. } \\
p \text { value }\end{array}$} \\
\hline & & & $\mathbf{N}$ & Wt. \% & & $\mathbf{N}$ & Wt. \% & $\mathbf{N}$ & Wt. \% & & $\mathbf{N}$ & Wt. \% & $\mathbf{N}$ & Wt. \% & & & & $\mathbf{N}$ & Wt. \% & \\
\hline & & & 19179 & 75.0 & & 1111 & 25.0 & 3333 & 75.0 & & 824 & 25.0 & 2472 & 75.0 & & & & 10908 & 75.0 & \\
\hline Region of the U.S. & & & & & 0.406 & & & & & 0.954 & & & & & 0.921 & & & & & 0.170 \\
\hline Northeast & 1235 & 22.0 & 3710 & 20.4 & & 198 & 21.0 & 594 & 20.1 & & 153 & 16.4 & 454 & 17.7 & & 615 & 19.6 & 1861 & 18.0 & \\
\hline Midwest & 1609 & 24.1 & 4825 & 23.8 & & 319 & 25.2 & 953 & 24.5 & & 213 & 24.3 & 632 & 23.7 & & 893 & 23.4 & 2670 & 22.4 & \\
\hline South & 1972 & 33.8 & 5926 & 34.3 & & 373 & 36.9 & 1125 & 37.4 & & 271 & 40.3 & 818 & 39.0 & & 1156 & 36.2 & 3522 & 39.8 & \\
\hline West & 1577 & 20.1 & 4718 & 21.5 & & 221 & 16.8 & 661 & 18.0 & & 187 & 19.0 & 568 & 19.5 & & 972 & 20.8 & 2855 & 19.9 & \\
\hline Metro Status & & & & & 0.067 & & & & & 0.300 & & & & & 0.893 & & & & & 0.274 \\
\hline Metro & 4264 & 82.1 & 12525 & 80.5 & & 693 & 77.9 & 2099 & 80.2 & & 516 & 79.1 & 1570 & 79.4 & & 2368 & 81.0 & 7119 & 79.8 & \\
\hline Non-Metro & 2106 & 17.9 & 6562 & 19.5 & & 414 & 22.1 & 1216 & 19.8 & & 303 & 20.9 & 893 & 20.6 & & 1253 & 19.0 & 3739 & 20.2 & \\
\hline Gender & & & & & 1.000 & & & & & 1.000 & & & & & 1.000 & & & & & 1.000 \\
\hline Female & 6393 & 100.0 & 19179 & 100.0 & & 1111 & 100.0 & 3333 & 100.0 & & 0 & 0.0 & 0 & 0.0 & & 0.0 & 0.0 & 0.0 & 0.0 & \\
\hline Male & 0 & 0.0 & 0 & 0.0 & & 0 & 0.0 & 0 & 0.0 & & 824 & 100.0 & 2472 & 100.0 & & 3636 & 100.0 & 10908 & 100.0 & \\
\hline Race/Ethnicity & & & & & 0.280 & & & & & 0.281 & & & & & 0.456 & & & & & 0.561 \\
\hline White & 5559 & 80.6 & 16681 & 81.6 & & 971 & 83.3 & 2913 & 80.3 & & 704 & 80.7 & 2116 & 79.8 & & 3057 & 78.6 & 9203 & 77.7 & \\
\hline AA & 407 & 9.9 & 1226 & 7.9 & & 78 & 10.5 & 231 & 8.8 & & 53 & 10.2 & 154 & 8.2 & & 355 & 12.4 & 1039 & 13.3 & \\
\hline Latino & 163 & 5.2 & 483 & 5.4 & & 26 & 2.1 & 79 & 5.2 & & 33 & 6.3 & 97 & 7.9 & & 93 & 5.5 & 277 & 4.6 & \\
\hline Other & 264 & 4.3 & 789 & 5.1 & & 36 & 4.2 & 110 & 5.6 & & 34 & 2.8 & 105 & 4.0 & & 131 & 3.6 & 389 & 4.4 & \\
\hline Age & & & & & 0.426 & & & & & 0.967 & & & & & 0.936 & & & & & 0.151 \\
\hline $18-49$ & 390 & 10.2 & 1170 & 12.0 & & 40 & 6.8 & 120 & 8.0 & & 36 & 8.8 & 108 & 10.9 & & 18 & 1.1 & 54 & 2.6 & \\
\hline $50-54$ & 477 & 10.6 & 1432 & 10.0 & & 57 & 8.2 & 170 & 8.6 & & 37 & 6.5 & 111 & 6.8 & & 63 & 3.4 & 189 & 2.7 & \\
\hline $55-59$ & 703 & 12.2 & 2119 & 11.7 & & 90 & 7.8 & 270 & 8.6 & & 75 & 10.4 & 225 & 9.3 & & 171 & 5.8 & 516 & 6.3 & \\
\hline $60-64$ & 906 & 13.0 & 2716 & 13.7 & & 114 & 10.6 & 342 & 10.4 & & 115 & 14.9 & 347 & 14.6 & & 412 & 13.2 & 1240 & 13.2 & \\
\hline $65-69$ & 989 & 13.4 & 2959 & 13.2 & & 129 & 10.4 & 388 & 9.2 & & 141 & 15.8 & 425 & 16.4 & & 602 & 13.3 & 1815 & 14.8 & \\
\hline $70-74$ & 938 & 11.9 & 2820 & 12.2 & & 190 & 16.7 & 570 & 15.0 & & 126 & 13.7 & 377 & 12.7 & & 735 & 17.8 & 2175 & 18.3 & \\
\hline$\geq 75$ & 1990 & 28.7 & 5963 & 27.2 & & 491 & 39.5 & 1473 & 40.1 & & 294 & 29.9 & 879 & 29.4 & & 1635 & 45.3 & 4919 & 42.0 & \\
\hline Marital Status & & & & & 0.107 & & & & & 0.296 & & & & & 0.401 & & & & & 0.192 \\
\hline Married & 3019 & 59.4 & 9174 & 58.9 & & 442 & 56.4 & 1321 & 52.0 & & 524 & 75.0 & 1614 & 75.3 & & 2501 & 77.1 & 7263 & 75.8 & \\
\hline Widowed & 1978 & 22.3 & 6169 & 22.8 & & 446 & 26.8 & 1362 & 30.9 & & 142 & 11.1 & 377 & 8.9 & & 561 & 10.6 & 1877 & 11.6 & \\
\hline Sep/Divorced & 1030 & 13.4 & 2813 & 12.1 & & 178 & 13.4 & 501 & 13.0 & & 107 & 9.4 & 334 & 10.8 & & 405 & 9.1 & 1228 & 8.3 & \\
\hline Never Married & 366 & 4.9 & 1023 & 6.2 & & 45 & 3.4 & 149 & 4.1 & & 51 & 4.4 & 147 & 5.0 & & 169 & 3.3 & 540 & 4.3 & \\
\hline Education & & & & & $0.000 * * *$ & & & & & 0.367 & & & & & 0.114 & & & & & 0.606 \\
\hline$<\mathrm{HS}$ & 445 & 6.4 & 1762 & 8.8 & & 142 & 15.2 & 415 & 13.9 & & 99 & 11.7 & 287 & 11.4 & & 385 & 9.7 & 1235 & 10.5 & \\
\hline HS Grad & 2008 & 29.6 & 6537 & 31.9 & & 414 & 36.4 & 1256 & 33.6 & & 264 & 30.5 & 747 & 28.8 & & 979 & 25.4 & 3151 & 26.7 & \\
\hline Some $\mathrm{Col} / \mathrm{TS}$ & 1832 & 27.5 & 5297 & 27.2 & & 324 & 26.6 & 836 & 25.6 & & 193 & 25.5 & 557 & 21.0 & & 795 & 22.7 & 2382 & 22.5 & \\
\hline Col/TS Grad & 2108 & 36.5 & 5583 & 32.1 & & 231 & 21.9 & 826 & 26.9 & & 268 & 32.3 & 881 & 38.9 & & 1477 & 42.1 & 4140 & 40.3 & \\
\hline
\end{tabular}

Abbreviations: BC, Breast Cancer; CC, Colorectal Cancer; PC, Prostate Cancer; AA, African American; Sep, Separated; HS, High School; Grad, Graduate; Col, College TS, Technical School; DK,

\section{Don't Know;}

Asterisks represent significant differences compared to the reference group. ${ }^{* * *} p<.001,{ }^{* *} p<.01, * 0<.05$ 
Table 1.

Description of Cancer Survivors and Non-Cancer Controls

Behavioral Risk Factor Surveillance System, 2009

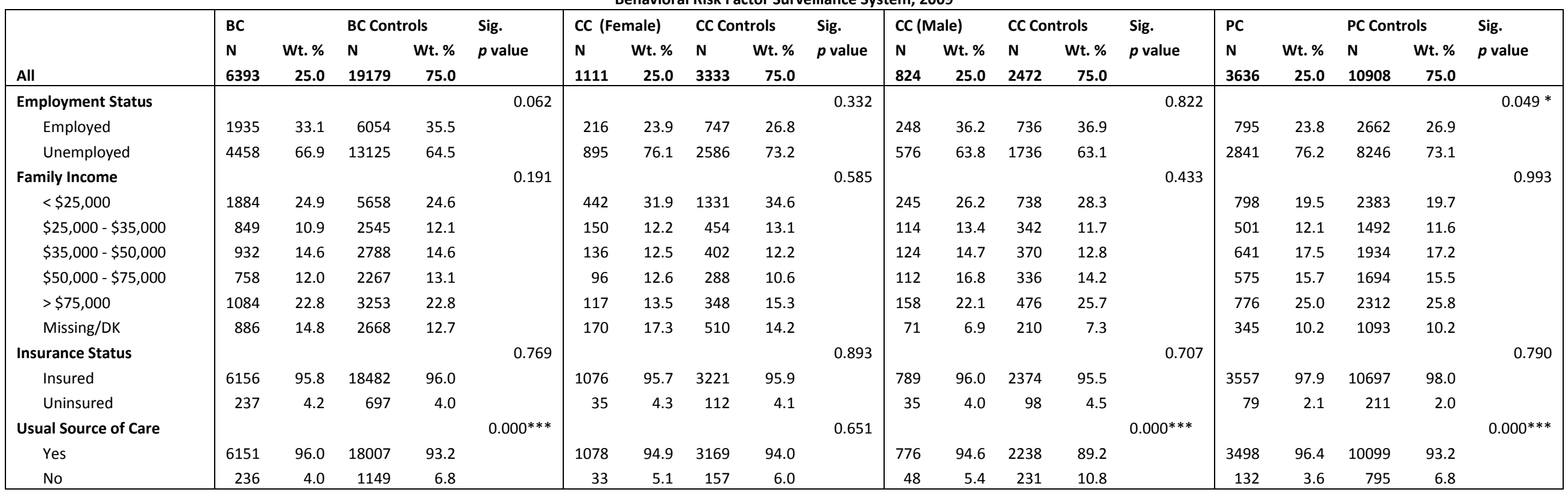

Abbreviations: BC, Breast Cancer; CC, Colorectal Cancer; PC, Prostate Cancer; AA, African American; Sep, Separated; HS, High School; Grad, Graduate; Col, College

TS, Technical School; DK, Don't Know;

Asterisks represent significant differences compared to the reference group. ${ }^{* * *} p<.001, * * p<.01, * p<.05$. 
Table 2.

Comparison of Chronic and Comorbid Health Conditions between Cancer Survivors and Non-Cancer Controls

Behavioral Risk Factor Surveillance System, 2009

\begin{tabular}{|c|c|c|c|c|c|c|c|c|c|c|c|c|c|c|c|c|c|c|c|c|}
\hline \multirow[b]{3}{*}{ All } & \multirow{3}{*}{$\begin{array}{l}\text { BC } \\
N \\
6393\end{array}$} & \multirow{3}{*}{$\begin{array}{r}\text { Wt. \% } \\
25.0\end{array}$} & \multicolumn{2}{|c|}{ BC Controls } & \multirow{3}{*}{$\begin{array}{l}\text { Sig. } \\
p \text { value }\end{array}$} & \multicolumn{2}{|c|}{ CC (Female) } & \multicolumn{2}{|c|}{ CC Controls } & \multirow{3}{*}{$\begin{array}{l}\text { Sig. } \\
p \text { value }\end{array}$} & \multicolumn{2}{|c|}{ CC (Male) } & \multicolumn{2}{|c|}{ CC Controls } & \multirow{3}{*}{$\begin{array}{l}\text { Sig. } \\
p \text { value }\end{array}$} & \multirow{3}{*}{$\begin{array}{l}\mathrm{PC} \\
\mathrm{N} \\
3636\end{array}$} & \multirow{3}{*}{$\begin{array}{r}\text { Wt. \% } \\
25.0\end{array}$} & \multicolumn{2}{|c|}{ PC Controls } & \multirow{3}{*}{$\begin{array}{l}\text { Sig. } \\
p \text { value }\end{array}$} \\
\hline & & & $\mathbf{N}$ & Wt. \% & & $\mathbf{N}$ & Wt. \% & $\mathbf{N}$ & Wt. \% & & $\mathbf{N}$ & Wt. \% & $\mathbf{N}$ & Wt. \% & & & & $\mathbf{N}$ & Wt. \% & \\
\hline & & & 19179 & 75.0 & & 1111 & 25.0 & 3333 & 75.0 & & 824 & 25.0 & 2472 & 75.0 & & & & 10908 & 75.0 & \\
\hline Arthritis & & & & & $0.001^{* *}$ & & & & & 0.083 & & & & & 0.068 & & & & & $0.000 * * *$ \\
\hline Yes & 3591 & 52.9 & 10003 & 48.4 & & 665 & 60.6 & 1873 & 55.0 & & 353 & 46.3 & 1061 & 41.0 & & 1815 & 47.8 & 4714 & 41.5 & \\
\hline No & 2788 & 47.1 & 9121 & 51.6 & & 442 & 39.4 & 1447 & 45.0 & & 469 & 53.7 & 1404 & 59.0 & & 1814 & 52.2 & 6133 & 58.5 & \\
\hline Asthma & & & & & 0.568 & & & & & 0.947 & & & & & $0.003^{* *}$ & & & & & 0.637 \\
\hline Yes & 832 & 13.4 & 2477 & 13.9 & & 148 & 12.5 & 384 & 12.4 & & 94 & 13.3 & 214 & 8.0 & & 366 & 9.5 & 916 & 9.0 & \\
\hline No & 5542 & 86.6 & 16656 & 86.1 & & 958 & 87.5 & 2941 & 87.6 & & 728 & 86.7 & 2253 & 92.0 & & 3263 & 90.5 & 9954 & 91.0 & \\
\hline Heart Disease & & & & & 0.260 & & & & & 0.580 & & & & & 0.538 & & & & & 0.093 \\
\hline Yes & 670 & 8.9 & 2029 & 9.7 & & 158 & 12.7 & 425 & 11.7 & & 177 & 18.9 & 578 & 20.2 & & 780 & 20.1 & 2524 & 22.3 & \\
\hline No & 5657 & 91.1 & 16954 & 90.3 & & 944 & 87.3 & 2861 & 88.3 & & 640 & 81.1 & 1864 & 79.8 & & 2807 & 79.9 & 8260 & 77.7 & \\
\hline Diabetes & & & & & $0.050 *$ & & & & & 0.445 & & & & & 0.184 & & & & & 0.722 \\
\hline Yes & 1144 & 17.8 & 3121 & 15.9 & & 246 & 18.8 & 639 & 20.5 & & 216 & 25.1 & 579 & 21.8 & & 814 & 23.6 & 2517 & 23.1 & \\
\hline No & 5245 & 82.2 & 16049 & 84.1 & & 865 & 81.2 & 2693 & 79.5 & & 606 & 74.9 & 1889 & 78.2 & & 2819 & 76.4 & 8380 & 76.9 & \\
\hline Hypertension & & & & & 0.779 & & & & & 0.301 & & & & & 0.096 & & & & & $0.007^{* *}$ \\
\hline Yes & 3268 & 46.4 & 9730 & 46.8 & & 636 & 56.7 & 1877 & 53.4 & & 455 & 53.1 & 1313 & 48.3 & & 2194 & 58.2 & 6065 & 53.7 & \\
\hline No & 3118 & 53.6 & 9412 & 53.2 & & 473 & 43.3 & 1444 & 46.6 & & 368 & 46.9 & 1150 & 51.7 & & 1439 & 41.8 & 4819 & 46.3 & \\
\hline High Cholesterol & & & & & $0.001^{* *}$ & & & & & 0.399 & & & & & 0.913 & & & & & $0.000^{* * *}$ \\
\hline Yes & 3246 & 48.7 & 9318 & 46.1 & & 554 & 47.0 & 1692 & 48.3 & & 390 & 49.3 & 1220 & 48.8 & & 1982 & 53.8 & 5321 & 48.1 & \\
\hline No & 2957 & 48.0 & 8957 & 48.2 & & 519 & 49.5 & 1492 & 46.6 & & 397 & 46.4 & 1142 & 46.3 & & 1562 & 43.7 & 5118 & 47.2 & \\
\hline No Test & 190 & 3.4 & 904 & 5.7 & & 38 & 3.5 & 149 & 5.1 & & 37 & 4.3 & 110 & 4.8 & & 92 & 2.5 & 469 & 4.7 & \\
\hline Stroke & & & & & 0.497 & & & & & 0.512 & & & & & 0.694 & & & & & 0.870 \\
\hline Yes & 327 & 4.7 & 1051 & 5.0 & & 90 & 8.0 & 206 & 6.7 & & 56 & 6.4 & 190 & 6.9 & & 266 & 6.9 & 814 & 6.7 & \\
\hline No & 6047 & 95.3 & 18077 & 95.0 & & 1018 & 92.0 & 3113 & 93.3 & & 765 & 93.6 & 2277 & 93.1 & & 3358 & 93.1 & 10064 & 93.3 & \\
\hline
\end{tabular}

Abbreviations: BC, Breast Cancer; CC, Colorectal Cancer; PC, Prostate Cancer; AA, African American; Sep, Separated; HS, High School; Grad, Graduate; Col, College

TS, Technical School; DK, Don't Know;

Asterisks represent significant differences compared to the reference group. ${ }^{* * *} p<.001, * * p<.01, * p<.05$. 
Table 3.

Comparison of Health Related Quality of Life of Cancer Survivors and Non-Cancer Controls

Behavioral Risk Factor Surveillance System, 2009

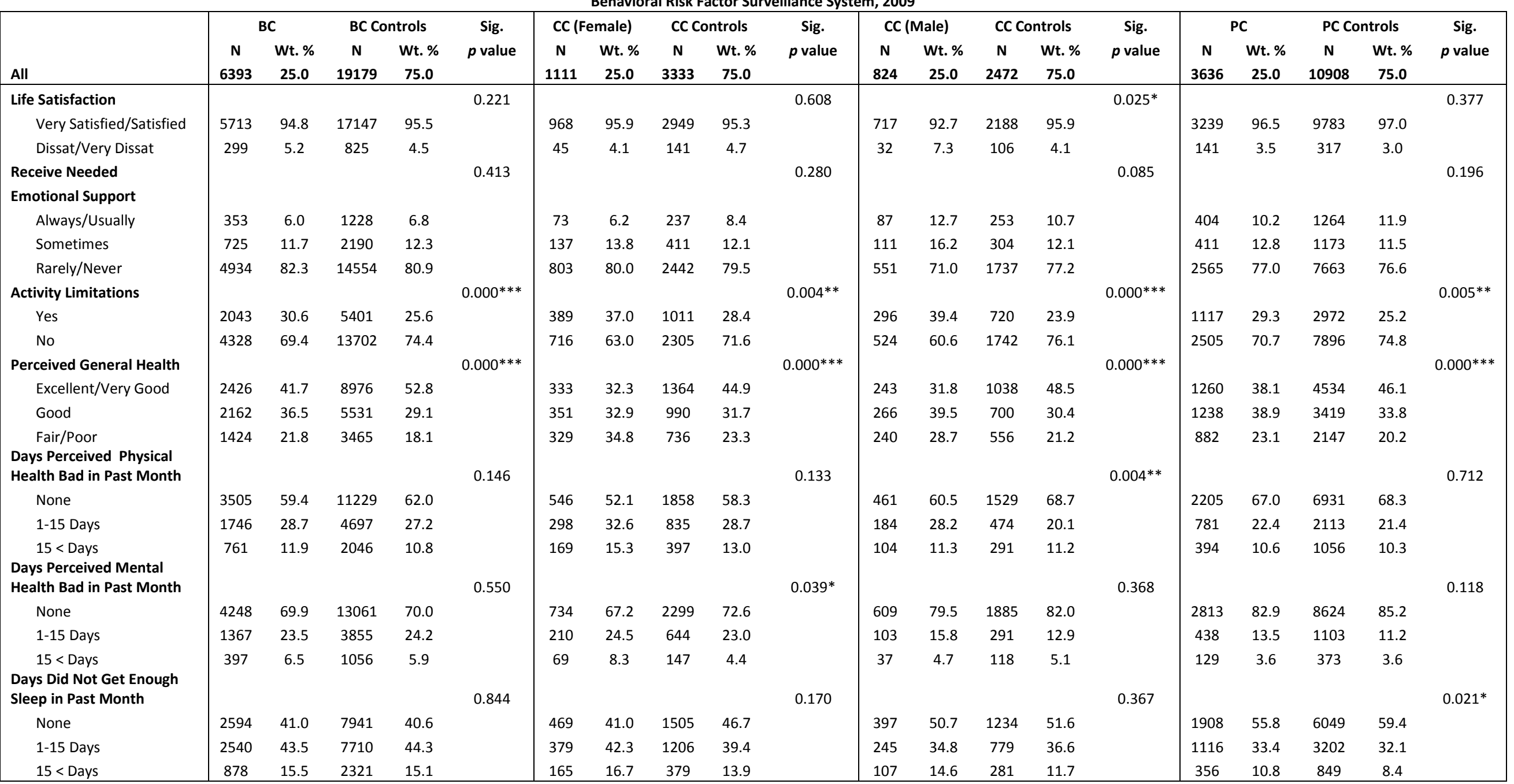

Abbreviations: BC, Breast Cancer; CC, Colorectal Cancer; PC, Prostate Cancer; Dissat, Dissatisfied;

Asterisks represent significant differences compared to the reference group. ${ }^{* * *} p<.001,{ }^{* *} p<.01,{ }^{*} p<.05$. 
Table 4.

Logistic Regression of the Health Related Quality of Life of Cancer Survivors to Non-Cancer Controls By Time Since Diagnosis

Behavioral Risk Factor Surveillance System, 2009

\begin{tabular}{|c|c|c|c|c|c|c|c|c|c|c|c|c|c|}
\hline & & \multicolumn{3}{|c|}{ Breast Cancer } & \multicolumn{3}{|c|}{ Colorectal Cancer (Female) } & \multicolumn{3}{|c|}{ Colorectal Cancer (Male) } & \multicolumn{3}{|c|}{ Prostate Cancer } \\
\hline & & AOR & $95 \% \mathrm{Cl}$ & Sig. & AOR & $95 \% \mathrm{Cl}$ & Sig. & AOR & $95 \% \mathrm{Cl}$ & Sig. & AOR & $95 \% \mathrm{Cl}$ & Sig. \\
\hline \multicolumn{14}{|l|}{ Life Satisfaction } \\
\hline \multirow[t]{2}{*}{ Very Satisfied/Satisfied } & 1 - 5 Years & 0.89 & {$[0.58,1.36]$} & & 3.32 & {$[1.21,9.13]$} & $*$ & 1.78 & {$[0.62,5.10]$} & & 0.96 & {$[0.54,1.73]$} & \\
\hline & $5<$ Years & 0.96 & {$[0.71,1.28]$} & & 0.62 & {$[0.36,1.04]$} & & 0.33 & {$[0.17,0.65]$} & $* *$ & 0.97 & {$[0.65,1.46]$} & \\
\hline \multicolumn{14}{|c|}{ Receive Needed Emotional Support } \\
\hline \multirow[t]{2}{*}{ Rarely/Never } & 1 - 5 Years & 0.89 & {$[0.57,1.38]$} & & 1.41 & {$[0.69,2.87]$} & & 0.93 & {$[0.45,1.95]$} & & 1.48 & {$[1.01,2.16]$} & $*$ \\
\hline & $5<$ Years & 1.21 & {$[0.91,1.60]$} & & 1.10 & {$[0.67,1.81]$} & & 0.70 & {$[0.41,1.20]$} & & 1.01 & {$[0.79,1.28]$} & \\
\hline \multirow[t]{2}{*}{ Sometimes } & 1 - 5 Years & 0.69 & {$[0.42,1.13]$} & & 1.15 & {$[0.49,2.71]$} & & 1.20 & {$[0.52,2.76]$} & & 1.78 & {$[1.08,2.95]$} & $*$ \\
\hline & $5<$ Years & 1.17 & {$[0.84,1.61]$} & & 1.22 & {$[0.68,2.18]$} & & 0.99 & {$[0.53,1.85]$} & & 0.98 & {$[0.71,1.35]$} & \\
\hline \multicolumn{14}{|l|}{ Activity Limitations } \\
\hline \multirow[t]{2}{*}{ Yes } & 1 - 5 Years & 1.41 & {$[1.11,1.80]$} & $* *$ & 2.25 & {$[1.45,3.51]$} & $* * *$ & 2.62 & {$[1.72,3.99]$} & $* * *$ & 1.09 & {$[0.83,1.43]$} & \\
\hline & $5<$ Years & 1.18 & {$[1.04,1.35]$} & $*$ & 1.23 & {$[0.89,1.70]$} & & 1.70 & {$[1.23,2.36]$} & $* *$ & 1.17 & {$[0.97,1.40]$} & \\
\hline \multicolumn{14}{|l|}{ Perceived General Health } \\
\hline \multirow[t]{2}{*}{ Fair/Poor } & 1 - 5 Years & 3.26 & {$[2.43,4.37]$} & $* * *$ & 3.51 & {$[2.09,5.91]$} & $* * *$ & 3.67 & {$[2.09,6.47]$} & $* * *$ & 1.72 & {$[1.26,2.35]$} & $* * *$ \\
\hline & $5<$ Years & 1.38 & {$[1.15,1.65]$} & $* * *$ & 1.91 & {$[1.30,2.79]$} & $* * *$ & 1.91 & {$[1.26,2.90]$} & $* *$ & 1.21 & {$[0.96,1.53]$} & \\
\hline \multirow[t]{2}{*}{ Good } & 1 - 5 Years & 2.42 & {$[1.91,3.06]$} & $* * *$ & 2.04 & {$[1.19,3.49]$} & $* *$ & 1.81 & {$[1.05,3.13]$} & $*$ & 1.52 & {$[1.17,1.97]$} & $* *$ \\
\hline & $5<$ Years & 1.44 & {$[1.23,1.68]$} & $* * *$ & 1.25 & {$[0.89,1.76]$} & & 2.24 & {$[1.59,3.17]$} & $* * *$ & 1.27 & {$[1.05,1.54]$} & $*$ \\
\hline \multirow{2}{*}{\multicolumn{14}{|c|}{$\begin{array}{l}\text { Days Perceived Physical Health } \\
\text { Bad in Past Month }\end{array}$}} \\
\hline & & & & & & & & & & & & & \\
\hline \multirow[t]{2}{*}{$15<$ Days } & 1 - 5 Years & 1.31 & {$[0.94,1.83]$} & & 1.05 & {$[0.58,1.90]$} & & 1.57 & {$[0.85,2.91]$} & & 0.95 & {$[0.63,1.44]$} & \\
\hline & $5<$ Years & 1.09 & {$[0.90,1.32]$} & & 1.36 & {$[0.91,2.04]$} & & 1.00 & {$[0.63,1.60]$} & & 1.00 & {$[0.77,1.31]$} & \\
\hline \multirow[t]{2}{*}{ 1-15 Days } & 1 - 5 Years & 1.17 & {$[0.93,1.46]$} & & 1.64 & {$[1.06,2.54]$} & $*$ & 1.56 & {$[0.95,2.55]$} & & 0.97 & {$[0.75,1.25]$} & \\
\hline & $5<$ Years & 1.05 & {$[0.90,1.22]$} & & 1.21 & {$[0.87,1.70]$} & & 1.77 & {$[1.23,2.55]$} & $* *$ & 1.06 & {$[0.86,1.30]$} & \\
\hline \multirow{2}{*}{\multicolumn{14}{|c|}{$\begin{array}{l}\text { Days Perceived Mental Health } \\
\text { Bad in Past Month }\end{array}$}} \\
\hline & & & & & & & & & & & & & \\
\hline \multirow[t]{2}{*}{$15<$ Days } & 1 - 5 Years & 1.18 & {$[0.75,1.85]$} & & 0.91 & {$[0.44,1.89]$} & & 1.06 & {$[0.55,2.05]$} & & 1.41 & {$[0.79,2.52]$} & \\
\hline & $5<$ Years & 1.03 & {$[0.80,1.34]$} & & 1.58 & {$[0.92,2.70]$} & & 1.27 & {$[0.62,2.60]$} & & 0.68 & {$[0.44,1.03]$} & \\
\hline \multirow[t]{2}{*}{ 1-15 Days } & 1 - 5 Years & 1.00 & {$[0.79,1.26]$} & & 0.88 & {$[0.54,1.43]$} & & 2.00 & {$[1.17,3.42]$} & $*$ & 1.40 & {$[1.01,1.93]$} & $*$ \\
\hline & $5<$ Years & 0.99 & {$[0.84,1.15]$} & & 1.31 & {$[0.87,1.98]$} & & 1.16 & {$[0.75,1.80]$} & & 1.13 & {$[0.89,1.45]$} & \\
\hline \multirow{2}{*}{\multicolumn{14}{|c|}{$\begin{array}{l}\text { Days Did Not Get Enough Sleep } \\
\text { in Past Month }\end{array}$}} \\
\hline & & & & & & & & & & & & & \\
\hline \multirow[t]{2}{*}{$15<$ Days } & 1 - 5 Years & 1.25 & {$[0.92,1.69]$} & & 1.54 & {$[0.83,2.86]$} & & 1.24 & {$[0.69,2.23]$} & & 1.61 & {$[1.13,2.29]$} & $* *$ \\
\hline & $5<$ Years & 0.99 & {$[0.81,1.21]$} & & 1.23 & {$[0.81,1.86]$} & & 1.28 & {$[0.84,1.96]$} & & 1.12 & {$[0.84,1.48]$} & \\
\hline \multirow[t]{2}{*}{ 1-15 Days } & 1 - 5 Years & 1.16 & {$[0.93,1.46]$} & & 1.22 & {$[0.78,1.91]$} & & 1.09 & {$[0.70,1.69]$} & & 1.25 & {$[0.99,1.58]$} & \\
\hline & $5<$ Years & 0.93 & {$[0.81,1.07]$} & & 1.23 & {$[0.91,1.67]$} & & 1.04 & {$[0.73,1.48]$} & & 0.98 & {$[0.81,1.17]$} & \\
\hline
\end{tabular}

Abbreviations: AOR, Adjusted Odds Ratios; Cl, Confidence Intervals;

Asterisks represent significant differences compared to the reference group. ${ }^{* * *} p<.001,{ }^{* *} p<.01,{ }^{*} p<.05$.

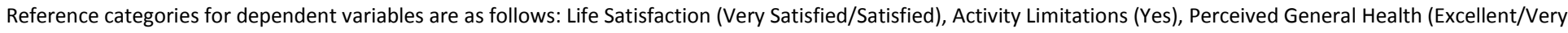
Good),

Days Perceived Physical Health Bad in Past Month (0 Days), Days Perceived Mental Health Bad in Past Month (0 Days), Received Needed Emotional Support (Always/Usually),

Days Did Not Get Enough Sleep in Past Month (0 Days).

Results shown are adjusted for the following covariates: Presence of Cancer (no), Race/Ethnicity (White), Age (18 - 54), Marital Status (married), Metro Status (non-metro), Region of U.S. (Northeast), Education (< high school), Employment Status (not employed), Income (< \$25,000),

Health Insurance (no), Usual Source of Care (no), Arthritis (no), Asthma (no), CVD-MS (no), and Stroke (no).

Reference categories given in parenthesis.

CVD-MS (Cardiovascular disease-Metabolic Syndrome) includes the presence of heart disease, high cholesterol, hypertension, and or diabetes. 
Table 5.

Logistic Regression Comparisons of Health Related Quality of Life of Cancer Survivors by Cancer Type and Gender

Behavioral Risk Factor Surveillance System, 2009

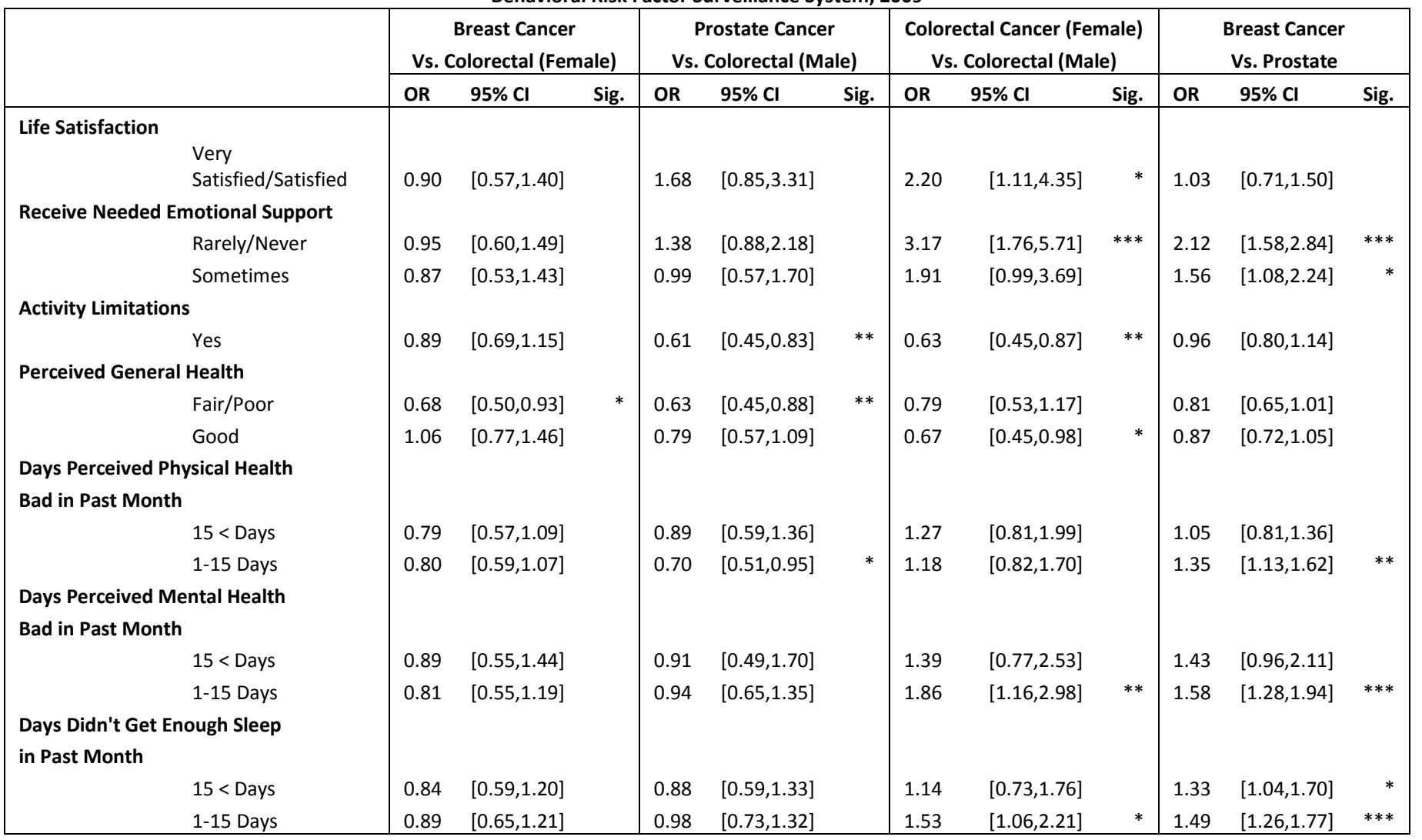

Abbreviations: AOR, Adjusted Odds Ratios; $\mathrm{Cl}$, Confidence Intervals;

Asterisks represent significant differences compared to the reference group. ${ }^{* * *} p<.001,{ }^{* *} p<.01,{ }^{*} p<.05$.

Reference categories for dependent variables are as follows: Life Satisfaction (Very Satisfied/Satisfied), Activity Limitations (Yes), Perceived General Health (Excellent/Very Good),

Days Perceived Physical Health Bad in Past Month (0 Days), Days Perceived Mental Health Bad in Past Month (0 Days), Received Needed Emotional Support (Always/Usually),

Days Did Not Get Enough Sleep in Past Month (0 Days).

Results shown are adjusted for the following covariates: Presence of Cancer (no), Race/Ethnicity (White), Age (18 - 54), Marital Status (married), Metro Status (non-metro), Region of U.S. (Northeast), Education (< high school), Employment Status (not employed), Income $(<\$ 25,000)$,

Health Insurance (no), Usual Source of Care (no), Arthritis (no), Asthma (no), CVD-MS (no), and Stroke (no).

Reference categories given in parenthesis.

CVD-MS (Cardiovascular disease-Metabolic Syndrome) includes the presence of heart disease, high cholesterol, hypertension, and or diabetes. 


\title{
CHAPTER 3
}

"A National Comparison of Health Conditions and Health Behaviors Among American Breast, Prostate, and Colorectal Cancer Survivors to Propensity Score Matched Controls and Between Cancer Type and Gender"

\author{
Traci LeMasters, M.A. ${ }^{1}$ \\ Suresh Madhavan, Ph.D. ${ }^{1}$ \\ Usha Sambamoorthi, Ph.D. ${ }^{1}$ \\ Sobha Kurian, M.D. ${ }^{2}$
}

\footnotetext{
${ }^{1}$ Department of Pharmaceutical Systems and Policy, School of Pharmacy, West Virginia University, Morgantown, WV

${ }^{2}$ Mary Babb Randolph Cancer Center, West Virginia University, Morgantown WV
} 


\begin{abstract}

\section{$\underline{\text { Objectives }}$}

The objectives of this study were to compare the prevalence of specific health conditions and health behaviors between breast, prostate, female, and male colorectal cancer survivors to propensity score matched controls, and to compare health behaviors by type of cancer and gender.
\end{abstract}

\title{
$\underline{\text { Methods }}$
}

A cross-sectional study was conducted using a sample of breast, prostate, and colorectal cancer survivors 18 years of age and older and > 1 year past diagnosis were selected from the 2009 BRFSS. A greedy algorithm and matching without replacement used propensity scores to match 3 controls to every 1 case on age, gender, race/ethnicity, income, insurance status, and region of the U.S. Health conditions compared were arthritis, asthma, heart disease, diabetes, hypertension, high cholesterol, stroke, activity limitations, and perceived general health. Health behaviors compared were flu immunization, physical check-up, cholesterol check, BMI, physical activity, fruit and vegetable consumption, smoking, and alcohol use. Chi-square tests were used to test for covariate balance and compared prevalence of health conditions and behaviors. Binomial and multinomial logistic regression models were used to estimate the probabilities of behaviors for cancer cases compared to controls.

\section{$\underline{\text { Results }}$}

Among a sample of 6,393 breast, 3,636 prostate, 1,111 female colorectal, and 824 male colorectal cancer survivors, breast and prostate cancer survivors reported a greater prevalence of chronic health conditions than matched controls and all survivors reported a greater prevalence of activity limitations and lower perception of perceived general health. Breast cancer survivors 
were more likely to engage in healthier behaviors $1-5$ years after diagnosis, but were more likely to be obese at $>5$ years after diagnosis than controls. Male colorectal cancer survivors were less likely to engage in clinical preventive care at $>5$ years after diagnosis than controls. Female colorectal and breast cancer survivors were less likely be overweight and/or obese, former and/or current smokers, drink any alcohol, and more likely to consume $\geq 5$ servings of

fruits and vegetables per day, but more likely to engage in none or insufficient levels of physical activity compared to male colorectal and prostate cancer survivors, respectively.

\section{Conclusions}

Overall, the current study findings suggest that breast and prostate cancer survivors have more chronic health conditions compared to matched controls than do female and male colorectal cancer survivors. Breast cancer survivors are more likely to engage in healthy behaviors than their matched controls. Female cancer survivors engage in healthier lifestyle behaviors, with the exception of physical activity, compared to male cancer survivors. 


\section{$\underline{\text { Introduction }}$}

Among the 12 million cancer survivors alive in the U.S. today, more than $2 / 3 \mathrm{~s}$ are living five or more years post cancer diagnosis. ${ }^{1,2}$ Despite these increased survival rates, many cancer survivors continue to live with a diminished health-related quality of life due to the late and long lasting effects of the cancer and its treatment. ${ }^{3,4}$ In addition to this post treatment sequelae, a large proportion of cancer survivors are also experiencing the added burden of illness and increasing non-cancer related mortality associated with the high prevalence of obesity related chronic and comorbid conditions. ${ }^{5,6}$ Not only is obesity a known risk factor for many types of cancer, as well as cancer recurrence, but it is also the main risk factor for developing chronic conditions such as heart disease, metabolic syndrome, diabetes, hypertension, and high cholesterol. $^{7,8}$ In fact, several studies have demonstrated that compared to individuals without a history of cancer, cancer survivors as a whole do indeed exhibit a greater number of these obesity related chronic and co-morbid conditions, as well as greater utilization of health care services and consequently, greater health care expenditures. ${ }^{9,10,11}$ Given these findings, it is alarming that $70 \%$ of breast, prostate, and colorectal cancer survivors, who together comprise over $50 \%$ of survivors, have been found to be overweight or obese. ${ }^{2,12,13}$ What is more, survivors of breast and prostate cancer treated with hormone specific therapies, specifically adjuvant estrogen or androgen deprivation, have been shown to be at an increased risk of cardiovascular disease, metabolic syndrome, diabetes, increased body fat composition, decreased lean muscle mass, and weight gain. ${ }^{14,15}$

Thus, recent research efforts have been directed towards characterizing and comparing the lifestyle and clinical preventive health behaviors of cancer survivors to those without a history of cancer, and evaluating the effectiveness of behavioral change upon the health 
outcomes and quality of life among cancer survivors. ${ }^{9,12,16,17,18,19,20}$ Yet, despite experiencing a health scare that many may consider a cue to action, the majority of cancer survivors do not engage in 30 minutes of moderate-to-vigorous physical activity at least 5 days a week, consume 5 or more servings of fruits and vegetables a day, refrain from the use of tobacco, consume no more than 2 alcoholic drinks per day for men, and 1 drink per day for women, as recommended by the American Cancer Society ${ }^{17,21}$, even though these behaviors can increase cancer survival, functional status, and overall health, while decreasing the risk of cancer recurrence, and all-cause morbidity and mortality ${ }^{17,18,19,22}$.

While the general trend in study findings suggest that the majority of cancer survivors do not engage in superior levels of these lifestyle behaviors, compared to those without a history of cancer $^{9,16}$, mixed study findings have left it unclear how each cancer type differs from those without a history of cancer, or how those with a history of cancer differ from one another with respect to cancer type and gender.

\section{$\underline{\text { Previous Research }}$}

\section{Comparing Individuals With \& Without a History of Cancer}

In regards to physical activity, Bellizzi et. al. reported that, as a whole, cancer survivors were $9 \%$ more likely to engage in recommended levels than those without a history of cancer ${ }^{23}$. Kwon et. al. reported that, within certain age groups, prostate cancer survivors engaged in an average of 20 minutes more moderate physical activity per week than those without a history of cancer ${ }^{24}$. Yet, several other studies did not find a difference in physical activity of cancer survivors and individuals without a history of cancer ${ }^{9,16}$.

Although receipt of clinical preventive care has not been as well studied as health behaviors, Bellizzi et. al. found that cancer survivors were more likely to receive recommended 
routine breast and prostate cancer screenings ${ }^{23}$. A study of general clinical preventive care among a British cohort of breast, prostate, and colorectal cancer survivors conducted by Khan et. al. found that cancer survivors were no different from those without a history of cancer in receipt of general clinical preventive care services, such as flu immunization and blood cholesterol checks, but survivors of breast and prostate cancer were less likely to receive blood pressure screenings 25 .

\section{Comparisons by Cancer Type \& Gender}

Among cancer types, study findings by Bellizzi et. al. suggest a higher proportion of prostate cancer survivors are more likely to engage in risky alcohol consumption compared to breast and colorectal cancer survivors ${ }^{23}$, whereas, findings by Coups \& Ostroff suggest a higher proportion of colorectal cancer survivors consume risky levels of alcohol when compared to breast and prostate cancer survivors ${ }^{16}$. A similar inconsistency exists for findings pertaining to nutrition. Coups \& Ostroff reported that prostate survivors are significantly more likely to consume $\geq 5$ servings of fruits and vegetables a day ${ }^{16}$, however Mosher et. al. reported that breast cancer and female colorectal cancer survivors were significantly more likely to be consuming $\geq 5$ servings of fruits and vegetables a day, suggesting females cancer survivors may have a superior diet ${ }^{26}$. Clinical preventive behaviors between cancer types and genders have not been studied among cancer survivors.

\section{Statement of the Problem}

Inconsistencies among the formerly mentioned studies may be attributable to variations in study design, including studies that compared non cancer controls matching only on age and gender $^{9,25}$, or nothing at all ${ }^{16,23,24}$, limited by small sample size ${ }^{9,16}$ or long-term $(\geq 5$ years $)$ survivors only ${ }^{26}$. To control for confounding bias, a few studies stratified analysis by age and or 
gender ${ }^{16,24}$ or used covariate adjustment ${ }^{9,16,23,24}$. However, these methods may not be sufficient to control for confounding effects inherent to observational studies. Reeve et. al. describe how propensity score matching is a superior and effective method of reducing bias in studies utilizing control groups to compare outcomes between cancer survivors and those without a history of cancer ${ }^{27}$.

Bearing these thoughts in mind, the aims of this study are to 1) compare the health conditions, specifically, the presence of arthritis, asthma, heart disease, diabetes, hypertension, high cholesterol, and stroke, as well as, activity limitations and perceived general health between breast, prostate, female colorectal, and male colorectal cancer survivors to their unique noncancer control groups matched for age, gender, race/ethnicity, income, insurance status, and region of the U.S using a propensity score; 2) compare the health behaviors, including physical activity, fruit and vegetable consumption, smoking, and alcohol consumption, as well as, measures of general preventive care, including receipt of flu immunization, physical check-up, and blood cholesterol check between survivors of breast, prostate, female colorectal, and male colorectal cancer and their propensity score matched controls; 3) estimate the probabilities of these health behaviors using logistic regression to compare each cancer type to their propensity score matched controls, stratified by time since diagnosis $(1-5$ years and $>5$ years $)$ to examine how these behaviors may change in comparison to matched controls over the course of the cancer survivorship continuum; and 4) compare the estimated probabilities of these behaviors between cancer type (breast cancer vs. female colorectal and prostate vs. male colorectal) and gender (male vs. female colorectal and prostate vs. breast) using logistic regression. These comparisons will not only compare cancer type, but will compare how unique experiences of 
having had a gender or hormone-specific cancer (prostate and breast) vs. a gender-neutral cancer (colorectal) are associated with differential outcomes.

Guided by Ronald M. Andersen's Behavioral Model of Health Services Use framework, the current study will examine the association between environmental, predisposing, enabling, need factors, and health behaviors among survivors of breast, prostate, colorectal cancers, and propensity score matched controls. Andersen's Behavioral Model is commonly used to guide studies utilizing national health survey data ${ }^{28}$. This study will use national population based

survey data from the 2009 Behavioral Risk Factor Surveillance System (BRFSS) survey ${ }^{29}$. The environmental factors assessed are region of United States and metro status. Predisposing characteristics include age, gender, race, education, and time since diagnosis. Enabling factors are employment status, insurance status, income, usual source of care, and marital status. Measures of need are presence of cancer, type of cancer, presence of heart disease, diabetes, hypertension, high cholesterol, stroke, asthma, arthritis, activity limitations, and perceived general health status. Measures of health behaviors include lifestyle behaviors and general clinical preventive care utilization. Lifestyle behaviors include physical activity, nutritional intake, BMI, tobacco, and alcohol use. General clinical preventive care includes last routine physical check-up, last cholesterol check, and last flu immunization.

\section{Methods}

Data Source

Study data was from the 2009 Centers for Disease Control's national Behavioral Risk Factor Surveillance System (BRFSS) survey ${ }^{29}$. The BRFSS is an annual, state-based telephone survey administered to non-institutionalized citizens of all 50 states, the District of Columbia, Puerto Rico, the U.S. Virgin Islands, and Guam aged 18 years and older. The survey collects 
information pertaining to prevalence of diseases, risky health behaviors, preventive health care utilization, perceived health status, access to health care services, sociodemographic, and environmental characteristics. The core component is a standard set of questions administered to all states and territories. Optional modules, however, collect information of specific health topics and are up to the discretion of each state as to whether they will be administered. Moreover, additional questions that are not evaluated by the CDC may be added to the questionnaire by individual states. The 2009 BRFSS response rate was $52.5 \%$, resulting in a total sample size of $432,607^{30,31}$. Post-stratification weights are used to insure representative national population based estimates ${ }^{32}$. All data used in this study was taken from the core component file, and excluded responses from Puerto Rico, the U.S. Virgin Islands, and Guam. $\underline{\text { Study Sample }}$

The cases of breast, prostate, and colorectal cancer survivors was identified through a series of questions in the 2009 BRFSS. The Cancer Survivors section of the core module begins by asking, "Have you ever been told by a doctor, nurse, or other health professional that you had cancer?" Of those who answered "yes" to this question, they were then asked, "How many different types of cancer have you had?" For purposes of this study, we only included survivors of one primary cancer. Cancers of the breast, prostate, colon, and rectum were identified with the question, "What type of cancer was it?" Colon and rectum were combined to form colorectal cancer. Male survivors of breast cancer were excluded from the sample. Only survivors age $\geq$ 18 years were included in the sample in order to comprise an adult sample. The question, "At what age were you told that you had cancer?", allowed for the calculation of time since diagnosis by subtracting the age at diagnosis from the currently reported age. To avoid the competing interest of possible ongoing treatment, only breast, prostate, and colorectal survivors who were 
$>1$ year post diagnosis were included in the study sample. However, questions regarding the type of treatment received and stage at diagnosis were not asked, and therefore these covariates could not be controlled for in this study. Finally, participants with missing information for any dependent variables were excluded from the sample. The final case sample consisted of 6,393 breast, 3,636 prostate, 1,111 female, and 824 male colorectal cancer survivors.

\section{$\underline{\text { Measures }}$}

\section{Dependent Variables}

Measures of health behaviors were classified into two categories: lifestyle behaviors and receipt of clinical preventive care. Measures of lifestyle behaviors were body mass index (BMI) (underweight/normal, overweight, and obese); calculated variable for recommended level of physical activity (recommended, insufficient, and none); calculated variable for fruit and vegetable consumption ( $\geq 5$ servings per day or $<5$ servings per day); calculated variable for smoking status (current smoker, former smoker, and never smoked); level of alcohol consumption (heavy drinker, light/moderate drinker, no drinks in the past 30 days). Level of alcohol consumption was calculated using calculated variables for male and female heavy drinkers and the number of days an individual consumed alcohol in the past 30 days. Measures of clinical preventive care include time since last physical check-up $(<2$ years ago, $2-5$ years ago, $>5$ years ago, and never), time since last cholesterol check $(<2$ years ago, $2-5$ years ago, $>5$ years ago, and never), and received a flu immunization within the past year (yes or no). Flu immunization was determined by responses to questions assessing receipt of flu shot or flu spray within the past year. 


\section{Independent Variables}

Environmental factors were metro status (metro or non-metro) where metro $=$ in center city of an MSA, outside center city of an MSA, but inside the county containing the center city, and inside a suburban county of the MSA and non-metro = in an MSA that has no center city and not in an MSA; and region of the U.S. (Northeast, Midwest, West, and South) grouped by state according to defined U.S census regions ${ }^{33}$. Enabling factors included marital status (married, widowed, separated/divorced, and never married); employment status (employed or unemployed) where employed $=$ employed for wages and self-employed and unemployed $=$ out of work for more than 1 year, out of work for less than 1 year, homemaker, student, retired and unable to work; annual household income $(<\$ 25,000, \$ 25,000-\$ 35,000, \$ 35,000-\$ 50,000$, $\$ 50,000$ - $\$ 75,000,>\$ 75,000$, and missing/don't know), insurance status (insured or uninsured), and have a usual source of care (yes or no).

Predisposing factors were age $(18-49,50-54,55-59,60-64,65-69,70-74$, and $\geq$ 75 years), gender (male or female), race/ethnicity (White, African American, Latino, and Other), education ( $<$ high school, high school graduate, some college or technical school, and college or technical school graduate) and time since diagnosis calculated by subtracting the cancer survivor's age at diagnosis from their current age.

Measures of need were considered to be the presence of specific health conditions according to an affirmative response to ever being told so by a health professional. Health conditions are as follows: heart disease (answered yes to ever been told to have myocardial infarction, angina or coronary heart disease), hypertension (yes to every been told to have high blood pressure), high cholesterol (adults who had their blood cholesterol checked and told it was high), diabetes (yes to ever been told to have it, have it only during pregnancy, or borderline 
diabetes), stroke (yes to ever been told to have had a stroke), asthma (yes to ever been told to have asthma), and arthritis (yes to ever been told to arthritis). Measures of need also included activity limitations (answering yes to being limited in any way in any activities because of physical, mental, or emotional problems) and perceived general health status (excellent, very good, good, fair, or poor).

$\underline{\text { Analysis }}$

\section{Propensity Score Matched Controls}

Like the cancer cases, potential controls were selected if they were of age $\geq 18$ years and did not have missing responses for the dependent variables. Logistic regression was used to derive a propensity score for each case and potential control based upon the probability of the individual having cancer and belonging to various categories of age, gender, race/ethnicity, income, insurance status, and region of the U.S. Matching without replacement was performed using a greedy matching algorithm to assign three controls to every case. A 3:1 control sample was used to control for the effects of any remaining bias. After matching, Chi-square tests were performed to determine if balance was achieved on the covariates between the cases and controls.

\section{Statistical Methods}

Descriptive statistics and Chi-square tests were performed to compare socio-demographic factors, health conditions, and health behaviors between cases and controls. Differences were determined to be significant for $p$ values $\leq .05$. The probabilities of engaging in specified levels of health behaviors were compared between cases and controls using binary and multinomial logistic regression adjusting for selected covariates. Regression models were stratified by time since diagnosis $(1-5$ years and $>5$ years $)$, preserving the propensity score matched control 
pairings for each group of survivors. The same health behavior comparisons were modeled between the types of cancers and genders, omitting the time since diagnosis stratifications. Specific covariates adjusted for in regression models were the presence of cancer (case vs. control comparisons only), race/ethnicity, age, marital status, metro status, region of the U.S., education, employment, income, health insurance, usual source of care, CVD-MS (Cardiovascular Disease - Metabolic Syndrome, includes the presence of heart disease, high cholesterol, hypertension, and or diabetes), stroke, asthma, arthritis, activity limitations, and general perceived health status. Health behaviors modeled using binary logistic regression were last flu immunization $(\leq 1$ year), last routine physical check-up $(<2$ years) (categories were collapsed to $<2$ years or $\geq 2$ years due to small cell sizes for other times), last cholesterol check ( $<2$ years) (categories were collapsed to $<2$ years or $\geq 2$ years due to small cell sizes for other times), alcohol consumption (light/moderate drinker) (categories were collapsed to drink or don't drink due to small number of responses to heavy drinker) and fruit and vegetable consumption ( $\geq$ 5 servings/day). Health behaviors modeled using multinomial logistic regressions were modeled for smoking status (never smoked), BMI (underweight/normal), and physical activity (recommended level). Reference categories are shown in parenthesis. Parameter estimates calculated in the regression models were converted to odds ratios and corresponding $95 \%$ confidence intervals.

Data was weighted so that all estimates provided are nationally representative. Poststratification weighs were applied to the data before the propensity score matching process. All analysis were conducted using SAS version 9.2 software (SAS Institute Inc., Cary, NC), to account for the complex sample design. 


\section{$\underline{\text { Results }}$}

\section{Description: Table 1}

While the majority of breast (28.7\%), female colorectal (39.5\%), male colorectal $(29.9 \%)$ and prostate $(45.3 \%)$ cancer survivors were 75 years of age and older. The four cancer groups were predominantly white $(78.6 \%-83.3 \%)$, married $(56.4 \%-77.1 \%)$, unemployed $(63.8 \%$ $76.6 \%)$, insured $(95.7 \%-97.9 \%)$, reporting a usual source of care $(94.6 \%-96.4 \%)$, residing in the South region of the U.S. $(33.8 \%-40.3 \%)$, and living in a metropolitan area $(77.9 \%-82.1 \%)$. The majority of breast, male colorectal, and prostate cancer survivors were a college or technical school graduate, whereas the majority of female colorectal cancer survivors were only a high school graduate. Most prostate cancer survivors had an annual income of $\$ 75,000$ or more, whereas most breast, female and male colorectal cancer survivors had an annual income less than $\$ 25,000$.

Balance was achieved between cancer survivors and their matched controls on covariate measures modeled in the propensity score matching process. Breast cancer survivors were more likely to report being a college or technical school graduate compared to their matched controls $(36.5 \%$ vs. $32.1 \%)(p<.000)$ and prostate cancer survivors were more likely to report being unemployed compared to their matched controls $(76.2 \%$ vs. $73.1 \%)(p=.049)$. All cancer survivor groups except for female colorectal were more likely to report having a usual source of care $(p<.000)$ compared to their matched controls.

\section{$\underline{\text { Aim 1: Table } 2}$}

All four cancer groups were significantly more likely to report activity limitations compared to their matched controls, ranging in $29.3 \%(p=.005)$ among prostate cancer survivors to $39.4 \%(p<.000)$ among male colorectal cancer survivors. Similarly, all four cancer 
groups were more likely to report perceiving their general health status as good or fair/poor $(p<$ .000) compared to their matched controls, whereas, the controls were more likely to report perceiving their general health status as excellent/very good. Breast cancer survivors reported an increased prevalence of arthritis $(52.9 \%$ vs. $48.4 \%)(p=.001)$, diabetes $(17.8 \%$ vs. $15.9 \%)(p=$ $.050)$, and high cholesterol (48.7\% vs. $46.1 \%)(p=.001)$ compared to their matched controls. Similarly, prostate cancer survivors reported an increased prevalence of arthritis (47.8\% vs. $41.5 \%)(p<.000)$, hypertension $(58.2 \%$ vs. $53.7 \%)(p=.007)$, and high cholesterol (53.8\% vs. 48.1\%) $(p<.000)$ compared to their matched controls. Male colorectal cancer survivors reported an increased prevalence of asthma $(13.3 \%$ vs. $8.0 \%)(p=.003)$ compared to their matched controls.

\section{$\underline{\text { Aim 2: Table } 3}$}

Breast cancer survivors were more likely to report having had a flu immunization within the past year $(63.7 \%$ vs. $57.5 \%)(p<.000)$, physical check-up within the past 2 years $(93.7 \%$ vs. $91.4 \%)(p<.000)$, and cholesterol check within the past 2 years $(90.9 \%$ vs. $87.5 \%)(p<.000)$ compared to their matched controls. Likewise, prostate cancer survivors were more likely to report having had a flu immunization within the past year $(70.9 \%$ vs. $65.7 \%)(p=.002)$, physical check-up within the past 2 years $(95.6 \%$ vs. 92.9\%) $(p<.000)$, and cholesterol check within the past 2 years $(94.5 \%$ vs. $91.0 \%)(p<.000)$ than their matched controls. Neither female nor male colorectal cancer survivors were more likely to receive routine general clinical preventive care than their matched controls. Breast cancer survivors reported a greater prevalence of being overweight (34.4\% vs. $31.9 \%)(p=.047)$ than their matched controls. Female colorectal $(30.9 \%$ vs. 38.4\%) $(p=.001)$, male colorectal $(39.6 \%$ vs. $46.8 \%)(p=.035)$, and prostate cancer survivors $(46.5 \%$ vs. $47.1 \%)(p=.022)$ engaged less often in the recommended levels of physical 
activity and more often in the insufficient levels of physical activity (48.2\% vs. 38.4\%), (44.6\% vs. $38.1 \%)$, and (39.2\% vs. $35.9 \%)$, respectively. Only breast cancer survivors consumed $\geq 5$ servings of fruits and vegetables a day (34.6\% vs. 31.7\%) $(p=.025)$ more often than their matched controls. Female colorectal cancer survivors reported an increased prevalence of current smoking (11.8\% vs. $10.9 \%)$ and former smoking (36.2\% vs. $29.2 \%)(p=.048)$ status than their matched controls. Prostate cancer survivors reported a decreased prevalence of current smoking status (7.9\% vs. 10.4\%) and higher prevalence of having never smoked (41.2\% vs. $38.3 \%)(p=.019)$.

Aim 3: Table 4

Adjusted models showed that breast cancer survivors $1-5$ years after diagnosis were $44 \%$ more likely $(\mathrm{OR}=1.44,95 \% \mathrm{CI}: 1.16-1.80)$ to reporting having received a flu immunization within the past year compared to their matched controls, but at $>5$ years after diagnosis, they were only $16 \%$ more likely $(\mathrm{OR}=1.16,95 \% \mathrm{CI}: 1.01-1.33)$ to report having received a flu immunization within the past year. Breast cancer survivors $1-5$ years after diagnosis were less likely to be overweight $(\mathrm{OR}=0.78,95 \% \mathrm{CI}: 0.67-0.92)$ than normal/underweight compared to their matched controls, but at $>5$ years after diagnosis, they were about $30 \%$ more likely to be obese $(\mathrm{OR}=1.29,95 \% \mathrm{CI}: 1.02-1.64)$ than normal/underweight than their matched controls. Compared to their matched controls, breast cancer survivors $1-5$ years after diagnosis were about $40 \%$ more likely to consume $\geq 5$ servings of fruits and vegetables a day $(\mathrm{OR}=1.39,95 \% \mathrm{CI}: 1.13-1.72)$, but were no more likely to meet this recommendation than their matched controls when $>5$ years after diagnosis. Breast cancer survivors $1-5$ years after diagnosis were almost $40 \%$ less likely to be current smokers than never have smoked $(\mathrm{OR}=0.63,95 \% \mathrm{CI}: 0.45-0.87)$ than their matched controls. 
Female colorectal cancer survivors 1 - 5 years after diagnosis were over $40 \%$ less likely to be obese than normal/underweight $(\mathrm{OR}=0.59,95 \% \mathrm{CI}: 0.35-0.99)$ than their matched controls. At $1-5$ years after diagnosis, female colorectal cancer survivors are about $60 \%$ less likely to report no physical activity $(\mathrm{OR}=0.42,95 \% \mathrm{CI}: 0.23-0.77)$ than the recommended level, and those $>5$ years after diagnosis were about $40 \%$ more likely to report insufficient levels of physical activity than the recommended level $(\mathrm{OR}=1.41,95 \% \mathrm{CI}=1.03-1.94)$ than their matched controls.

Male colorectal cancer survivors $>5$ years after diagnosis were almost $60 \%(\mathrm{OR}=0.42$, 95\% CI: $0.24-0.74)$ and $50 \%$ less likely $(\mathrm{OR}=0.51,95 \% \mathrm{CI}: 0.28-0.95)$ to have received a physical check-up and a cholesterol check within the past 2 years compared to their matched controls.

Prostate cancer survivors $1-5$ years after diagnosis were $35 \%$ less likely $(\mathrm{OR}=0.65$, $95 \%$ CI: $0.48-0.89)$ to report no physical activity than the recommended level compared to their matched controls.

\section{$\underline{\text { Aim 4: Table } 5}$}

Compared to female colorectal cancer survivors, survivors of breast cancer were $25 \%$ less likely $(\mathrm{OR}=0.75,95 \% \mathrm{CI}$ : $0.57-0.98)$ to engage in insufficient levels of physical activity than the recommended level. Prostate cancer survivors did not significantly differ from male colorectal cancer survivors.

Compared to male colorectal cancer survivors, female survivors of colorectal cancer were about $50 \%$ less likely $(\mathrm{OR}=0.43,95 \% \mathrm{CI}: 0.30-0.61)$ to be overweight than normal/underweight and $75 \%$ more likely $(\mathrm{OR}=1.76,95 \% \mathrm{CI}: 1.23-2.52)$ to consume $\geq 5$ servings of fruits and vegetables a day. Female colorectal cancer survivors were also $50 \%$ less 
likely to be a former smoker than having never smoked, and about 35\% less likely $(\mathrm{OR}=0.64$, 95\% CI: $0.45-0.92$ ) to drink any amount of alcohol in the past 30 days compared to male colorectal cancer survivors.

Compared to prostate cancer survivors, survivors of breast cancer about $40 \%$ less likely (OR: $0.57,95 \%$ CI: $0.46-0.71)$ to be obese and $50 \%$ less likely (OR $=0.49,95 \%$ CI: $0.41-$ $0.59)$ to be overweight. Breast cancer survivors were also more than twice as likely $(\mathrm{OR}=2.29$, $95 \%$ CI: $1.92-2.74)$ to consume $\geq 5$ servings of fruits and vegetables a day than prostate cancer survivors, but were $65 \%$ more likely $(\mathrm{OR}=1.65,95 \% \mathrm{CI}: 1.31-2.06)$ to report no physical activity than the recommended level and about $30 \%$ more likely $(\mathrm{OR}=1.28,95 \% \mathrm{CI}: 1.07-$ 1.52) to report insufficient levels of physical activity than the recommended level compared to prostate cancer survivors. Yet, breast cancer survivors were $45 \%$ less likely $(\mathrm{OR}=0.55,95 \% \mathrm{CI}$ : $0.41-0.73)$ to be a current smoker than never smoked, $56 \%$ less likely (OR $=0.44,95 \% \mathrm{CI}$ : $0.38-0.52)$ to be a former smoker than never smoked, and $46 \%$ less likely $(\mathrm{OR}=0.54,95 \% \mathrm{CI}$ : $0.46-0.63)$ to drink any alcohol in the past thirty days compared to prostate cancer survivors.

\section{$\underline{\text { Discussion }}$}

This study is the first to have compared both prevalence of chronic and comorbid conditions and health behaviors among the three largest groups of cancer survivors in the U.S. to controls using the propensity score matching method to rigorously control for the effects of confounding bias. This study further extends the extant literature by comparing health behaviors between the breast, prostate and colorectal cancer survivors by cancer type and gender to identify differences associated with either having had a gender-specific or gender-neutral cancer and/or gender itself. 
All survivors were much more likely to report the presence of activity limitations and less likely to perceive their general health to be excellent or very good than their matched controls. Survivors of breast and prostate cancer exhibited a greater number of obesity related chronic and comorbid conditions, including high cholesterol, diabetes and/or hypertension, as well as arthritis, compared to their matched controls than did survivors of colorectal cancer. Moreover, survivors of breast cancer who were living > 5 years past diagnosis were almost $30 \%$ more likely to be obese compared to their matched controls. These differences in the presence of chronic and comorbid health condition between breast and prostate compared to colorectal cancer survivors may in part be explained by the adverse health risks associated with the use of the sexhormone modifying therapies commonly used to treat breast and prostate cancer. Survivors of breast cancer treated with adjuvant hormone therapy and prostate cancer treated with androgen deprivation therapy have been shown to be at an increased risk of metabolic syndrome, cardiovascular disease, diabetes, and weight gain ${ }^{14,15,34}$.

Prevalence comparison of cancer survivors to their matched controls, demonstrated that survivors of breast and prostate cancer engaged in higher rates of all three general clinical preventive care services, while female and male colorectal cancer survivors did not differ in receipt of any clinical preventive care service compared to their controls. In regards to lifestyle behaviors, only breast cancer survivors were more likely to meet recommended levels of fruit and vegetable consumption compared to matched controls. Survivors of prostate and both male and female colorectal cancers reported lower levels of recommended physical activity and higher rates of the insufficient levels compared to their matched controls. Prostate cancer survivors self-identified as current smokers less frequently and more frequently as never having smoked than did their controls. Female colorectal cancer survivors more frequently reported themselves 
to be current and former smokers than did their matched controls, but less reported having never smoked.

However, after adjusting for covariates, logistic regression models of receipt of general clinical preventive care stratified by time since diagnosis showed that only survivors of breast cancer at both times since diagnosis were more likely to have received a flu immunization within the past year compared to their controls. Male colorectal cancer survivors $>5$ years after diagnosis were less likely to have received blood cholesterol screenings and physical check-ups than their matched controls. With respect to lifestyle behaviors, prostate and female colorectal cancer survivors were both less likely than their matched controls to report no physical activity 1 - 5 years after diagnosis, but female colorectal cancer survivors were about $40 \%$ more likely report insufficient levels of activity $>5$ years after diagnosis. Breast cancer survivors $1-5$ years after diagnosis remained about $40 \%$ more likely to consume $\geq 5$ servings of fruits and vegetables per day than their matched controls and about $40 \%$ less likely to be current smokers.

These findings differ slightly from previous studies that compared the individual cancer types to those without a history of cancer. Khan and colleagues (2010) compared clinical preventive care behaviors of breast, prostate, and colorectal cancer survivors in the United Kingdom to controls matched on age and gender. They found that all three cancer groups were superior in receipt of flu immunization compared to matched controls, but were no different cholesterol screening ${ }^{26}$. Eakin and colleagues (2007) compared health behaviors among a small sample of breast, prostate, and colorectal cancer survivors in Australia to controls matched on age and gender. Regression models did not identify differences between breast and female colorectal survivors and controls, but prostate male colorectal cancer survivors were more likely to have regular skin checks and male colorectal cancer survivors were less likely than controls to 
be sedentary. However, prostate cancer survivors were more likely to consume moderate amounts of alcohol ${ }^{9}$. A recent study by Kwon and colleagues (2011) utilizing the same data set as this study (2009 BRFSS), compared the prevalence rates for physical activity among breast, prostate, and colorectal cancer survivors age $40-64$ and $65-79$ years to all others in these age groups without a history of cancer. Prevalence rates for engaging in recommended levels physical activity and median minutes of physical activity per week were similar between survivors of breast cancer and those without a history of cancer, but female survivors of colorectal cancer had lower rates of each compared to those without a history of cancer. A similar pattern was observed among prostate and male colorectal cancer survivors. Survivors of prostate were similar to those without a history of cancer with respect to prevalence of engaging in recommended levels of physical activity, but those $40-64$ years of age reported participating in 20 minutes of moderate physical activity per week than those without a history of cancer. Male colorectal cancer survivors engaged in lower levels for both measures of physical activity compared to those without a history of cancer ${ }^{24}$.

Thus far, cancer vs. control comparisons have demonstrated that survivors of a gender or hormone-specific cancer such as breast and prostate demonstrated a greater prevalence of obesity related chronic and comorbid conditions compared to their controls, which may explain their increased participation in routine general clinical preventive care services compared to their controls. Yet, there were very few differences in regards to lifestyle behaviors between any of the survivors and their controls.

A different pattern emerged when health behaviors were compared between the cancer types and genders. When breast cancer survivors were compared to female colorectal cancer survivors and prostate survivors were compared to male colorectal cancer survivors, almost no 
differences were observed between the gender-specific and gender-neutral cancers. However, when female colorectal cancer survivors were compared to male colorectal cancer survivors and breast cancer survivors were compared to prostate cancer survivors, numerous differences emerged. Both groups of female cancer survivors were less likely to be overweight and/or obese, more likely to consume $\geq 5$ servings of fruits and vegetables per day, less likely to be former and/or current smokers, and less likely to drink any alcohol compared to their male counterparts. Breast cancer survivors were however, more likely to engage in no or insufficient levels of physical activity compared to prostate cancer survivors. These findings suggest that, in comparison to male cancer survivors, females engage in equal or superior levels of every behavior except physical activity, the one behavior that has been the promoted the most among these groups of survivors, particularly among survivors of breast cancer. A study comparing lifestyle factors among older, long-term breast, prostate, and colorectal cancer survivors identified a similar pattern relative to diet and exercise. Mosher and colleagues [2009] found that survivors of breast cancer had a better diet quality, but engaged in less physical activity than both prostate and male colorectal cancer survivors, and female colorectal cancer survivors had a better diet quality than male colorectal cancer survivors ${ }^{25}$. This phenomenon of men engaging in higher levels of physical activity, but maintaining a poorer diet as compared to women, and vice versa has not been limited to cancer survivors. A study of gender differences in relation the physical activity and life satisfaction among patients with coronary heart disease also found a higher prevalence of physical activity among men as compared to women ${ }^{35}$. Furthermore, a large study of young adults across countries found that compared to men, women reported avoiding high fat foods and salt, but consuming more fruit and high fiber foods ${ }^{36}$. 
This study utilized data from a relatively recent and large national survey. Breast, prostate, and colorectal cancer survivors sampled represented a diverse range in age and time since diagnosis. A rigorous method of matching cases to controls was used to control for the effects of confounding bias. This study comprehensively compared the presence of chronic and comorbid health conditions and health behaviors between cancer survivors and their matched controls, while also comparing health behaviors between cancer types and genders. However, inherent in self-reported data is responder bias, particularly for self-reported physical activity. While the this study did not adjust for stage of diagnosis or type of treatment, the sample of cancer survivors were limited to those who were $>1$ year past diagnosis to avoid survivors who may still be undergoing treatment and therefore have competing interest with engaging in healthy behaviors. Furthermore, the association between time since diagnosis and health behaviors was examined by stratifying comparisons by short-term (1 - 5 years) and long-term (> 5 years) cancer survivors. In addition to the three measures of clinical preventive care, cancer screenings including mammogram, pap test, prostate specific antigen test, and colonoscopy are also recommended routinely among the majority of the age groups sampled, but were not able to be examined in this study.

\section{Conclusions}

In conclusion, this study demonstrated that survivors of breast and prostate cancer having a greater prevalence of certain chronic and comorbid health condition compared to matched controls than did female and male colorectal cancer survivors. In accordance with these findings, survivors of breast and prostate cancer received clinical preventive care services more frequently compared to their matched controls than did female and male colorectal cancer survivors. Comparisons of healthy lifestyle behaviors between survivors and controls resulted in 
mixed findings according to cancer type. Yet, none of the cancer survivors engaged in superior levels of physical activity compared to their controls. Only survivors of breast cancer had higher rates of consuming $\geq 5$ servings of fruits and vegetables per day than their controls. However, comparisons between male and female cancer survivors revealed that the women engage in superior or equal levels of all health behaviors, except physical activity, while the men lack in their intake of fruits and vegetables. Given these findings, it is necessary for health care providers to be aware of the increased burden of illness among survivors of breast and prostate cancer in comparison to others in their cohort in order to provide proper monitoring, treatment and health promotion. Moreover, provider awareness of health behavior disparities in physical activity and diet according to gender can help guide individualized counseling to target desired behaviors among cancer survivors.

\section{Acknowledgements}

The study authors acknowledge partial financial funding by the WV CoHORTS Center and AHRQ Grant \# 1R24H5018622-01. 


\section{$\underline{\text { References }}$}

1. Howlander N, Noone AM, Krapcho M, et. al. Estimated United States cancer prevalence. SEER Cancer Statistics Review, 1975 - 2008. National Cancer Institute, Bethesda, MD, 2011. Available at http://seer.cancer.gov/csr/1975_2008/. Last accessed April 9, 2012.

2. Altekruse SF, Kosary CL, Krapcho M, et. al. Estimated number of persons alive in the U.S. diagnosied with cancer on January 1, 2008 by site. SEER Cancer Statistics Review, 1975 - 2008. National Cancer Institute, Bethesda, MD, 2011. Available at http://seer.cancer.gov/csr/1975_2008/. Last accessed April 9, 2012.

3. Harrington CB, Hansen JA, Moskowitz M, Todd BL, and Feuerstein M. It's not over when it's over: long-term symptoms in cancer survivors - a systematic review. Int J Psychiat Med. 2010; 40(2): 163 - 181.

4. Richardson LC, Wingo PA, Zack MM, Zahran HS, and King JB. Health-related quality of life in cancerSurvivors between ages 20 and 64 years: population-based estimates from the behavior risk factorsurveillance system. Cancer. 2008; 112(6): 1380 - 1389.

5. Hewitt M, Rowland JH, and Yancik R. Cancer survivors in the United States: age, health, and disability. J Gerontol A Biol Sci Med Sci 2003; 58(1): 82 - 91.

6. Patnaik JL, Byers T, DiGuiseppi C, Dabelea D, and Denberg TD. Cardiovascular disease competes with breast cancer as the leading cause of death for older females diagnosed with breast cancer: a retrospective cohort study. Breast Cancer Res. 2011; 13(R64): 1 -9 .

7. Renehan AG, Tyson M, Egger M, Heller RF, and Zwahlen M. Body-mass index and incidence of cancer: a systematic review and meta-analysis of prospective observations studies. Lancet. 2008; 371: 569 - 578.

8. Crawford AG, Cote C, Couto J, et. al. Prevalence of obesity, type II diabetes mellitus, hyperlipidemia, and hypertension in the United States: findings from the GE centricity electronic medical record database. Popul Health Manag. 2009; 13(3): 151 - 161.

9. Eakin EG, Youlden DR, Baade PD, et. al. Health behaviors of cancer survivors: data from an Australian population-based survey. Cancer Cause Control. 2007; 18: 881 - 894.

10. Wilder Smith A, Reeve BB, Bellizzi KM, et. al. Cancer, comorbidities, and health-related quality of life of older adults. Health Care Financ R. 2008; 29(4): 41 - 56.

11. Farley Short P, Moran JR, and Punekar R. Medical expenditures of adult cancer survivors ages < 65 years in the United States. Cancer. 2011; 117(12): 2791 - 2800. 
12. Denmark-Wahnefried W, Aziz NM, Rowland JH, and Pinto BM. Riding the crest of the teachable moment: promoting long-term health after the diagnosis of cancer. $\mathrm{J}$ Clin Oncol. 2005; 23(24): 5814 - 5830.

13. Haydon AMM, Maclnnis RJ, English DR, and Giles GG. Effect of physical activity and body size on survival after diagnosis with colorectal cancer. Gut. 2006; 55: 62 - 67.

14. Saylor PJ and Smith MR. Adverse effects of androgen deprivation therapy: defining the problem and promoting health among men with prostate cancer. J Natl Compr Canc Netw. 2010; 8(2): 211- 223.

15. Thomson CA, Thompson PA, Wright-Bea J, Nardi E, Frey GR, and Stopeck A. Metabolic syndrome and elevated c-reactive protein in breast cancer survivors on adjuvant hormone therapy. J Womens Health. 2009; 18(12): 2041 - 2047.

16. Coups EJ and Ostroff JS. A population-based estimate of the prevalence of behavioral risk factors among adult cancer survivors and noncancer controls. Prev Med. 2005; 40: $702-711$.

17. Blanchard CM, Courneya KS, and Stein K. Cancer survivors' adherence to lifestyle behavior recommendations and associations with health-related quality of life: results from the American Cancer Society's SCS-II. J Clin Oncol. 2008; 26(13): 2198 - 2204.

18. Morey MC, Snyder DC, Sloane R, et. al. Effects of home-based diet and exercise on functional outcomes among older, overweight long-term cancer survivors. JAMA. 2009; 301(18): 1883 - 1891.

19. Winters-Stone KM, Dobek J, Nail L, et. al. Strength training stops bone loss and builds muscle in postmenopausal breast cancer survivors: a randomized, controlled trial. Breast Cancer Res Treat. 2011; 127(2): 447 - 456.

20. Duffy SA, Ronis DL, Valenstein M, et. al. A tailored smoking, alcohol, and depression intervention forhead and neck cancer patients. Cancer Epidem Biomar. 2006; 15(11): $2203-2208$.

21. Doyle C, Kushi LH, Byers T, et. al. Nutrition and physical activity during and after cancer treatment:an American Cancer Society guide for informed choices. CA-Cancer J Clin. 2006; 56: $323-353$.

22. Thomson CA, Rock CL, Thompson PA, et. al. Vegetable intake is associated with reduced breast cancer recurrence in tamoxifen users: a secondary analysis from the women's healthy eating and living study. Breast Cancer Res T. 2010; 125(2): 519 - 527.

23. Bellizzi KM, Rowland JH, Jeffery DD, and McNeel T. Health behaviors of cancer survivors: examining opportunities for cancer control intervention. J Clin Oncol. 2005; 23(34): $8884-8893$. 
24. Kwon S, Hou N, and Wang M. Comparison of physical activity levels between cancer survivors and non-cancer participants in the 2009 BRFSS. J Cancer Surviv. 2012; 6(1): $54-62$.

25. Khan NF, Carpenter L, Watson E, and Rose PW. Cancer screening and preventive care among long-term cancer survivors in the United Kingdom. Brit J Cancer. 2010; 102: $1085-1090$.

26. Mosher CE, Sloane R, Morey MC, et. al. Associations between lifestyle factors and quality of life among older long-term breast, prostate, and colorectal cancer survivors. Cancer. 2009; 115(17): 4001 - 4009.

27. Reeve BB, Wilder Smith A, Arora NK, and Hays RD. Reducing bias in cancer research: application of propensity score matching. Health Care Financ R. 2008; 29(4): 69 - 80.

28. Andersen RM. Health surveys and the behavioral model of health services use. Med Care. 2008; 46(7): $647-653$.

29. Centers for Disease Control and Prevention (CDC). Behavioral risk factor surveillance system survey data. Atlanta, GA: U.S. Department of Health and Human Services, Centers for Disease Control and Prevention, 2009.

30. Centers for Disease Control and Prevention (CDC). 2009 Summary data quality report. Atlanta, GA: U.S. Department of Health and Human Services, Centers for Disease Control and Prevention, 2009. Available at http://www.cdc.gov/brfss/technical_infodata/quality.htm. Last accessed April 9, 2012.

31. Centers for Disease Control and Prevention (CDC). 2009 BRFSS codebook. Atlanta, GA:

U.S. Department of Health and Human Services, Centers for Disease Control and Prevention, 2009. Available at http://www.cdc.gov/brfss/technical_infodata/surveydata/2009.htm\#survey. Last accessed April 9, 2012.

32. Centers for Disease Control and Prevention (CDC). 2009 BRFSS overview. Atlanta, GA: U.S. Department of Health and Human Services, Centers for Disease Control and Prevention, 2009. Available at http://www.cdc.gov/brfss/technical_infodata/surveydata/2009.htm . Last accessed April 9, 2012.

33. U.S. Census Bureau. Census regions and divisions with state FIPS codes. Washington, DC: U.S. Census Bureau. Available at http://www.census.gov/geo/www/us_regdiv.pdf. Last accessed April 9,2012.

34. Redig AJ, and Munshi HG. Care of the cancer survivor: metabolic syndrome after hormonemodifying therapy. Am J Med. 2010; 123: 86.e1 - 87.e6. 
35. McDonnell LA, Riley DL, Blanchard CM, et. al. Gender differences in satisfaction with life in patients with coronary heart disease: physical activity as a possible mediating factor. $\mathrm{J}$ Behav Med. 2011; 34: 192 - 200.

36. Wardle J, Haase AM, and Steptoe A. Gender differences in food choice: the contribution of health beliefs and dieting. Ann Behav Med. 2004; 27(2): 107 - 116. 
Table 1.

Description of Cancer Survivors and Matched Controls

Behavioral Risk Factor Surveillance System, 2009

\begin{tabular}{|c|c|c|c|c|c|c|c|c|c|c|c|c|c|c|c|c|c|c|c|c|}
\hline \multirow[b]{3}{*}{ All } & \multirow{3}{*}{$\begin{array}{l}\text { BC } \\
N \\
6393 \\
\end{array}$} & \multirow{3}{*}{$\begin{array}{r}\text { Wt. \% } \\
25.0 \\
\end{array}$} & \multicolumn{2}{|c|}{ BC Controls } & \multirow{3}{*}{$\begin{array}{l}\text { Sig. } \\
p \text { value }\end{array}$} & \multicolumn{2}{|c|}{ CC (Female) } & \multicolumn{2}{|c|}{ CC Controls } & \multirow{3}{*}{$\begin{array}{l}\text { Sig. } \\
p \text { value }\end{array}$} & \multicolumn{2}{|c|}{ CC (Male) } & \multicolumn{2}{|c|}{ CC Controls } & \multirow{3}{*}{$\begin{array}{l}\text { Sig. } \\
p \text { value }\end{array}$} & \multirow{3}{*}{$\begin{array}{l}\mathrm{PC} \\
\mathrm{N} \\
3636 \\
\end{array}$} & \multirow{3}{*}{$\begin{array}{r}\text { Wt. \% } \\
25.0 \\
\end{array}$} & \multicolumn{2}{|c|}{ PC Controls } & \multirow{3}{*}{$\begin{array}{l}\text { Sig. } \\
p \text { value }\end{array}$} \\
\hline & & & $\mathbf{N}$ & Wt. \% & & $\mathbf{N}$ & Wt. \% & $N$ & Wt. \% & & $\mathbf{N}$ & Wt. \% & $\mathbf{N}$ & Wt. \% & & & & $\mathbf{N}$ & Wt. \% & \\
\hline & & & 19179 & 75.0 & & 1111 & 25.0 & 3333 & 75.0 & & 824 & 25.0 & 2472 & 75.0 & & & & 10908 & 75.0 & \\
\hline Age & & & & & 0.426 & & & & & 0.967 & & & & & 0.936 & & & & & 0.151 \\
\hline $18-49$ & 390 & 10.2 & 1170 & 12.0 & & 40 & 6.8 & 120 & 8.0 & & 36 & 8.8 & 108 & 10.9 & & 18 & 1.1 & 54 & 2.6 & \\
\hline $50-54$ & 477 & 10.6 & 1432 & 10.0 & & 57 & 8.2 & 170 & 8.6 & & 37 & 6.5 & 111 & 6.8 & & 63 & 3.4 & 189 & 2.7 & \\
\hline $55-59$ & 703 & 12.2 & 2119 & 11.7 & & 90 & 7.8 & 270 & 8.6 & & 75 & 10.4 & 225 & 9.3 & & 171 & 5.8 & 516 & 6.3 & \\
\hline $60-64$ & 906 & 13.0 & 2716 & 13.7 & & 114 & 10.6 & 342 & 10.4 & & 115 & 14.9 & 347 & 14.6 & & 412 & 13.2 & 1240 & 13.2 & \\
\hline $65-69$ & 989 & 13.4 & 2959 & 13.2 & & 129 & 10.4 & 388 & 9.2 & & 141 & 15.8 & 425 & 16.4 & & 602 & 13.3 & 1815 & 14.8 & \\
\hline $70-74$ & 938 & 11.9 & 2820 & 12.2 & & 190 & 16.7 & 570 & 15.0 & & 126 & 13.7 & 377 & 12.7 & & 735 & 17.8 & 2175 & 18.3 & \\
\hline$\geq 75$ & 1990 & 28.7 & 5963 & 27.2 & & 491 & 39.5 & 1473 & 40.1 & & 294 & 29.9 & 879 & 29.4 & & 1635 & 45.3 & 4919 & 42.0 & \\
\hline Gender & & & & & 1.000 & & & & & 1.000 & & & & & 1.000 & & & & & 1.000 \\
\hline Female & 6393 & 100.0 & 19179 & 100.0 & & 1111 & 100.0 & 3333 & 100.0 & & 0 & 0.0 & 0 & 0.0 & & 0.0 & 0.0 & 0.0 & 0.0 & \\
\hline Male & 0 & 0.0 & 0 & 0.0 & & 0 & 0.0 & 0 & 0.0 & & 824 & 100.0 & 2472 & 100.0 & & 3636 & 100.0 & 10908 & 100.0 & \\
\hline Race/Ethnicity & & & & & 0.280 & & & & & 0.281 & & & & & 0.456 & & & & & 0.561 \\
\hline White & 5559 & 80.6 & 16681 & 81.6 & & 971 & 83.3 & 2913 & 80.3 & & 704 & 80.7 & 2116 & 79.8 & & 3057 & 78.6 & 9203 & 77.7 & \\
\hline AA & 407 & 9.9 & 1226 & 7.9 & & 78 & 10.5 & 231 & 8.8 & & 53 & 10.2 & 154 & 8.2 & & 355 & 12.4 & 1039 & 13.3 & \\
\hline Latino & 163 & 5.2 & 483 & 5.4 & & 26 & 2.1 & 79 & 5.2 & & 33 & 6.3 & 97 & 7.9 & & 93 & 5.5 & 277 & 4.6 & \\
\hline Other & 264 & 4.3 & 789 & 5.1 & & 36 & 4.2 & 110 & 5.6 & & 34 & 2.8 & 105 & 4.0 & & 131 & 3.6 & 389 & 4.4 & \\
\hline Marital Status & & & & & 0.107 & & & & & 0.296 & & & & & 0.401 & & & & & 0.192 \\
\hline Married & 3019 & 59.4 & 9174 & 58.9 & & 442 & 56.4 & 1321 & 52.0 & & 524 & 75.0 & 1614 & 75.3 & & 2501 & 77.1 & 7263 & 75.8 & \\
\hline Widowed & 1978 & 22.3 & 6169 & 22.8 & & 446 & 26.8 & 1362 & 30.9 & & 142 & 11.1 & 377 & 8.9 & & 561 & 10.6 & 1877 & 11.6 & \\
\hline Sep/Divorced & 1030 & 13.4 & 2813 & 12.1 & & 178 & 13.4 & 501 & 13.0 & & 107 & 9.4 & 334 & 10.8 & & 405 & 9.1 & 1228 & 8.3 & \\
\hline Never Married & 366 & 4.9 & 1023 & 6.2 & & 45 & 3.4 & 149 & 4.1 & & 51 & 4.4 & 147 & 5.0 & & 169 & 3.3 & 540 & 4.3 & \\
\hline Education & & & & & $0.000 * * *$ & & & & & 0.367 & & & & & 0.114 & & & & & 0.606 \\
\hline$<\mathrm{HS}$ & 445 & 6.4 & 1762 & 8.8 & & 142 & 15.2 & 415 & 13.9 & & 99 & 11.7 & 287 & 11.4 & & 385 & 9.7 & 1235 & 10.5 & \\
\hline HS Grad & 2008 & 29.6 & 6537 & 31.9 & & 414 & 36.4 & 1256 & 33.6 & & 264 & 30.5 & 747 & 28.8 & & 979 & 25.4 & 3151 & 26.7 & \\
\hline Some Col/TS & 1832 & 27.5 & 5297 & 27.2 & & 324 & 26.6 & 836 & 25.6 & & 193 & 25.5 & 557 & 21.0 & & 795 & 22.7 & 2382 & 22.5 & \\
\hline Col/TS Grad & 2108 & 36.5 & 5583 & 32.1 & & 231 & 21.9 & 826 & 26.9 & & 268 & 32.3 & 881 & 38.9 & & 1477 & 42.1 & 4140 & 40.3 & \\
\hline Employment Status & & & & & 0.062 & & & & & 0.332 & & & & & 0.822 & & & & & $0.049 *$ \\
\hline Employed & 1935 & 33.1 & 6054 & 35.5 & & 216 & 23.9 & 747 & 26.8 & & 248 & 36.2 & 736 & 36.9 & & 795 & 23.8 & 2662 & 26.9 & \\
\hline Unemployed & 4458 & 66.9 & 13125 & 64.5 & & 895 & 76.1 & 2586 & 73.2 & & 576 & 63.8 & 1736 & 63.1 & & 2841 & 76.2 & 8246 & 73.1 & \\
\hline Family Income & & & & & 0.191 & & & & & 0.585 & & & & & 0.433 & & & & & 0.993 \\
\hline$<\$ 25,000$ & 1884 & 24.9 & 5658 & 24.6 & & 442 & 31.9 & 1331 & 34.6 & & 245 & 26.2 & 738 & 28.3 & & 798 & 19.5 & 2383 & 19.7 & \\
\hline$\$ 25,000-\$ 35,000$ & 849 & 10.9 & 2545 & 12.1 & & 150 & 12.2 & 454 & 13.1 & & 114 & 13.4 & 342 & 11.7 & & 501 & 12.1 & 1492 & 11.6 & \\
\hline$\$ 35,000-\$ 50,000$ & 932 & 14.6 & 2788 & 14.6 & & 136 & 12.5 & 402 & 12.2 & & 124 & 14.7 & 370 & 12.8 & & 641 & 17.5 & 1934 & 17.2 & \\
\hline$\$ 50,000-\$ 75,000$ & 758 & 12.0 & 2267 & 13.1 & & 96 & 12.6 & 288 & 10.6 & & 112 & 16.8 & 336 & 14.2 & & 575 & 15.7 & 1694 & 15.5 & \\
\hline$>\$ 75,000$ & 1084 & 22.8 & 3253 & 22.8 & & 117 & 13.5 & 348 & 15.3 & & 158 & 22.1 & 476 & 25.7 & & 776 & 25.0 & 2312 & 25.8 & \\
\hline Missing/DK & 886 & 14.8 & 2668 & 12.7 & & 170 & 17.3 & 510 & 14.2 & & 71 & 6.9 & 210 & 7.3 & & 345 & 10.2 & 1093 & 10.2 & \\
\hline
\end{tabular}

Abbreviations: BC, Breast Cancer; CC, Colorectal Cancer; PC, Prostate Cancer; AA, African American; Sep, Separated; HS, High School; Grad, Graduate; Col, College; TS, Technical School; DK, Don't Know; Asterisks represent significant differences compared to the reference group. ${ }^{* * *} p<.001,{ }^{* *} p<.01,{ }^{*} p<.05$. 
Table 2.

Health Conditions of Cancer Survivors and Matched Controls

Behavioral Risk Factor Surveillance System, 2009

\begin{tabular}{|c|c|c|c|c|c|c|c|c|c|c|c|c|c|c|c|c|c|c|c|c|}
\hline \multirow[b]{3}{*}{ All } & \multirow{3}{*}{$\begin{array}{l}\text { BC } \\
N \\
6393\end{array}$} & \multirow{3}{*}{$\begin{array}{r}\text { Wt. \% } \\
25.0 \\
\end{array}$} & \multicolumn{2}{|c|}{ BC Controls } & \multirow{3}{*}{$\begin{array}{l}\text { Sig. } \\
p \text { value }\end{array}$} & \multicolumn{2}{|c|}{ CC (Female) } & \multicolumn{2}{|c|}{ CC Controls } & \multirow{3}{*}{$\begin{array}{l}\text { Sig. } \\
p \text { value }\end{array}$} & \multicolumn{2}{|c|}{ CC (Male) } & \multicolumn{2}{|c|}{ CC Controls } & \multirow{3}{*}{$\begin{array}{l}\text { Sig. } \\
p \text { value }\end{array}$} & \multirow{3}{*}{$\begin{array}{l}\text { PC } \\
\mathbf{N} \\
3636 \\
\end{array}$} & \multirow{3}{*}{$\begin{array}{r}\text { Wt. \% } \\
25.0 \\
\end{array}$} & \multicolumn{2}{|c|}{ PC Controls } & \multirow{3}{*}{$\begin{array}{l}\text { Sig. } \\
p \text { value }\end{array}$} \\
\hline & & & $\mathbf{N}$ & Wt. \% & & $\mathbf{N}$ & Wt. \% & $\mathbf{N}$ & Wt. \% & & $\mathbf{N}$ & Wt. \% & $\mathbf{N}$ & Wt. \% & & & & $\mathbf{N}$ & Wt. \% & \\
\hline & & & 19179 & 75.0 & & 1111 & 25.0 & 3333 & 75.0 & & 824 & 25.0 & 2472 & 75.0 & & & & 10908 & 75.0 & \\
\hline Arthritis & & & & & $0.001^{* *}$ & & & & & 0.083 & & & & & 0.068 & & & & & $0.000 * * *$ \\
\hline Yes & 3591 & 52.9 & 10003 & 48.4 & & 665 & 60.6 & 1873 & 55.0 & & 353 & 46.3 & 1061 & 41.0 & & 1815 & 47.8 & 4714 & 41.5 & \\
\hline No & 2788 & 47.1 & 9121 & 51.6 & & 442 & 39.4 & 1447 & 45.0 & & 469 & 53.7 & 1404 & 59.0 & & 1814 & 52.2 & 6133 & 58.5 & \\
\hline Asthma & & & & & 0.568 & & & & & 0.947 & & & & & $0.003^{* *}$ & & & & & 0.637 \\
\hline Yes & 832 & 13.4 & 2477 & 13.9 & & 148 & 12.5 & 384 & 12.4 & & 94 & 13.3 & 214 & 8.0 & & 366 & 9.5 & 916 & 9.0 & \\
\hline No & 5542 & 86.6 & 16656 & 86.1 & & 958 & 87.5 & 2941 & 87.6 & & 728 & 86.7 & 2253 & 92.0 & & 3263 & 90.5 & 9954 & 91.0 & \\
\hline Heart Disease & & & & & 0.260 & & & & & 0.580 & & & & & 0.538 & & & & & 0.093 \\
\hline Yes & 670 & 8.9 & 2029 & 9.7 & & 158 & 12.7 & 425 & 11.7 & & 177 & 18.9 & 578 & 20.2 & & 780 & 20.1 & 2524 & 22.3 & \\
\hline No & 5657 & 91.1 & 16954 & 90.3 & & 944 & 87.3 & 2861 & 88.3 & & 640 & 81.1 & 1864 & 79.8 & & 2807 & 79.9 & 8260 & 77.7 & \\
\hline Diabetes & & & & & $0.050^{*}$ & & & & & 0.445 & & & & & 0.184 & & & & & 0.722 \\
\hline Yes & 1144 & 17.8 & 3121 & 15.9 & & 246 & 18.8 & 639 & 20.5 & & 216 & 25.1 & 579 & 21.8 & & 814 & 23.6 & 2517 & 23.1 & \\
\hline No & 5245 & 82.2 & 16049 & 84.1 & & 865 & 81.2 & 2693 & 79.5 & & 606 & 74.9 & 1889 & 78.2 & & 2819 & 76.4 & 8380 & 76.9 & \\
\hline Hypertension & & & & & 0.779 & & & & & 0.301 & & & & & 0.096 & & & & & $0.007^{* *}$ \\
\hline Yes & 3268 & 46.4 & 9730 & 46.8 & & 636 & 56.7 & 1877 & 53.4 & & 455 & 53.1 & 1313 & 48.3 & & 2194 & 58.2 & 6065 & 53.7 & \\
\hline No & 3118 & 53.6 & 9412 & 53.2 & & 473 & 43.3 & 1444 & 46.6 & & 368 & 46.9 & 1150 & 51.7 & & 1439 & 41.8 & 4819 & 46.3 & \\
\hline High Cholesterol & & & & & $0.001^{* *}$ & & & & & 0.399 & & & & & 0.913 & & & & & $0.000 * * *$ \\
\hline Yes & 3246 & 48.7 & 9318 & 46.1 & & 554 & 47.0 & 1692 & 48.3 & & 390 & 49.3 & 1220 & 48.8 & & 1982 & 53.8 & 5321 & 48.1 & \\
\hline No & 2957 & 48.0 & 8957 & 48.2 & & 519 & 49.5 & 1492 & 46.6 & & 397 & 46.4 & 1142 & 46.3 & & 1562 & 43.7 & 5118 & 47.2 & \\
\hline No Test & 190 & 3.4 & 904 & 5.7 & & 38 & 3.5 & 149 & 5.1 & & 37 & 4.3 & 110 & 4.8 & & 92 & 2.5 & 469 & 4.7 & \\
\hline Stroke & & & & & 0.497 & & & & & 0.512 & & & & & 0.694 & & & & & 0.870 \\
\hline Yes & 327 & 4.7 & 1051 & 5.0 & & 90 & 8.0 & 206 & 6.7 & & 56 & 6.4 & 190 & 6.9 & & 266 & 6.9 & 814 & 6.7 & \\
\hline No & 6047 & 95.3 & 18077 & 95.0 & & 1018 & 92.0 & 3113 & 93.3 & & 765 & 93.6 & 2277 & 93.1 & & 3358 & 93.1 & 10064 & 93.3 & \\
\hline Activity Limitations & & & & & $0.000 * * *$ & & & & & $0.004^{* *}$ & & & & & $0.000 * * *$ & & & & & $0.005^{* *}$ \\
\hline Yes & 2043 & 30.6 & 5401 & 25.6 & & 389 & 37.0 & 1011 & 28.4 & & 296 & 39.4 & 720 & 23.9 & & 1117 & 29.3 & 2972 & 25.2 & \\
\hline No & 4328 & 69.4 & 13702 & 74.4 & & 716 & 63.0 & 2305 & 71.6 & & 524 & 60.6 & 1742 & 76.1 & & 2505 & 70.7 & 7896 & 74.8 & \\
\hline Perc. General Health & & & & & $0.000 * * *$ & & & & & $0.000 * * *$ & & & & & $0.000 * * *$ & & & & & $0.000 * * *$ \\
\hline Excel/Very Good & 2426 & 41.7 & 8976 & 52.8 & & 333 & 32.3 & 1364 & 44.9 & & 243 & 31.8 & 1038 & 48.5 & & 1260 & 38.1 & 4534 & 46.1 & \\
\hline Good & 2162 & 36.5 & 5531 & 29.1 & & 351 & 32.9 & 990 & 31.7 & & 266 & 39.5 & 700 & 30.4 & & 1238 & 38.9 & 3419 & 33.8 & \\
\hline Fair/Poor & 1424 & 21.8 & 3465 & 18.1 & & 329 & 34.8 & 736 & 23.3 & & 240 & 28.7 & 556 & 21.2 & & 882 & 23.1 & 2147 & 20.2 & \\
\hline
\end{tabular}

Abbreviations: BC, Breast Cancer; CC, Colorectal Cancer; PC, Prostate Cancer; AA, African American; Perc, Perceived; Excel, Excellent;

Asterisks represent significant differences compared to the reference group. ${ }^{* * *} p<.001,{ }^{* *} p<.01,{ }^{*} p<.05$. 
Table 3.

Comparison of Health Behaviors of Cancer Survivors and Matched Controls

\begin{tabular}{|c|c|c|c|c|c|c|c|c|c|c|c|c|c|c|c|c|c|c|c|c|}
\hline \multirow[b]{3}{*}{ All } & \multirow{3}{*}{$\begin{array}{l}\text { BC } \\
N \\
6393 \\
\end{array}$} & \multirow{3}{*}{$\begin{array}{l}\text { Wt. } \\
\% \\
25.0 \\
\end{array}$} & \multirow{3}{*}{$\begin{array}{l}\text { BC Con } \\
\mathrm{N} \\
19179 \\
\end{array}$} & \multirow{3}{*}{$\begin{array}{l}\text { ols } \\
\text { Wt. } \\
\% \\
75.0 \\
\end{array}$} & \multirow{3}{*}{$\begin{array}{l}\text { Sig. } \\
p \text { value }\end{array}$} & \multicolumn{2}{|c|}{ CC (Female) } & \multicolumn{2}{|c|}{ CC Controls } & \multirow{3}{*}{$\begin{array}{l}\text { Sig. } \\
p \text { value }\end{array}$} & \multicolumn{2}{|c|}{ CC (Male) } & \multicolumn{2}{|c|}{ CC Controls } & \multirow{3}{*}{$\begin{array}{r}\text { Sig. } \\
p \\
\text { value }\end{array}$} & \multirow{3}{*}{$\begin{array}{l}\text { PC } \\
N \\
3636 \\
\end{array}$} & \multirow{3}{*}{$\begin{array}{l}\begin{array}{l}\text { Wt. } \\
\%\end{array} \\
25.0 \\
\end{array}$} & \multicolumn{2}{|c|}{ PC Controls } & \multirow{3}{*}{$\begin{array}{l}\text { Sig. } \\
p \text { value }\end{array}$} \\
\hline & & & & & & $\mathbf{N}$ & $\begin{array}{l}\text { Wt. } \\
\%\end{array}$ & $\mathbf{N}$ & $\begin{array}{l}\text { Wt. } \\
\%\end{array}$ & & $\mathbf{N}$ & $\begin{array}{l}\text { Wt. } \\
\%\end{array}$ & $\mathbf{N}$ & $\begin{array}{l}\text { Wt. } \\
\%\end{array}$ & & & & $\mathbf{N}$ & $\begin{array}{l}\text { Wt. } \\
\%\end{array}$ & \\
\hline & & & & & & 1111 & 25.0 & & 75.0 & & 824 & 25.0 & 2472 & 75.0 & & & & 10908 & 75.0 & \\
\hline Flu Immunization $\leq 1$ Year & & & & & $0.000^{* * *}$ & & & & & 0.642 & & & & & 0.490 & & & & & $0.002 * *$ \\
\hline Yes & 4282 & 63.7 & 11752 & 57.5 & & 767 & 62.7 & 2149 & 61.3 & & 523 & 60.1 & 1548 & 58.1 & & 2649 & 70.9 & 7367 & 65.7 & \\
\hline No & 2111 & 36.3 & 7427 & 42.5 & & 344 & 37.3 & 1184 & 38.7 & & 301 & 39.9 & 924 & 41.9 & & 987 & 29.1 & 3541 & 34.3 & \\
\hline Physical Check-up & & & & & $0.000 * * *$ & & & & & 0.629 & & & & & 0.063 & & & & & $0.000^{* * *}$ \\
\hline$<2$ years ago & 5955 & 93.7 & 17365 & 91.4 & & 1033 & 94.0 & 3057 & 91.9 & & 750 & 91.2 & 2231 & 91.3 & & 3435 & 95.6 & 9995 & 92.9 & \\
\hline $2-5$ years ago & 217 & 3.6 & 807 & 3.9 & & 40 & 2.8 & 110 & 3.5 & & 41 & 4.2 & 107 & 4.2 & & 101 & 2.2 & 409 & 3.1 & \\
\hline$>5$ years ago & 179 & 2.3 & 880 & 4.1 & & 28 & 2.7 & 139 & 3.8 & & 30 & 3.4 & 125 & 4.3 & & 94 & 2.2 & 459 & 3.4 & \\
\hline Never & 42 & 0.4 & 127 & 0.6 & & 10 & 0.5 & 27 & 0.8 & & 3 & 1.2 & 9 & 0.2 & & 6 & 0.0 & 45 & 0.6 & \\
\hline Cholesterol Check & & & & & $0.000 * * *$ & & & & & 0.568 & & & & & 0.183 & & & & & $0.000 * * *$ \\
\hline$<2$ years ago & 5758 & 90.9 & 16801 & 87.5 & & 998 & 91.6 & 2938 & 89.6 & & 729 & 90.3 & 2200 & 87.9 & & 3389 & 94.5 & 9822 & 91.0 & \\
\hline $2-5$ years ago & 269 & 4.2 & 848 & 4.8 & & 40 & 3.9 & 130 & 3.8 & & 37 & 2.5 & 89 & 5.2 & & 95 & 2.2 & 334 & 2.9 & \\
\hline$>5$ years ago & 113 & 1.5 & 454 & 2.0 & & 17 & 1.0 & 78 & 1.5 & & 16 & 3.0 & 53 & 2.0 & & 33 & 0.8 & 203 & 1.5 & \\
\hline Never & 190 & 3.4 & 904 & 5.8 & & 38 & 3.5 & 149 & 5.1 & & 37 & 4.3 & 110 & 4.9 & & 92 & 2.5 & 469 & 4.7 & \\
\hline BMI & & & & & $0.047^{*}$ & & & & & 0.668 & & & & & 0.150 & & & & & 0.751 \\
\hline Underweight/Normal & 2529 & 41.1 & 7771 & 41.0 & & 437 & 38.0 & 1342 & 39.9 & & 219 & 25.4 & 679 & 28.2 & & 1010 & 28.3 & 3182 & 28.8 & \\
\hline Overweight & 2254 & 34.4 & 6420 & 31.9 & & 369 & 30.9 & 1114 & 31.5 & & 351 & 44.3 & 1125 & 46.5 & & 1748 & 47.1 & 5019 & 45.9 & \\
\hline Obese & 1610 & 24.4 & 4988 & 27.0 & & 305 & 31.1 & 877 & 28.6 & & 254 & 30.3 & 668 & 25.3 & & 878 & 24.5 & 2707 & 25.3 & \\
\hline Physical Activity & & & & & 0.626 & & & & & $0.001 * *$ & & & & & $0.035^{*}$ & & & & & $0.022 *$ \\
\hline Recommended Level & 2646 & 41.4 & 7994 & 42.6 & & 392 & 30.9 & 1266 & 38.4 & & 318 & 39.6 & 1146 & 46.8 & & 1694 & 46.5 & 5018 & 47.1 & \\
\hline Insufficient Level & 2559 & 41.4 & 7643 & 40.2 & & 442 & 48.2 & 1298 & 38.4 & & 343 & 44.6 & 883 & 38.1 & & 1326 & 39.2 & 3903 & 35.9 & \\
\hline None & 1188 & 17.2 & 3542 & 17.2 & & 277 & 20.9 & 769 & 23.2 & & 163 & 15.8 & 443 & 15.0 & & 616 & 14.3 & 1987 & 17.0 & \\
\hline Fruits and Vegetables & & & & & $0.025^{*}$ & & & & & 0.088 & & & & & 0.581 & & & & & 0.501 \\
\hline $5 \leq$ Servings/Day & 2075 & 34.6 & 5951 & 31.7 & & 319 & 28.7 & 1064 & 33.5 & & 153 & 19.9 & 500 & 21.3 & & 806 & 21.5 & 2307 & 22.5 & \\
\hline $5>$ Servings/Day & 4318 & 65.4 & 13228 & 68.3 & & 792 & 71.3 & 2269 & 66.5 & & 671 & 80.1 & 1972 & 78.7 & & 2830 & 78.5 & 8601 & 77.5 & \\
\hline Smoking Status & & & & & 0.062 & & & & & $0.048^{*}$ & & & & & 0.213 & & & & & $0.019 *$ \\
\hline Current Smoker & 637 & 10.3 & 2258 & 12.3 & & 130 & 11.8 & 340 & 10.9 & & 89 & 10.9 & 318 & 14.2 & & 297 & 7.9 & 1082 & 10.4 & \\
\hline Former Smoker & 2168 & 31.2 & 5997 & 29.6 & & 395 & 36.2 & 1044 & 29.6 & & 457 & 51.0 & 1240 & 47.6 & & 1932 & 50.9 & 5817 & 51.4 & \\
\hline Never Smoked & 3588 & 58.4 & 10924 & 58.1 & & 586 & 52.0 & 1949 & 59.5 & & 278 & 38.1 & 914 & 38.2 & & 1407 & 41.2 & 4009 & 38.3 & \\
\hline Alcohol & & & & & 0.497 & & & & & 0.326 & & & & & 0.135 & & & & & 0.628 \\
\hline Heavy Drinker & 280 & 3.9 & 758 & 4.4 & & 30 & 2.9 & 109 & 4.7 & & 40 & 4.7 & 86 & 3.5 & & 130 & 3.9 & 389 & 4.0 & \\
\hline Light/Moderate Drinker & 2301 & 38.4 & 6764 & 37.3 & & 317 & 33.0 & 984 & 30.8 & & 372 & 45.1 & 1160 & 50.5 & & 1716 & 50.7 & 5116 & 49.0 & \\
\hline None in last 30 days & 3812 & 57.6 & 11657 & 58.4 & & 764 & 64.0 & 2240 & 64.5 & & 412 & 50.2 & 1226 & 46.0 & & 1790 & 45.5 & 5403 & 47.0 & \\
\hline
\end{tabular}

Abbreviations: BC, Breast Cancer; CC, Colorectal Cancer; PC, Prostate Cancer;

Asterisks represent significant differences compared to the reference group. ${ }^{* *} p<.001,{ }^{* *} p<.01,{ }^{*} p<.05$. 
Table 4.

Logistic Regression of the Health Behaviors of Cancer Survivors to Matched Controls

Behavioral Risk Factor Surveillance System, 2009

\begin{tabular}{|c|c|c|c|c|c|c|c|c|c|c|c|c|c|}
\hline & & \multicolumn{3}{|c|}{ Breast Cancer } & \multicolumn{3}{|c|}{ Colorectal Cancer (Female) } & \multicolumn{3}{|c|}{ Colorectal Cancer (Male) } & \multicolumn{3}{|c|}{ Prostate Cancer } \\
\hline & & AOR & $95 \% \mathrm{Cl}$ & Sig. & AOR & $95 \% \mathrm{Cl}$ & Sig. & AOR & $95 \% \mathrm{Cl}$ & Sig. & AOR & $95 \% \mathrm{Cl}$ & Sig. \\
\hline \multicolumn{14}{|l|}{ Last Flu Immunization } \\
\hline \multirow[t]{2}{*}{$\leq 1$ Year } & 1 - 5 Years & 1.44 & {$[1.16,1.80]$} & $* *$ & 0.81 & {$[0.53,1.22]$} & & 1.29 & {$[0.83,2.02]$} & & 1.12 & {$[0.89,1.42]$} & \\
\hline & $5<$ Years & 1.16 & {$[1.01,1.33]$} & * & 1.01 & {$[0.75,1.35]$} & & 0.78 & {$[0.56,1.08]$} & & 1.13 & {$[0.93,1.37]$} & \\
\hline \multicolumn{14}{|l|}{ Last Physical Check-up } \\
\hline \multirow[t]{2}{*}{$<2$ Years } & $1-5$ Years & 1.15 & {$[0.74,1.79]$} & & 2.04 & {$[0.99,4.22]$} & & 0.99 & {$[0.48,2.03]$} & & 1.29 & {$[0.81,2.06]$} & \\
\hline & $5<$ Years & 1.14 & {$[0.91,1.44]$} & & 0.92 & {$[0.52,1.62]$} & & 0.42 & {$[0.24,0.74]$} & $* *$ & 1.06 & {$[0.75,1.48]$} & \\
\hline \multicolumn{14}{|l|}{ Last Cholesterol Check } \\
\hline \multirow[t]{2}{*}{$<2$ Years } & 1 - 5 Years & 1.35 & {$[0.90,2.02]$} & & 2.24 & {$[0.81,6.20]$} & & 0.78 & {$[0.35,1.74]$} & & 1.46 & {$[0.92,2.34]$} & \\
\hline & $5<$ Years & 0.97 & {$[0.76,1.24]$} & & 0.66 & {$[0.39,1.12]$} & & 0.51 & {$[0.28,0.95]$} & $*$ & 0.89 & {$[0.63,1.26]$} & \\
\hline \multicolumn{14}{|c|}{ BMI (Underweight/Normal) } \\
\hline \multirow[t]{2}{*}{ Obese } & 1 - 5 Years & 0.82 & {$[0.62,1.08]$} & & 0.59 & {$[0.35,0.99]$} & $*$ & 1.51 & {$[0.86,2.64]$} & & 0.89 & {$[0.65,1.23]$} & \\
\hline & $5<$ Years & 1.29 & {$[1.02,1.64]$} & $*$ & 1.13 & {$[0.77,1.66]$} & & 0.82 & {$[0.55,1.23]$} & & 0.85 & {$[0.67,1.07]$} & \\
\hline \multirow[t]{2}{*}{ Overweight } & 1 - 5 Years & 0.78 & {$[0.67,0.92]$} & $* *$ & 0.65 & {$[0.40,1.08]$} & & 1.39 & {$[0.83,2.32]$} & & 0.97 & {$[0.75,1.25]$} & \\
\hline & $5<$ Years & 0.92 & {$[0.79,1.06]$} & & 1.09 & {$[0.80,1.48]$} & & 0.85 & {$[0.60,1.21]$} & & 1.06 & {$[0.87,1.28]$} & \\
\hline \multicolumn{14}{|c|}{ Physical Activity (Recommended) } \\
\hline \multirow[t]{2}{*}{ None } & 1 - 5 Years & 0.79 & {$[0.57,1.09]$} & & 0.42 & {$[0.23,0.77]$} & $* *$ & 0.98 & {$[0.56,1.70]$} & & 0.65 & {$[0.48,0.89]$} & $* *$ \\
\hline & $5<$ Years & 0.88 & {$[0.73,1.07]$} & & 1.13 & {$[0.79,1.61]$} & & 1.13 & {$[0.74,1.71]$} & & 0.87 & {$[0.68,1.10]$} & \\
\hline \multirow[t]{2}{*}{ Insufficient } & 1 - 5 Years & 1.01 & {$[0.81,1.27]$} & & 1.16 & {$[0.72,1.88]$} & & 1.25 & {$[0.78,2.01]$} & & 1.09 & {$[0.86,1.39]$} & \\
\hline & $5<$ Years & 0.95 & {$[0.83,1.10]$} & & 1.41 & {$[1.03,1.94]$} & $*$ & 1.33 & {$[0.95,1.86]$} & & 1.04 & {$[0.86,1.26]$} & \\
\hline \multicolumn{14}{|l|}{ Fruits \& Vegetables } \\
\hline \multirow[t]{2}{*}{$5 \leq$ Servings/Day } & 1 - 5 Years & 1.39 & {$[1.13,1.72]$} & $* *$ & 0.86 & {$[0.55,1.34]$} & & 0.81 & {$[0.47,1.41]$} & & 1.11 & {$[0.85,1.44]$} & \\
\hline & $5<$ Years & 1.07 & {$[0.93,1.23]$} & & 0.80 & {$[0.60,1.08]$} & & 0.91 & {$[0.66,1.27]$} & & 0.85 & {$[0.70,1.04]$} & \\
\hline \multicolumn{14}{|c|}{ Smoking Status (Never Smoked) } \\
\hline \multirow[t]{2}{*}{ Current } & 1 - 5 Years & 0.63 & {$[0.45,0.87]$} & $* *$ & 0.94 & {$[0.46,1.90]$} & & 0.61 & {$[0.34,1.11]$} & & 0.77 & {$[0.52,1.14]$} & \\
\hline & $5<$ Years & 0.90 & {$[0.71,1.15]$} & & 1.15 & {$[0.72,1.86]$} & & 0.82 & {$[0.44,1.52]$} & & 0.73 & {$[0.52,1.03]$} & \\
\hline \multirow[t]{2}{*}{ Former } & 1 - 5 Years & 1.08 & {$[0.87,1.33]$} & & 1.28 & {$[0.85,1.94]$} & & 0.85 & {$[0.52,1.39]$} & & 0.79 & {$[0.63,1.00]$} & \\
\hline & $5<$ Years & 1.01 & {$[0.89,1.15]$} & & 1.30 & {$[0.95,1.79]$} & & 1.00 & {$[0.74,1.35]$} & & 0.89 & {$[0.75,1.06]$} & \\
\hline \multicolumn{14}{|l|}{ Alcohol Consumption } \\
\hline \multirow[t]{2}{*}{ Drink Any } & $1-5$ Years & 1.08 & {$[0.88,1.34]$} & & 1.02 & {$[0.63,1.67]$} & & 0.92 & {$[0.60,1.41]$} & & 1.17 & {$[0.93,1.48]$} & \\
\hline & $5<$ Years & 1.09 & {$[0.95,1.25]$} & & 1.18 & {$[0.84,1.66]$} & & 0.90 & {$[0.65,1.24]$} & & 0.97 & {$[0.82,1.16]$} & \\
\hline
\end{tabular}

Abbreviations: AOR, Adjusted Odds Ratios; Cl, Confidence Intervals; BMI, Body Mass Index; CVD-MS, Cardiovascular Disease-Metabolic Syndrome;

CVD-MD includes the presence of heart disease, high cholesterol, hypertension, and or diabetes.

Asterisks represent significant differences compared to the reference group. ${ }^{* * *} p<.001,{ }^{* *} p<.01, * p<.05$.

Reference categories for dependent variables are as follows: Last Flu Immunization ( $>1$ Year), Last Physical Check-up ( $\geq 2$ Years), Last Cholesterol Check-up ( $\geq 2$

Years), Alcohol Consumption (No Drinks in Past 30 Days),

Fruits \& Vegetables ( 5 > Servings /Day), Smoking Status (Never Smoked), BMI (Underweight/Normal), Physical Activity (Recommended Level).

Results shown are adjusted for the following covariates: Presence of Cancer (no), Race/Ethnicity (White), Age (18 - 54), Marital Status (married),

Metro Status (non-metro), Region of U.S. (Northeast), Education (< high school), Employment Status (not employed), Income $(<\$ 25,000)$,

Health Insurance (no), Usual Source of Care (no), Arthritis (no), Asthma (no), CVD-MS (no), and Stroke (no), Perceived General Health Status (fair/poor),

Activity Limitations (no). 
Table 5.

Logistic Regression Comparison of Health Behaviors of Cancer Survivors by Cancer Type and Gender

Behavioral Risk Factor Surveillance System, 2009

\begin{tabular}{|c|c|c|c|c|c|c|c|c|c|c|c|c|}
\hline & \multicolumn{3}{|c|}{$\begin{array}{c}\text { Breast Cancer } \\
\text { Vs. Colorectal (Female) }\end{array}$} & \multicolumn{3}{|c|}{$\begin{array}{c}\text { Prostate Cancer } \\
\text { Vs. Colorectal (Male) }\end{array}$} & \multicolumn{3}{|c|}{$\begin{array}{c}\text { Colorectal Cancer (Female) } \\
\text { Vs. Colorectal (Male) }\end{array}$} & \multicolumn{3}{|c|}{$\begin{array}{l}\text { Breast Cancer } \\
\text { Vs. Prostate }\end{array}$} \\
\hline & AOR & $95 \% \mathrm{Cl}$ & Sig. & AOR & $95 \% \mathrm{Cl}$ & Sig. & AOR & $95 \% \mathrm{Cl}$ & Sig. & AOR & $95 \% \mathrm{Cl}$ & Sig. \\
\hline \multicolumn{13}{|l|}{ Last Flu Immunization } \\
\hline$\leq 1$ Year & 1.22 & {$[0.93,1.60]$} & & 1.21 & {$[0.91,1.61]$} & & 1.10 & {$[0.78,1.54]$} & & 1.03 & {$[0.86,1.23]$} & \\
\hline \multicolumn{13}{|l|}{ Last Physical Check-up } \\
\hline$<2$ Years & 0.94 & {$[0.55,1.59]$} & & 1.68 & {$[0.97,2.91]$} & & 1.72 & {$[0.91,3.27]$} & & 0.86 & {$[0.62,1.19]$} & \\
\hline \multicolumn{13}{|l|}{ Last Cholesterol Check } \\
\hline$<2$ Years & 1.00 & {$[0.59,1.70]$} & & 1.32 & {$[0.77,2.25]$} & & 1.38 & {$[0.73,2.59]$} & & 0.88 & {$[0.63,1.23]$} & \\
\hline \multicolumn{13}{|l|}{ BMI } \\
\hline Obese & 0.78 & {$[0.56,1.09]$} & & 0.96 & {$[0.67,1.36]$} & & 0.69 & {$[0.45,1.05]$} & & 0.57 & {$[0.46,0.71]$} & $* * *$ \\
\hline Overweight & 1.10 & {$[0.83,1.45]$} & & 1.01 & {$[0.74,1.38]$} & & 0.43 & {$[0.30,0.61]$} & $* * *$ & 0.49 & {$[0.41,0.59]$} & $* * *$ \\
\hline \multicolumn{13}{|l|}{ Physical Activity } \\
\hline None & 0.94 & {$[0.69,1.28]$} & & 0.73 & {$[0.51,1.04]$} & & 1.37 & {$[0.91,2.05]$} & & 1.65 & {$[1.31,2.06]$} & $* * *$ \\
\hline Insufficient & 0.75 & {$[0.57,0.98]$} & $*$ & 0.74 & {$[0.55,1.00]$} & & 1.41 & {$[0.98,2.02]$} & & 1.28 & {$[1.07,1.52]$} & $* *$ \\
\hline \multicolumn{13}{|l|}{ Fruits \& Vegetables } \\
\hline $5 \leq$ Servings/Day & 1.20 & {$[0.93,1.54]$} & & 1.00 & {$[0.71,1.39]$} & & 1.76 & {$[1.23,2.52]$} & $* *$ & 2.29 & {$[1.92,2.74]$} & $* * *$ \\
\hline \multicolumn{13}{|l|}{ Smoking Status } \\
\hline Current & 0.83 & {$[0.56,1.23]$} & & 0.95 & {$[0.58,1.56]$} & & 0.69 & {$[0.41,1.17]$} & & 0.55 & {$[0.41,0.73]$} & $* * *$ \\
\hline Former & 0.84 & {$[0.64,1.10]$} & & 0.92 & {$[0.69,1.21]$} & & 0.47 & {$[0.33,0.66]$} & $* * *$ & 0.44 & {$[0.38,0.52]$} & $* * *$ \\
\hline \multicolumn{13}{|l|}{ Alcohol Consumption } \\
\hline Drink Any & 0.94 & {$[0.69,1.27]$} & & 1.13 & {$[0.86,1.49]$} & & 0.64 & {$[0.45,0.92]$} & $*$ & 0.54 & {$[0.46,0.63]$} & $* * *$ \\
\hline
\end{tabular}

Abbreviations: AOR, Adjusted Odds Ratios; Cl, Confidence Intervals; BMI, Body Mass Index; CVD-MS, Cardiovascular Disease-Metabolic Syndrome; CVD-MD includes the presence of heart disease, high cholesterol, hypertension, and or diabetes.

Asterisks represent significant differences compared to the reference group. ${ }^{* * *} p<.001, * * p<.01,{ }^{*} p<.05$.

Reference categories for dependent variables are as follows: Last Flu Immunization (> 1 Year), Last Physical Check-up ( $\geq 2$ Years), Last Cholesterol Check-up ( $\geq 2$ Years), Alcohol Consumption (No Drinks in Past 30 Days),

Fruits \& Vegetables (5 > Servings /Day), Smoking Status (Never Smoked), BMI (Underweight/Normal), Physical Activity (Recommended Level). Results shown are adjusted for the following covariates: Presence of Cancer (No), Race/Ethnicity (White), Age (18 - 54), Marital Status (Married), Metro Status, (Non-Metro), Region of U.S. (Northeast),

Education (< High School), Employment Status (Not employed), Income $(<\$ 25,000)$, Health Insurance (No), Usual Source of Care (No), Arthritis (No), CVD-MS (No), Perceived General Health Status (Fair/Poor),

Activity Limitations (No).

Reference categories are given in parenthesis. 


\section{CHAPTER 4}

\section{$\underline{\text { Study Findings }}$}

The number of cancer survivors has continued to grow in the U.S. and worldwide due to advances in early detection and treatment methods. However, many cancer survivors continue to experience late and long-lasting symptoms and effects from the cancer and its treatment that diminish their Health-Related Quality of Life (HRQOL). What is more, is that after surviving cancer, which may be considered a teachable moment, many cancer survivors do not engage in superior health behaviors compared to those who do not have a history of cancer. Survivors of breast, prostate, and colorectal cancer are the three largest groups of cancer survivors and together comprise over $50 \%$ of survivors living in the U.S. Few studies have HRQOL, heath conditions, and health behaviors among these groups of survivors to those without a history of cancer while rigorously controlling for known confounders. Moreover, few studies have compared HRQOL between these groups of survivors by cancer type and gender. It remains uncertain how survivors may differ in these aspects from those without a history of cancer and from one another. Therefore, two studies were conducted to address these questions. The first

study compared domains of HRQOL among these groups of cancer survivors to propensity score matched controls and between type of cancer and gender. The second study compared the prevalence of health conditions among these groups of survivors to propensity score matched controls, and also compared health behaviors among these survivor groups to propensity score matched controls and between cancer type and gender.

In the study of HRQOL among survivors of breast, prostate and colorectal cancer survivors to propensity score matched controls and by cancer type and gender, survivors were more likely to report worse outcomes for multiple domains of HRQOL, compared to matched 
controls. The number of domains that survivors reported worse outcomes than their matched controls varied according to type of cancer. Compared to their matched controls, breast cancer survivors were more likely to report activity limitations and to perceive their general health as poorer at both $1-5$ and $>5$ years since diagnosis. Female colorectal cancer survivors were also more likely to report activity limitations and have a poorer perceived general health both time periods, as well as reporting a greater number of bad physical health days in the past month, but greater life satisfaction for the first $1-5$ years, compared to their matched controls. Similar to the two groups of female cancer survivors, male survivors of colorectal cancer were also more likely to report activity limitations and hold poorer perception of their general health status for both time periods compared to their matched controls. Male colorectal cancer survivors were also more likely to report a greater number of bad mental health days in the past month at $1-5$ years since diagnosis and more bad physical health days in the past month and poorer life satisfaction at $>5$ years since diagnosis, compared to their matched controls. Prostate cancer survivors were more likely to hold poorer perceptions of their general health at both times since diagnosis, and were also more likely to report a greater number of bad mental health days in the past month, a greater days of days they did not get enough sleep in the past month, and not receiving enough emotional support at $1-5$ years since diagnosis, compared to their matched controls.

In the comparison of HRQOL between cancer types and genders, survivors of breast cancer were less likely to perceive their general health as poor or fair, compared to female colorectal cancer survivors. Compared to male colorectal cancer survivors, survivors of prostate cancer were less likely to report activity limitations, perceive their general health as poor or fair, and less likely to report bad physical health days in the past month. Compared to male colorectal 
cancer survivors, female colorectal cancer survivors were less likely to report activity limitations, hold poorer perceptions of their general health and more likely to have greater life satisfaction, but were more likely to report more bad mental health days and day of not enough sleep in the past month and not receiving enough emotional support. Compared to prostate cancer survivors, survivors of breast cancer were more likely to report a greater number of bad physical health days, bad mental health days, and not enough sleep in the past month, and not receiving enough emotional support.

In the study of health conditions and health behaviors, survivors of breast and prostate cancer reported a greater prevalence of certain chronic and comorbid health conditions compared to their matched controls than did female and male colorectal cancer survivors. Compared to their matched controls, survivors of breast cancer reported a higher rate of arthritis, diabetes, high cholesterol, and activity limitations. Compared to their matched controls, survivors of prostate cancer reported higher rates of arthritis, hypertension, high cholesterol, and activity limitations. Female colorectal cancer survivors reported a greater number of activity limitations than their matched controls and male colorectal cancer survivors reported higher rates of asthma and activity limitations than their matched controls.

In the comparison of health behaviors between cancer survivors and their matched controls, breast cancer survivors demonstrated the most differences. Compared to their matched controls, survivors of breast cancer at both times since diagnosis were more likely to have received a flu immunization in the past year, were more likely to consume $\geq 5$ servings of fruits and vegetables a day, less likely to be overweight and or a current smoker at $1-5$ years after diagnosis, but were more likely to be obese at $>5$ years since diagnosis, compared to their matched controls. At $1-5$ years since diagnosis, female colorectal cancer survivors were less 
likely to be obese, and less likely to no physical activity, but at $>5$ years after diagnosis they were more likely to get insufficient levels of physical activity compared to their matched controls. Compared to their matched controls, male colorectal cancer survivors at $>5$ years since diagnosis were less likely to have had a physical check-up of a blood cholesterol check in the past 2 years. Prostate cancer survivors were only different from their matched controls in that they were less likely to get no physical activity at $1-5$ years since diagnosis.

The comparison of health behaviors between cancer types and genders, few differences were observed between cancer types. Compared to female colorectal cancer survivors, survivors of breast cancer were less likely to engage in insufficient levels of physical activity. Comparisons of health behaviors between genders revealed a greater number of differences. Compared to male colorectal cancer survivors, female colorectal cancer survivors were less likely to be overweight, be a former smoker, or consume any amount of alcohol, and more likely to consume $\geq 5$ servings of fruits and vegetables a day. Additionally, while not significant, female colorectal cancer survivors tended to be more likely to engage in none or insufficient levels of physical activity than male colorectal cancer survivors. Compared to prostate cancer survivors, survivors of breast cancer were less likely to be overweight and/or obese, to be current and/or former smokers, drink any amount of alcohol, and more likely to consume $\geq 5$ servings of fruits and vegetables a day, but they were more likely to engage in none or insufficient levels of physical activity.

\section{$\underline{\text { Summary \& Conclusions }}$}

Overall, this study has shown that breast, female colorectal, male colorectal and prostate cancer survivors experience worse HRQOL of life outcomes than do similar individuals without a history of cancer. The magnitude of the differences in health behaviors between cancer 
survivors and controls varied by type of cancer. However, the most notable differences appear to have been related to gender differences. Certain aspects of HRQOL may be more adversely affected among male survivors than female survivors when they are compared to matched controls. These differences may be related to differences in higher levels of physical activity prior to cancer and the greater expectations for physical functioning among men than women. Therefore, the limiting effects of cancer and its treatment upon physical functioning may more negatively affect mental health psychosocial well-being among male cancer survivors compared to female cancer survivors. Previous research has documented relatively high rates of depression, anxiety, and sleep disturbances among women, with rates being higher than those observed in men. Therefore, when female cancer survivors were compared to female controls, no differences were observed in relation to mental health, psychosocial well-being and quality of sleep. Yet, when female cancer survivors were compared to male cancer survivors, women demonstrated worse outcomes for these measures.

Similarly to the findings regarding HRQOL, while there was variation in health behaviors according to cancer type, with breast cancer survivors seeming to engage in better health behaviors than their controls, more differences emerged in the gender comparisons between cancer survivors. Female cancer survivors had better health behaviors than did male cancer survivors, with the exception that prostate cancer survivors engaged in more physical activity than did breast cancer survivors. Thus, cancer survivors do have worse HRQOL outcomes than do similar individuals without a history of cancer, but health behaviors between the two groups may vary according to cancer type. However, when women are compared to men, observed patterns regarding HRQOL and health behaviors appear to be similar to those in the general population. 


\section{$\underline{\text { Strengths \& Limitations }}$}

This study was conducted using a large national, population-based sample of cancer survivors representing a wide range of ages and times since diagnosis. Confounding effects in survivor vs. control comparisons were robustly controlled for using the propensity score matching method. This study was able to compare a diverse range of measures of HRQOL and health behaviors between survivors and controls, for both short and long-term cancer survivors. However, this study's effort to control for confounding effects were limited by the lack of information concerning type of treatment received and stage at diagnosis among cancer survivors. Additionally, outcomes could not be measured for survivors who have died. Therefore, it is uncertain outcomes for HRQOL and health behaviors would have affected study findings. Finally, this study was conducted using self-reported data that may contain responder bias.

\section{Study Implications \& Future Research}

Hormone treatment related weight gain, obesity related diseases, and the symptoms and effects affecting the HRQOL of survivors of breast, prostate, and colorectal cancer should be monitored for as closely as cancer recurrence. Educating survivors before treatment about the benefits of health behaviors and possible symptoms and effects they may experience after treatment, as well as providing them with information regarding treatment or coping mechanisms for these symptoms and effects before cancer treatment may help survivors maintain a good HRQOL throughout the survivorship continuum. Moreover, education health care professionals who provide care for cancer survivors as to these issues and possible differences among types the cancer survivors and genders could help them to identify needed interventions. 
As cancer detection and treatment strategies improve, the population of other types of survivors will also grow. Therefore, studies of this kind should be replicated among other types of cancer survivors. Future research efforts should be directed towards developing and evaluating educating and intervention plans that are intending to improve the health status and HRQOL of cancer survivors. 


\section{Traci LeMasters M.S, M.A, B.S.}

Graduate Student/Research Assistant

Department of Pharmaceutical Systems and Policy

School of Pharmacy

West Virginia University

(304) 293-8194

tlemasters@hsc.wvu.edu

\section{Education:}

- Complete Master of Science in Pharmaceutical Sciences

WVU School of Pharmacy

Morgantown, WV

Degree to be conferred, May 2012

- Master of Arts in Secondary Education in General Science

West Virginia University

Morgantown, WV

Degree conferred, December 2006

- Bachelors of Science in Psychology

West Virginia University

Morgantown, WV

Degree conferred, August 2004

- Salutatorian of Nicholas County High School graduating class of 2000

\section{Professional Experience:}

- West Virginia University Graduate Research Assistant for the West Virginia Collaborative Health Outcomes of Research of Therapies and Services Center

(WV COHORTS)

- Morgantown, WV

- Entered survey data collected from women who utilized the Bonnie Wells Wilson Mobile Mammography Program and who agreed to participate in a study being conducted by the WV CoHORTS Center

- Conducted literature review for anticipated manuscripts from the research study of the Bonnie Wells Wilson Mobile Mammography Program

- West Virginia University Teaching Assistant for the School of Pharmacy's Professional Program

- Morgantown, WV

- $\quad$ Lead small group lab activities for $1^{\text {st }}$ year students 
- Graded various assignments, quizzes, and tests

- Managed various aspects of the official school SOLE web page pertaining said classes

- Assisted in administering exams

- South Middle School Teaching Intern, August 23 - October 112006

- Morgantown, WV

- Designed and implemented lesson plans according to WV Curriculum Standards for $7^{\text {th }}$ grade Science

- Organized classroom atmosphere and managed student behavior

- East Fairmont High School Teaching Intern, October 13 - December 132006

- Fairmont, WV

- Designed and implemented lesson plans according to WV Curriculum Standards for $9^{\text {th }}$ grade Science, Earth Science and Conceptual Biology

- Organized classroom atmosphere and managed student behavior

- West Virginia University Department of Psychology Behavioral Analysis Lab Intern, January - May 2004

- Morgantown, WV

- Computed data analysis

- Observed and categorized child behavior

- Participated in professional article reviews

- Chestnut Ridge Department of Psychological Testing Intern, January - May 2003

- Morgantown, WV

- Administered and scored a variety of psychological tests

- Participated in professional article reviews

- West Virginia University Residential Assistant, January - May 2003

- Morgantown, WV

- Managed and disciplined behavior of dormitory residents

- Designed and implemented social activities

- Managed the front desk

\section{Honors/Activities}

- Member of Rho Chi National Pharmacy Honor Society

- National member of the International Society for Pharmacoeconomics and Outcomes Research

- National member of the Golden Key International Honor Society 
- 2009 - 2011 Secretary for the WVU Student Chapter of ISPOR

- Write agenda for monthly meetings

- Record minutes of monthly meetings

- 2008-2010 Member of the WVU Student Chapter of ISPOR

- Chair of the WVU ISPOR Potluck Fundraiser Committee for Fall and Spring Potlucks

\section{Publications}

- "A National Study of Out-of-Pocket Expenditures for Mammography Screening" Traci LeMasters M.A. \& Usha Sambamoorthi PhD.

Analysis of out of pocket expenditures for women age $40-64$ years of age receiving mammograms and factors correlating with higher and or lower out of pocket expenditures among a nationally representative sample

Data is from the Medical Expenditure Panel Survey 2006 - 2007

Used SAS software to analyze data

Accepted for publication in the October, 2011 Issue of the Journal of Women's Health

\section{Manuscripts to be Submitted for Publication}

- A comparison of health behaviors and health status between survivors of breast, prostate and colorectal cancers and to propensity score matched non-cancer controls, as well as, comparisons by cancer type and gender

- Data is from 2009 BRFSS

- Used SAS to conduct analysis

- A comparison of the HRQOL between survivors of breast, prostate, and colorectal cancers among survivors to propensity score matched controls, as well as, comparisons by cancer type and gender

- Data is from 2009 BRFSS

- Used SAS to conduct analysis

- "A Study of Relationships between Perceived and Actual Risk of Breast Cancer and Mammography Utilization among Women Attending a Mobile Mammography Program in a Rural Appalachian State"

Traci LeMasters, M.A., Suresh Madhavan, Ph.D., Elvonna Atkins, M.S.c, Ami Vyas, M.S., M.B.A., Susan Faulkner, Ed.D., Sara Jane Gainor, M.B.A., Stephenie Kennedy, M.A., Scott Remick, M.D., \& Linda Vona-Davis, Ph.D. 
Model of the relationship between mammography utilization, perceived risk, actual risk and other psychosocial and individual characteristics among women attending the Bonnie Wells Wilson Mobile Mammography Program

Data is from the Bonnie's Bus Mammography Screening and Preventive Care Survey Years 2009 \& 2010

Used SPSS software to analyze data

\section{Assisting Research}

- "Young Adult Smoking Cessation in West Virginia: Attitudes, Perceptions, and Quitting Methods." Cindy Tworek, PhD, MPH1,2, Robin Danek, MPH3, Traci LeMasters, MS2, Traci Jarrett,MA1,3 , Kimberly Horn, EdD, MSW1,3

\section{$\underline{\text { Posters }}$}

- "A National Study of Out-of-Pocket Expenditures for Mammography Screening" - presented at the Fall 2010 WVU School of Pharmacy Research Day and at the 2011 Annual International Meeting of the International Society for Pharmacoeconomics and Health Outcomes Research conference in Baltimore, MD.

- "A Study of Relationships between Perceived and Actual Risk of Breast Cancer and Mammography Utilization among Women Attending a Mobile Mammography Program in a Rural Appalachian State" -

Presented at the Spring 2011 WVU Health Sciences Van Lier Research Day and at the 2011 Annual Women's Health Conference in Crystal City, VA.

\section{Presentations}

- "Propensity Score Modeling in Health Outcomes Research"

- Graduate Seminar, Spring 2012

- "Conceptual Frameworks for Studies of Health Care Quality"

- Graduate Seminar, Fall 2011

- "The Role of Cost in Comparative Effectiveness Research."

- Graduate Seminar, Spring 2011

- "Absolute and Perceived Risk of Breast Cancer among Women and Associations with Mammography Utilization."

- Graduate Seminar, Fall 2010 
- "Breast Cancer Survivorship: Survivorship Care Plans \& Modifiable Lifestyle Factors." - Graduate Seminar, Spring 2010

- "A Cost-effective Analysis of Donepezil, Galantamine, Memantine, and Rivastigmine for the Treatment of Mild to Moderate and Moderate to Severe Stages of Alzheimer's Disease in the United States: Study Proposal."

- Graduate Seminar, Fall 2009

- "Effects of Various Alzheimer's Disease Drug Treatment Options on Caregiver Burden Associated with Neuropsychiatric Disturbances"

- Patient Reported Outcomes Class, Fall 2009

- "Health Disparities Among the American Indian/Alaska Native Population: A Focus on Prenatal Care."

- Graduate Seminar, Spring 2009

- "Health Disparities in Prenatal Care Resulting in Poor Birth Outcomes in West Virginia." - Health Disparities Class, Spring 2009

- "Zomepirac sodium: The History of its Entrance and Withdrawal from the Market." - Pharmacoepidemiology Class, Spring 2009

- "Thalidomide: The Harm Done and Lessons Learned."

- Pharmacoepidemiology Class, Spring 2009

- "A Cost Benefit Analysis of West Virginia's redesigned Medicaid program, Mountain Health Choices, Affecting Adults and Children."

- Pharmacoeconomics Class, Fall 2008

- "Stay The Course: An Intervention to Target Patient Compliance of Antibiotic Therapy for Respiratory Tract Infections among Medicare Part D Recipients Utilizing Medication Therapy Management Programs."

- Social \& Behavioral Theory Class, Fall 2008

- "Social Network Theory."

- Graduate Seminar, Fall 2008

\section{$\underline{\text { Miscellaneous }}$}

- Served as a review for the Journal of Health Care for the Poor and Underserved - Jan - April, 2012 